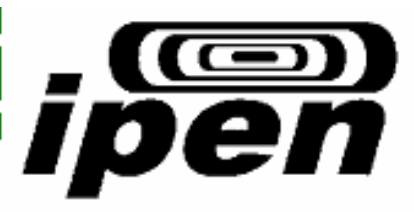

Autarquia associada à Universidade de São Paulo

\title{
ESTABELECIMENTO DE UM NOVO MÉTODO DE CALIBRAÇÃO DE CÂMARAS DE IONIZAÇÃO TIPO LÁPIS PARA DOSIMETRIA EM FEIXES DE TOMOGRAFIA COMPUTADORIZADA
}

\author{
Daniel Menezes Dias
}

\begin{abstract}
Dissertação apresentada como parte dos requisitos para obtenção do Grau de Mestre em Ciências na Área de Tecnologia Nuclear - Aplicações.
\end{abstract}

Orientadora:

Dra. Maria da Penha A. Potiens

SÃO PAULO 
INSTITUTO DE PESQUISAS ENERGÉTICAS E NUCLEARES

Autarquia associada à Universidade de São Paulo

\section{ESTABELECIMENTO DE UM NOVO MÉTODO DE CALIBRAÇÃO DE CÂMARAS DE IONIZAÇÃO TIPO LÁPIS PARA DOSIMETRIA EM FEIXES DE TOMOGRAFIA COMPUTADORIZADA}

Daniel Menezes Dias

Dissertação apresentada como parte dos requisitos para obtenção do Grau de Mestre em Ciências na Área de Tecnologia Nuclear - Aplicações.

Orientadora:

Dra. Maria da Penha A. Potiens

SÃO PAULO 
Aos meus pais, Tânia e Anselmo, que foram fundamentais em mais esta etapa da minha vida. Obrigado pelo apoio e por sempre acreditarem em mim. 
"A mente que se abre a uma idéia, jamais voltará ao seu tamanho original."

Albert Einsteisn. 


\section{AGRADECIMENTOS}

À minha orientadora, Dra. Maria da Penha A. Potiens, pela confiança, paciência, amizade e principalmente pela oportunidade de crescimento que me proporcionou durante a orientação do mestrado.

Ao IPEN, pela infra-estrutura e pela oportunidade de executar este trabalho. Agradeço também a todos que compõem a divisão de ensino (CPG) pelo auxílio burocrático.

Ao CNPq, pelo apoio financeiro durante a realização deste trabalho.

À Dra. Linda V. E. Caldas, sempre muito prestativa e atenciosa.

Ao Dr. Vitor Vivolo, pela amizade, pelo apoio técnico e pela sua colaboração durante as calibrações de rotina.

À Dra. Ana Maia, pelas sugestões durante o desenvolvimento deste trabalho.

À Dra. Denise Yanikian Nersissian, pelos ensinamentos de Dosimetria em Tomografia e pela oportunidade de algumas vezes presenciar sua rotina de trabalho.

À Dra. Tânia Furquim, que me deu a oportunidade de estagiar no IEE e assim facilitou o meu ingresso no mestrado. Obrigado pelo incentivo e pela amizade construída.

A todos os alunos e funcionários do GMR, que de maneira direta ou indireta contribuíram para a realização deste trabalho.

Ao grande amigo e parceiro Iremar, que muito me ajudou compartilhando de muitos experimentos apresentados nesta dissertação e acabou se tornando não apenas um grande companheiro de trabalho, mas também um grande amigo.

Ao casal de amigos, Fred e Juliana, que me acolheram e me apoiaram muito durante o tempo que passei em São Paulo. Não tenho palavras para agradecer.

Aos meus amigos e sócios, Marcela e Fábio, pela compreensão e pelo apoio durante este trabalho.

A toda a minha família, em especial aos meus irmãos, meus avós, meus tios e meus primos, cujo apoio sempre foi fundamental na minha carreira acadêmica e em minha vida profissional. 


\title{
ESTABELECIMENTO DE UM NOVO MÉTODO DE CALIBRAÇÃO DE CÂMARAS DE IONIZAÇÃO TIPO LÁPIS PARA DOSIMETRIA EM FEIXES DE TOMOGRAFIA COMPUTADORIZADA
}

\section{Daniel Menezes Dias}

\begin{abstract}
RESUMO
As câmaras de ionização tipo lápis são utilizadas para dosimetria de feixes em equipamentos de tomografia computadorizada (CT). Neste estudo foi estabelecida uma nova metodologia de calibração destas câmaras, visando a adequação do Laboratório de Calibração de Instrumentos do Instituto de Pesquisas Energéticas e Nucleares (LCI) aos atuais padrões metrológicos internacionais que tratam dos procedimentos específicos para calibração das câmaras utilizadas em CT. Primeiramente partiu-se da implantação das novas qualidades de radiação padrão RQT, que simulam feixes não atenuados usados para aplicações em CT, de acordo com a IEC 61267 da International Electrotechnical Commission (IEC). Após o estabelecimento dos campos padrões de radiação, foi implantada a metodologia de calibração específica para câmaras lápis segundo o Technical Report Series No. 457, da International Atomic Energy Agency (IAEA), que descreve as particularidades do procedimento a ser seguido pelos Laboratórios de Dosimetria Padrão Secundário (SSDL's) em termos de colimação e posicionamento em relação ao feixe de radiação. Inicialmente, foram realizadas medições de PPV $(\mathrm{kV})$ e determinação das filtrações adicionais de cobre por meio dos valores de camada semi-redutora (CSR) recomendados pela norma IEC 61267, para que as qualidades de radiação de referência: RQT 8, RQT 9 e RQT 10 fossem implantadas. Para os filtros adicionais, foram utilizados alumínio e cobre de alta pureza (maior ou igual a 99,9\%). Uma metodologia alternativa para determinar as filtrações adicionais também foi utilizada, através da qual se encontrou diretamente as RQT's em espessuras de filtros de cobre equivalente ao conjunto "RQR (Al) + Filtração Adicional (Cu)", sendo esta uma opção quando não se têm implantadas as RQR's. Com a implantação desta nova metodologia de calibração das câmaras de ionização tipo lápis, o LCl está pronto para calibrar estes instrumentos de acordo com as recentes recomendações internacionais. Permitindo assim uma melhoria na rastreabilidade das calibrações, como também na qualidade dos serviços metrológicos que o IPEN oferece para todo o País.
\end{abstract}




\title{
ESTABLISHMENT OF A NEW CALIBRATION METHOD OF PENCIL IONIZATION CHAMBER FOR DOSIMETRY IN COMPUTED TOMOGRAPHY
}

\author{
Daniel Menezes Dias
}

\begin{abstract}
Pencil ionization chambers are used for beam dosimetry in computed tomography equipment (CT). In this study, a new calibration methodology was established, in order to make the Calibration Laboratory of Instituto de Pesquisas Energéticas e Nucleares (LCl) suitable to international metrological standards, dealing with specific procedures for calibration of these chambers used in CT. Firstly, the setup for the new RQT radiation qualities was mounted, in agreement with IEC61267 from the International Electrotechnical Commission (IEC). After the establishment of these radiation qualities, a specific calibration methodology for pencil ionization chambers was set, according to Technical Report Series No. 457, from the International Atomic Energy Agency (IAEA), which describes particularities of the procedure to be followed by the Secondary Standard Dosimetry Laboratories (SSDL's), concerning to collimation and positioning related to the radiation beam. Initially, PPV (kV) measurements and the determination of copper additional filtrations were carried out, measuring the half value layers (HVL) recommended by the IEC 61267 standard, after that the RQT 8, RQT 9 and RQT 10 radiation quality references were established. For additional filters, aluminum and copper of high purity (around 99.9\%) were used. RQT's in thickness of copper filters equivalent to the set "RQR (AI) + Additional Filtration (Cu)" was directly found by an alternative methodology used to determine additional filtrations, which is a good option when RQR's have not the possibility of be setting up. With the establishment of this new methodology for the ionization pencil chambers calibration, the $\mathrm{LCl}$ is ready to calibrate these instruments according to the most recent international standards. Therefore, an improvement in calibration traceability, as well as in metrological services offered by IPEN to all Brazil is achieved.
\end{abstract}




\section{SUMÁRIO}

1. INTRODUÇÃO

1.1 OBJETIVOS.

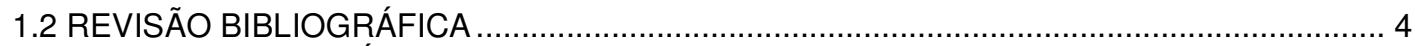

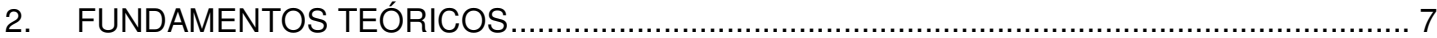

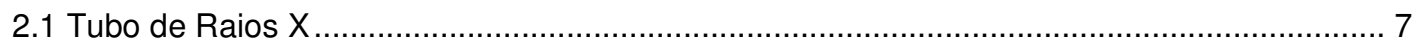

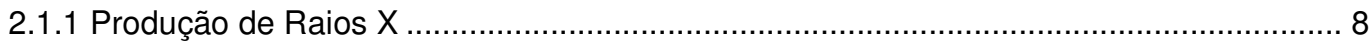

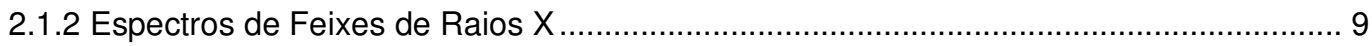

2.2. Aspectos Gerais da Tomografia Computadorizada ........................................................ 11

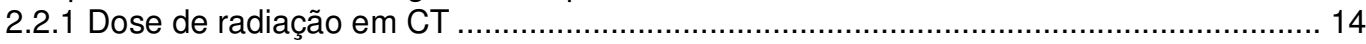

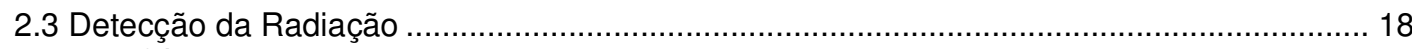

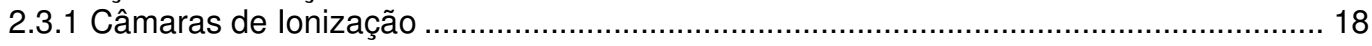

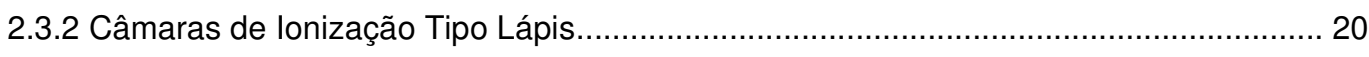

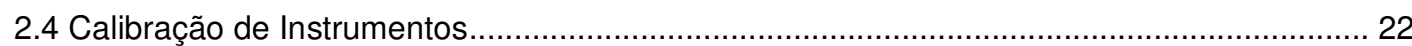

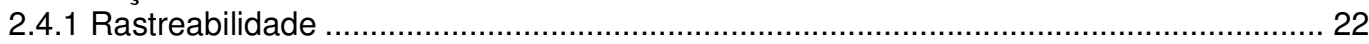

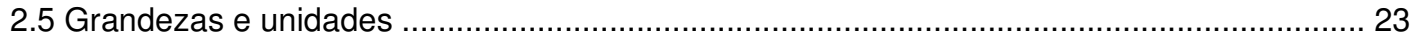

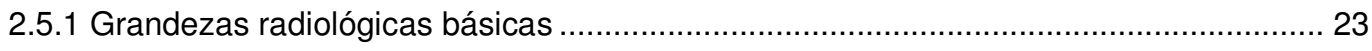

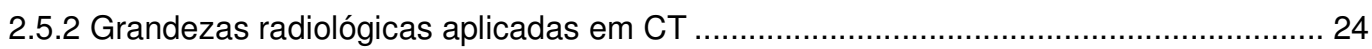

2.5.3 Tensão de Pico Aplicada ao Tubo de Raios X (kVp) ................................................. 26

2.5.4 Tensão de Pico Prático "Practical Peak Voltage" (PPV).............................................. 27

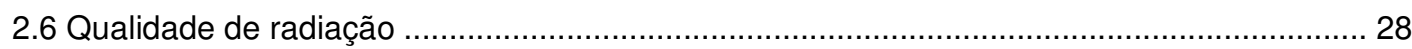

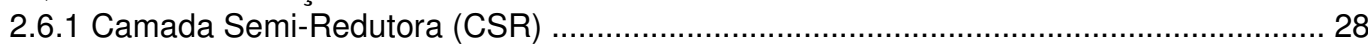

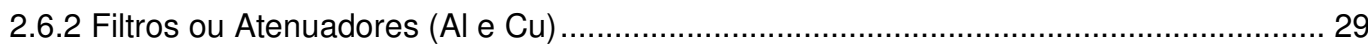

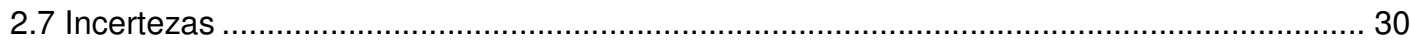

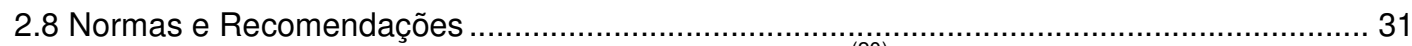

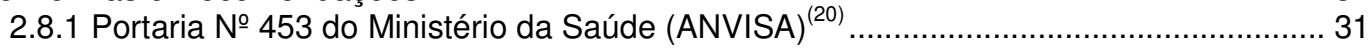

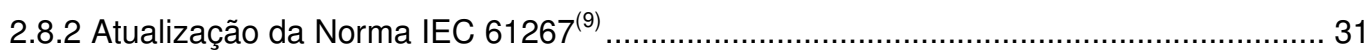

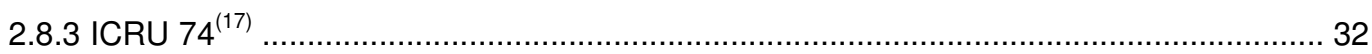

2.8.4 Código de Prática Internacional para Dosimetria em Radiodiagnóstico TRS 457 da

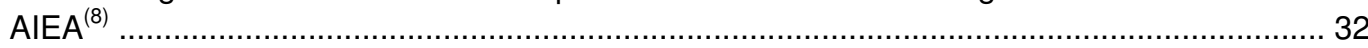

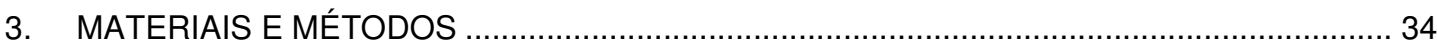

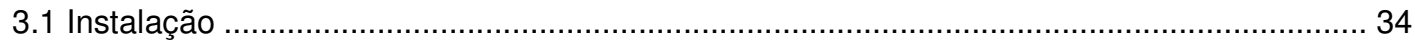

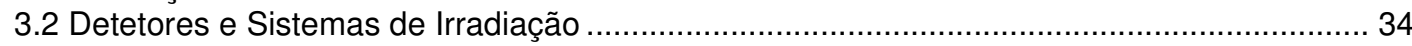

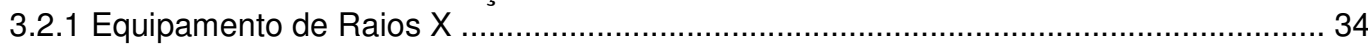

3.2.2 Sistema de Referência Padrão Secundário ............................................................ 35

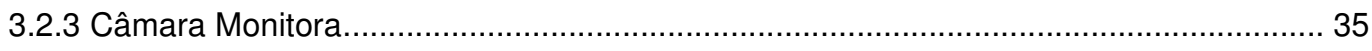

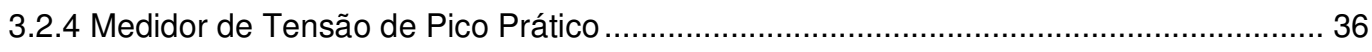

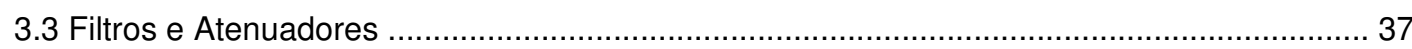

3.4 Fatores determinados na Caracterização das Qualidades de radiação ................................ 38

3.5 Metodologia para estabelecimento de campos padrões ...................................................... 39

3.5.1 Metodologia para Caracterização de Qualidades de Feixes de Raios X ....................... 40

3.5.2 Metodologia Alternativa recomendada pela IEC 61267 e pelo TRS-457 para

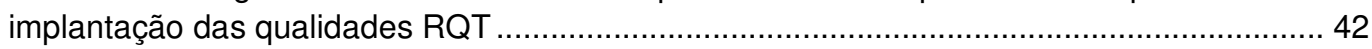

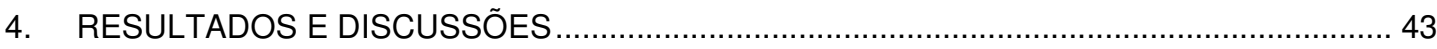

4.1 Controle de Qualidade da Câmara de ionização tipo lápis e do tubo de raios X.................... 43

4.1.1 Controle de Qualidade da Câmara de Ionização ............................................................ 43 
4.1.2 Exatidão e Reprodutibilidade da tensão no tubo (kV):.... 45

4.1.3 Linearidade e Reprodutibilidade da Taxa de Kerma no ar: .................................... 47

4.1.4 Exatidão e Reprodutibilidade do Tempo de Exposição: ......................................... 49

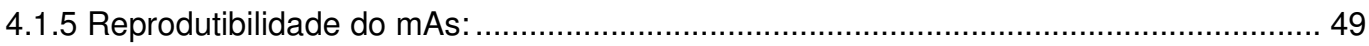

4.2 Determinação da homogeneidade do campo de radiação ......................................... 50

4.3 Determinação da filtração inerente do tubo ............................................................ 51

4.4 Determinação do "Practical Peak Voltage" (PPV) ................................................... 52

4.5 Estabelecimento das qualidades de feixe (RQT8, RQT9 e RQT10)...............................54

4.6 Estabelecimento das qualidades de radiação (RQT 8, RQT 9, RQT 10) pela Metodologia

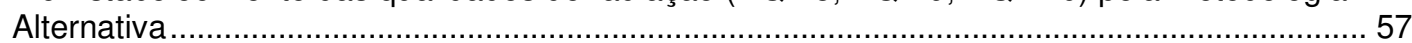
4.7 Determinação dos Fatores de Qualidade e das Taxas de Kerma no Ar para as Qualidades $\mathrm{RQT}$

4.8 Metodologia de Calibração das Câmaras de Ionização Tipo Lápis ..................................62

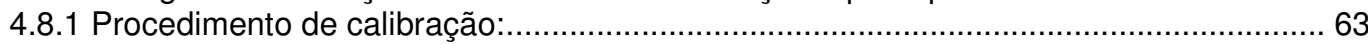

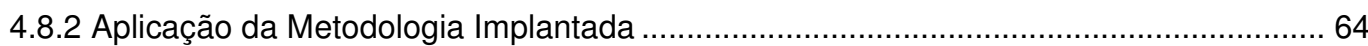

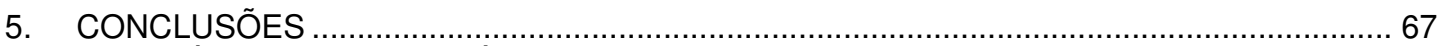

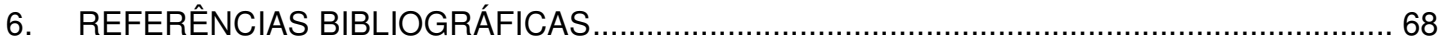




\section{INTRODUÇÃO}

Radiodiagnóstico é a prática, na qual feixes de radiação, geralmente radiação $X$, são usados para produzir uma imagem com o propósito de se obter um diagnóstico, que irá excluir ou avaliar o desenvolvimento de uma condição patológica ${ }^{(1)}$.

A prática médica envolvendo a radiação ionizante é de longe a maior contribuição à exposição da população à radiação produzida pelo homem, cerca de $95 \%$ da dose total é proveniente deste tipo de radiação. Em todo o mundo são realizados anualmente aproximadamente 2 bilhões de exames de radiodiagnóstico, 32 milhões de procedimentos de medicina nuclear e 5,5 milhões em radioterapia ${ }^{(2)}$. Dentre as exposições diagnósticas, $78 \%$ são devidas a raios $X$ médico, $21 \%$ devidas a raios $X$ dental e $1 \%$ devido a técnicas de medicina nuclear ${ }^{(3)}$. Entre os métodos de diagnóstico por imagem que utilizam radiação ionizante, a tomografia computadorizada é o exame que proporciona maior dose para o paciente ${ }^{(4)}$.

Nos anos 70, a técnica de tomografia computadorizada (CT) revolucionou o radiodiagnóstico. Está técnica, normalmente utiliza um feixe de raios $\mathrm{X}$ rotacional, um grupo de detectores e um computador para a reconstrução das imagens da anatomia interna do paciente. O princípio básico da tomografia computadorizada é baseado na possibilidade de se reproduzir um objeto bi ou tridimensional a partir de múltiplas projeções deste objeto. A imagem tomográfica é formada a partir de um conjunto de projeções de uma região do corpo ${ }^{(5)}$.

Devido à característica especial de construção e de utilização de um tomógrafo, uma grandeza específica, derivada da principal grandeza radiológica aplicada ao radiodiagnóstico (Kerma no ar) foi definida. Essa grandeza é chamada de índice de kerma em tomografia computadorizada (CTKI), também conhecido como CTDI e é dado pelo quociente da integral do kerma no ar ao longo de uma linha paralela ao eixo de rotação de um scanner de CT sobre um comprimento de $100 \mathrm{~mm}$ pelo produto entre o número de seções tomográficas (n) 
e a espessura nominal de corte (T). Para esta medição, é necessária a utilização de um instrumento de medição especial, conhecida como câmara de ionização tipo lápis, cuja principal característica é apresentar uma resposta uniforme a radiações incidentes em todos os ângulos ao redor do seu eixo ${ }^{(5)}$.

Existem requisitos para o controle e otimização do projeto e uso dos sistemas de radiodiagnóstico. Os principais objetivos da dosimetria de pacientes em radiodiagnóstico são o estabelecimento, uso e avaliação dos níveis de orientação $^{(6)}$ ou níveis de referência $^{(7)}$ e a determinação dos parâmetros dosimétricos e de desempenho do sistema de raios $X$.

O Laboratório de Calibração de Instrumentos (LCI) do IPEN realiza, há mais de 30 anos, calibração de instrumentos medidores de radiação, que são empregados em medições de radioproteção, radiodiagnóstico e radioterapia. Este serviço é prestado a hospitais, indústrias, clínicas e outros usuários localizados em todo o Brasil. Além do serviço de calibração, também são oferecidos os serviços de irradiação em campos padrões de amostras e novos materiais tanto para o Brasil como para outros países da América Latina. O aumento do número de equipamentos testados anualmente faz necessário o desenvolvimento contínuo de novos projetos para o aperfeiçoamento e a implementação dos métodos já existentes, bem como o estabelecimento de novas técnicas e a consequente ampliação dos serviços de calibração prestados.

Desde a publicação do Código de Prática da Agência Internacional de Energia Atômica, TRS $457^{(8)}$, observa-se que muitos laboratórios a nível nacional e internacional vêm estudando e realizando trabalhos relacionados à aplicabilidade desta norma. No Brasil, no ano de 2009 foram caracterizadas algumas qualidades de radiação no $\mathrm{LCl}$ já utilizando a nova revisão da norma IEC $61267^{(9)}$ e o Código de Prática da AIEA ${ }^{(8)}$. A partir desta data, foram estudadas as principais características das novas qualidades de radiação, referentes às várias técnicas radiológicas aplicadas clinicamente, como a fluoroscopia ${ }^{(10)}$, radiologia convencional $^{(11)}$, mamografia ${ }^{(12)} \mathrm{e}$, neste trabalho, a tomografia computadorizada. Além disso, também foi implementado um programa de controle da qualidade para os equipamentos de radiação $X$ do Laboratório de Calibração de Instrumentos do IPEN, que são utilizados tanto para atividades de calibração como para o desenvolvimento de projetos de pesquisa ${ }^{(13)}$. 
Alguns laboratórios no exterior vêm implantando e estudando métodos de calibração e dosimetria relacionados a todo o campo de radiodiagnóstico ${ }^{(14,15,16)}$, buscando assim, uma melhor abordagem da dosimetria clínica como relata o documento ICRU $74^{(17)}$ do ano de 2005 e de procedimentos para calibração e realização de medidas dosimétricas como relata o Código de Prática TRS 457 do ano de $2007^{(8)}$. Estes estudos demonstram preocupações atuais em relação aos procedimentos para calibração e a realização de medições dosimétricas aplicadas tanto em laboratórios como em centros clínicos de radiodiagnóstico.

$\mathrm{O}$ LCl implantou, inicialmente, qualidades de radiação $\mathrm{X}$ abrangendo o intervalo de energia variando de 50 a $150 \mathrm{kV}$, com feixes de radiação simulando a entrada e saída em um paciente, conforme a recomendação da IEC 1267, de $1994^{(18)}$. De acordo com a norma IEC $61674^{(19)}$ os instrumentos utilizados em dosimetria de sistemas de CT devem ser calibrados nos feixes de $120 \mathrm{kV}$, correspondendo às qualidades RQR9, feixe não atenuado e RQA9, feixe atenuado, definidas na IEC $1267^{(18)}$. Finalmente, no ano de 2009, após a recalibração de seus instrumentos de referência, estas qualidades foram novamente implantadas, agora seguindo a revisão da IEC 61267 do ano de $2005^{(9)}$.

Para calibração nas qualidades de $\mathrm{CT}$, esta revisão prevê a utilização de energias entre 100 e $150 \mathrm{kV}$, implantadas a partir das qualidades não atenuadas, denominadas $R Q R$, utilizando-se filtros especiais de cobre inseridos no feixe de radiação, aqui estas qualidades recebem a denominação RQT.

\subsection{OBJETIVOS}

O objetivo deste estudo foi estabelecer, no Laboratório de Calibração de Instrumentos do Instituto de Pesquisas Energéticas e Nucleares (LCl), as novas qualidades de radiação (RQT's) utilizadas em aplicações de CT segundo norma IEC 61267. Além disso, estabelecer uma nova metodologia de calibração específica para as câmaras de ionização tipo lápis, que são utilizadas na dosimetria de feixes de CT, seguindo recomendações do novo Código de Prática da AIEA (TRS 457). Com isso, objetivo final deste trabalho é tornar o LCl apto a 
realizar a calibração das câmaras lápis dentro das mais recentes recomendações metrológicas internacionais, além de promover um alto nível de rastreabilidade em seus serviços de calibração.

\subsection{REVISÃO BIBLIOGRÁFICA}

No Brasil, foi publicada pelo Ministério da Saúde, em 1998, a Portaria no. $453^{(20)}$ aprovando o Regulamento Técnico que estabelece as diretrizes básicas de proteção radiológica em radiodiagnóstico médico e odontológico e dispõe sobre o uso dos raios $X$ diagnósticos em todo o território nacional. Esta portaria estabelece que os serviços de saúde devam implantar Programas de Garantia da Qualidade que compreendam a execução do controle de qualidade dos equipamentos e do controle de procedimentos, estabelecendo as freqüências com que devem ser realizados. Além disso, esta portaria estabelece que os instrumentos para medição de níveis de radiação em levantamentos radiométricos e dosimetria de feixes devem ser calibrados a cada dois anos em laboratórios credenciados, rastreados à rede nacional ou internacional de metrologia das radiações ionizantes, nas qualidades de feixes de raios $X$ diagnósticos.

Em 2006, a IAEA publicou um conjunto de recomendações de segurança aplicadas ao radiodiagnóstico utilizando radiação $X^{(21)}$ visando auxiliar as autoridades regulatórias na aplicação do International Basic Safety Standards for Protection against lonizing Radiation and for the Safety of Radiation Sources (BSS), que também foi publicado como Safety Series No. 115 em 1996 ${ }^{(22)}$. Este documento recomenda que para a garantia da qualidade, as medições em radiodiagnóstico devem ser realizadas com instrumentação rastreável a laboratórios padrões de dosimetria ou com certificados de calibrações fornecidos por laboratórios acreditados.

Em 2007, a Agência Internacional de Energia Atômica (AIEA) desenvolveu um código de prática (Technical Reports Series no $457^{(8)}$ ) para a dosimetria em radiodiagnóstico que deve ser adotada pelos laboratórios de dosimetria e calibração, além de apresentar recomendações sobre a utilização de equipamentos de medida e da aplicação de procedimento de controle de qualidade nas clínicas de radiodiagnóstico. O seu principal objetivo é ajudar a se alcançar e manter um alto nível de qualidade metrológica em dosimetria, para o 
aperfeiçoamento e implementação de padrões rastreáveis a nível nacional e garantir o controle da dose em radiodiagnóstico em todo o mundo.

Desde a primeira publicação da norma IEC 1267, na área de radiodiagnóstico, foram desenvolvidos no IPEN, por meio de trabalhos de doutorado, uma metodologia para a calibração de instrumentos utilizados em radiodiagnóstico e um sistema de referência para a calibração de medidores de tensão de pico $(\mathrm{kVp})^{(23,24)}$ além do estabelecimento de um método específico para calibração de câmaras de ionização utilizadas em sistemas de tomografia computadorizada $^{(5)}$. Estes métodos foram implantados seguindo as recomendações desta primeira versão da norma IEC 1267, publicada em $1994^{(18)}$. Desde 1997 o LCl vem calibrando cerca de 200 instrumentos por ano nestas qualidades. Depois de alguns anos de revisão a IEC publicou uma nova versão da norma IEC 1267, passando a ser chamada de IEC $61267^{(9)}$, no final do ano de 2005.

As principais alterações dizem respeito à introdução da grandeza tensão de pico prático (PPV) para medir a tensão do tubo de raios $X$; introdução de um novo procedimento para estabelecer as qualidades de radiação; determinação da quantidade de filtração adicional e a revisão das qualidades de radiação e das condições de radiação. Para tomografia computadorizada foram introduzidos filtros especiais de cobre para simulação do paciente.

Estudos recentes possibilitaram a adaptação desta revisão da norma pelo $\mathrm{LCl}$. Foram implantadas as qualidades RQR (feixe de entrada) RQA (feixes atenuados), qualidades para mamografia (RQR-M e RQA-M), para fluoroscopia (RQC), além de um programa de base para controle de qualidade dos equipamentos de raios $\mathrm{X}$ do $\mathrm{LCl}$. As características, aspectos e propriedades do sistema de radiação $X$ já utilizado para as calibrações foram determinadas para se estabelecer um conjunto bem definido de condições de radiação que podem oferecer uma ferramenta importante em muitas situações.

Após esta caracterização será necessário estabelecer novas metodologias de acordo com as variadas aplicações em radiodiagnóstico de acordo com o código de prática recomendado pela AIEA ${ }^{(8)}$. Foram identificadas sete aplicações diferentes, dentro das técnicas de radiodiagnóstico, para os instrumentos que normalmente são encaminhados para a calibração no $\mathrm{LCl}^{(25)}$, são elas: fluoroscopia, mamografia, tomografia computadorizada, radiologia 
convencional, proteção radiológica, medidores multi-função, e proteção radiológica/radiologia convencional. Para a Tomografia Computadorizada, ainda não existe, no Brasil, uma metodologia específica para se utilizar as câmaras de ionização do tipo lápis com calibração em filtração de cobre para serem utilizadas nos simuladores específicos para determinação da dose dos pacientes em CT. 


\section{FUNDAMENTOS TEÓRICOS}

Neste capítulo são abordados os conceitos teóricos básicos necessários para o entendimento do que vai ser relatado neste trabalho. Será feita uma explanação das principais grandezas e unidades utilizadas no trabalho, do princípio de funcionamento de um sistema de raios $X$, das câmaras de ionização, das principais características dos campos de radiação utilizadas para diferenciar as qualidades de feixes, como também do procedimento de calibração de câmaras lápis (CT) e do conceito de rastreabilidade, tão fundamental na metrologia.

\subsection{TUBO DE RAIOS $X$}

Os tubos de raios $\mathrm{X}$ são constituídos basicamente de um eletrodo negativo, denominado catodo, e um eletrodo positivo denominado anodo. Estes elementos estão dispostos no interior de um invólucro de vidro dentro do qual é produzido alto vácuo e mantido a pressões menores que $1,3 \times 10^{-6} \mathrm{kPa}$ $\left(1,3 \times 10^{-8} \mathrm{~Pa}\right)$. Este invólucro possui uma pequena área com uma espessura de vidro menor que o restante do tubo, chamada janela, por onde saem os fótons de raios $X$ que serão utilizados na produção da radiografia, conforme esquema demonstrado na FIG. 1.

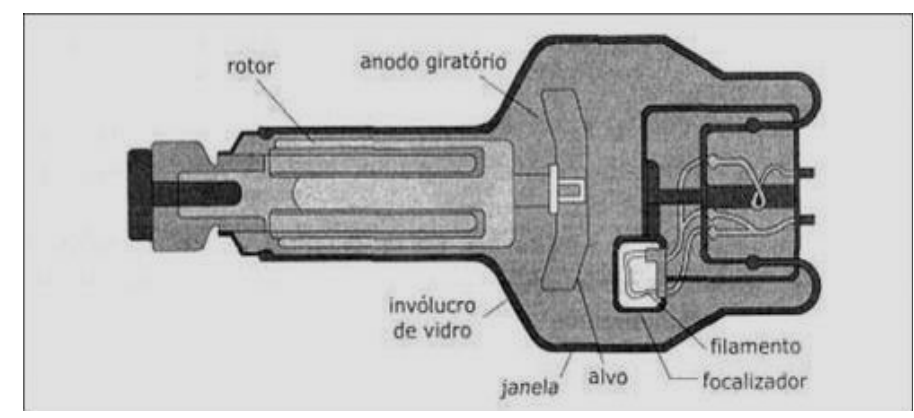

Figura 1. Arranjo de um tubo de raios $\mathrm{X}$. 


\subsubsection{Produção de Raios X}

Em um tubo de raios $X$ a maioria dos elétrons incidentes sobre 0 alvo perde sua energia cinética devido às inúmeras colisões, convertendo-a em calor. Por esse motivo o alvo deve ser feito de material de alto ponto de fusão, sendo ainda necessário o seu resfriamento por diversos métodos.

Apenas uma pequena parte dos elétrons incidentes se aproxima dos núcleos atômicos do alvo, sendo gerado nesse processo fótons de raios $\mathrm{X}$ devido à desaceleração brusca desses elétrons (radiação de freamento ou bremsstrahlung). Os fótons de raios $\mathrm{X}$ podem ter qualquer energia, desde valores próximos do zero até um valor máximo, determinado pela energia do elétron incidente. Quando se tem um feixe de elétrons, haverá sempre um espectro contínuo de raios $X$ de várias energias (vários comprimentos de onda) ${ }^{(26)}$.

Existem dois mecanismos de produção de raios $\mathrm{X}$, dependendo do tipo de interação entre os elétrons e $O$ alvo: radiação de freamento e raios $X$ característicos. A radiação de freamento ocorre quando elétrons rápidos interagem com a matéria e parte de sua energia é convertida em radiação eletromagnética na forma de Bremstrahlung. Enquanto que os raios $X$ característicos ocorrem devido ao deslocamento de um elétron de seu orbital por algum processo de excitação, esse átomo pode ir para um estado excitado por um curto período de tempo, podendo logo após voltar ao seu estado natural (estado de energia mais baixo), liberando energia na forma de raios $X$ característicos nesse processo ${ }^{(26)}$. Os esquemas da FIG.2 demonstram este processo. 

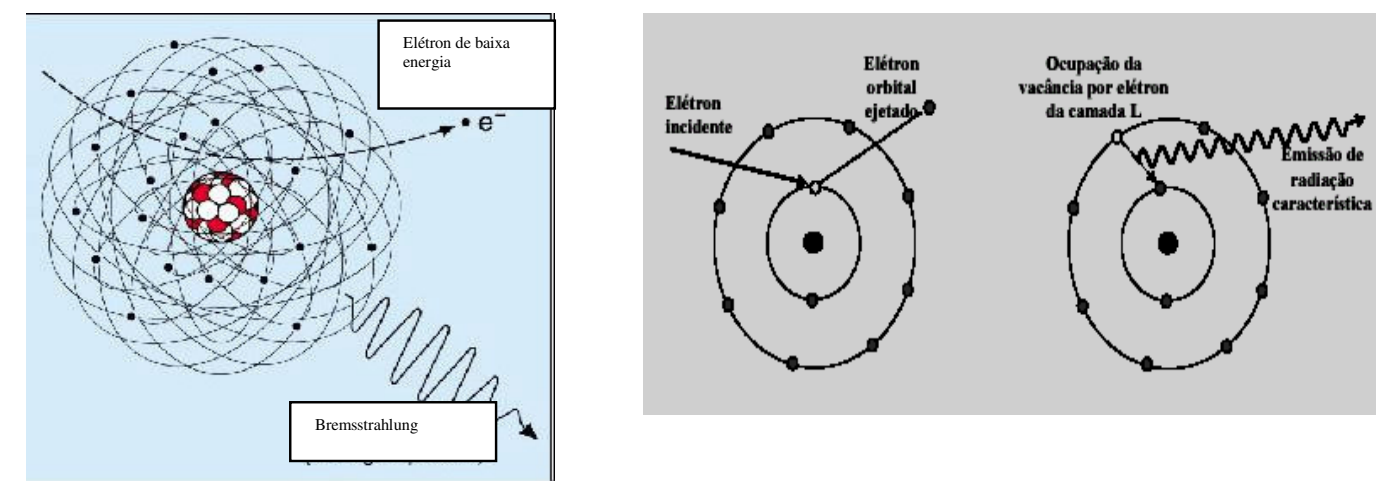

Figura 2. Radiação de freamento (à esquerda) e Radiação característica (à direita).

\subsubsection{Espectros de Feixes de Raios X}

Pode-se definir um espectro de raios $X$ como a distribuição de energia da radiação produzida em um feixe de raios $X$. $O$ conhecimento do espectro de raios $\mathrm{X}$ permite, por exemplo, o entendimento das etapas de produção de imagens diagnósticas e, desse modo, viabilizando a redução de dose no paciente com a melhoria da qualidade da imagem produzida. $O$ espectro de energia e o número de fótons de um feixe de raios $\mathrm{X}$ podem ser modificados por alguns parâmetros de ajuste do sistema gerador de raios $X$, que alteram a intensidade $e$ a qualidade do feixe.

Um espectro de raios $X$ é basicamente formado por duas partes: uma contínua e outra em linhas discretas (estas partes são distintas e superpostas). A contínua é causada pelos raios $X$ de bremsstrahlung e surge de energias muito baixas até uma energia máxima, que é numericamente igual à diferença de potencial aplicada ao tubo (tensão). As linhas discretas decorrem dos raios $X$ característicos. A filtração inerente e adicional minimiza as energias baixas (indesejáveis), que poderiam ser absorvidas pelo paciente.

$A$ intensidade de um feixe de raios $X$ representa a quantidade de fótons produzidos e emitidos de um tubo de raios $X$. A quantidade de raios $X$ gerados é proporcional ao número atômico $(Z)$ do material componente do alvo. Além disso, existem ainda outros fatores que interferem na intensidade do feixe de raios $\mathrm{X}$ : a 
corrente aplicada ao tubo (mA), a forma de onda da tensão que pode alterar o número de elétrons emitidos em direção ao anodo, a espessura de material atenuador que o feixe atravessa e a distância percorrida pelo feixe até o ponto de medição. Assim, a qualidade de um feixe de raios $X$ também é afetada por vários fatores: material do alvo do tubo, forma de onda da tensão, filtração do feixe, tensão de pico. O material do alvo e a forma de onda da tensão são característicos do equipamento de raios $X$, desse modo não podendo ser alterados ou modificados pelo operador.

Pode-se dizer que a energia máxima dos fótons emitidos de um tubo de raios $X$ é igual à energia cinética máxima dos elétrons que se chocam no alvo, determinada pela escolha da tensão de pico (kVp). Assim, a qualidade do feixe de raios $X$ produzido é proporcional à tensão de pico escolhida: quanto mais energética for a radiação, maior também será o valor da camada semi-redutora necessária para reduzir a intensidade do feixe à metade. Tem-se que a produção de raios $X$ é diretamente proporcional ao número de elétrons emitidos pelo filamento que atingem e colidem com o alvo. Quanto maior for a corrente no catodo do tubo de raios $\mathrm{X}$, maior será a quantidade de elétrons, e assim maior será a produção de raios X. O aumento da corrente não modifica a qualidade do feixe, embora possa ocorrer uma ligeira variação do fator de ondulação (ou ripple) da tensão com o novo valor de corrente selecionada ${ }^{(26)}$.

É importante lembrar que quanto maior o número atômico do material do alvo do tubo de raio $X$, maior também será a energia dos raios $X$ característicos. A FIG. 3 demonstra um espectro típico de um feixe de raios $\mathrm{X}$.

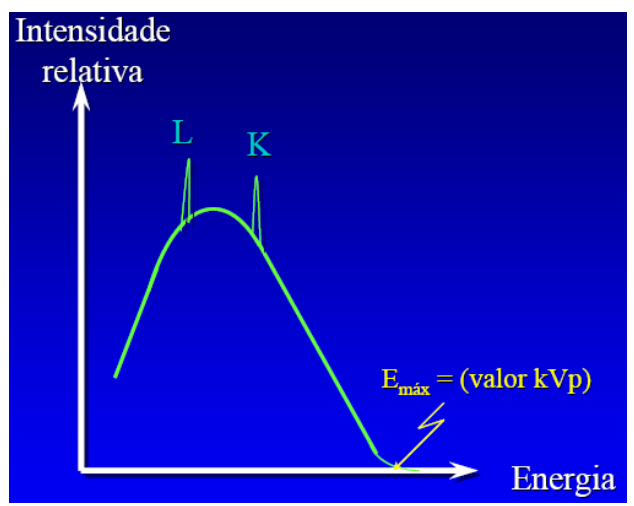

Figura 3: Espectro típico de um feixe de raios $\mathrm{X}$. 


\subsection{ASPECTOS GERAIS DA TOMOGRAFIA COMPUTADORIZADA}

A imagem radiográfica vem apresentando mudanças significativas nas áreas clínica e tecnológica. $\mathrm{O}$ desenvolvimento e o aperfeiçoamento das técnicas têm como objetivo otimizar a aquisição de imagens radiológicas e melhorar os cuidados com o paciente. $\mathrm{O}$ aparecimento da tomografia computadorizada, ferramenta que revolucionou a radiologia, contribuiu fortemente para os avanços no campo do radiodiagnóstico por imagem ${ }^{(27)}$.

A tomografia computadorizada, como a maioria das invenções, foi resultado de muitas pesquisas. J. Radon, um matemático australiano, trabalhando com teoria gravitacional, provou em 1917 que um objeto bi ou tri-dimensional poderia ser reproduzido através de um conjunto infinito de todas as suas projeções.

Goldfrey N. Hounsfield, engenheiro eletrônico em Middlesex, na Inglaterra, foi quem apresentou à sociedade a tomografia computadorizada como método de radiodiagnóstico por imagem no ano de 1972, o original tomógrafo EMI (Electric and Musical Industries). Hounsfield e Cormack dividiram o Prêmio Nobel de Medicina em $1979^{(26)}$. O primeiro equipamento foi fabricado pela empresa EMI e constava de um tubo de raios $\mathrm{X}$ simples de anodo fixo e alvo de dimensões relativamente grandes, mas suficientemente capaz de suportar o calor produzido pelos sucessivos bombardeios de elétrons. Essa primeira máquina era utilizada para escanear o cérebro. Em 1974, Dr. Robert Ledley, professor da Universidade de Georgetown, desenvolveu o primeiro equipamento de CT de corpo inteiro, provavelmente o primeiro desenvolvimento técnico de grande importância em radiodiagnóstico.

$\mathrm{Na}$ tomografia computadorizada, um feixe de raios $\mathrm{X}$ colimado é direcionado ao paciente, e a radiação atenuada em diferentes proporções é medida por detectores cujos sinais são digitalizados e transmitidos a um computador para o processamento dos dados. Analisando o sinal dos detectores, a imagem é reconstruída e disponibilizada no monitor do computador. A reconstrução da imagem da seção transversal da anatomia é realizada por meio 
de equações matemáticas adaptadas ao processamento computacional ${ }^{(28)}$. Um esquema de funcionamento de um sistema de CT pode ser verificado na FIG. 4

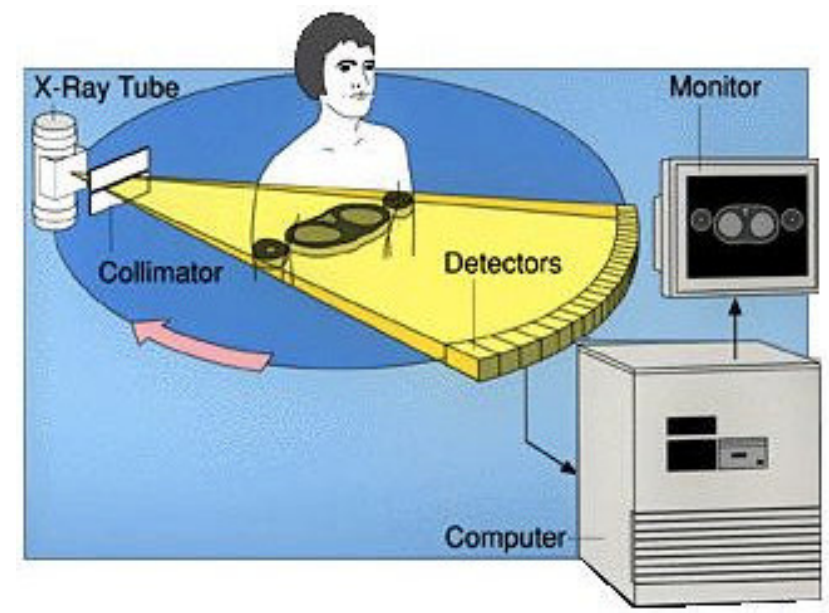

Figura 4 : Esquema de funcionamento de um sistema de $\mathrm{CT}^{(28)}$

Atualmente nos tomógrafos, os detectores estão distribuídos nos 360 graus do gantry, ocupando todo $\mathrm{o}$ anel. $\mathrm{A}$ fonte de raios $\mathrm{X}$ passou a girar em torno do conjunto de detectores fixos havendo uma melhoria significativa na estabilidade dos detectores. As principais desvantagens dessa geração foram o aumento da dose nos pacientes e o aumento do custo, devido ao crescimento no número detectores ${ }^{(28,29,30)}$. As diferentes gerações de tomógrafos são demostradas na FIG. 5.

\section{Feixe lápis (1972)}

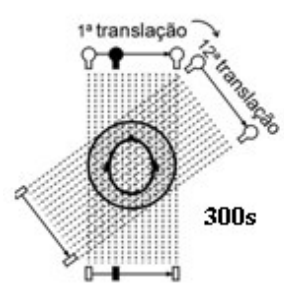

(a) 1a Geração

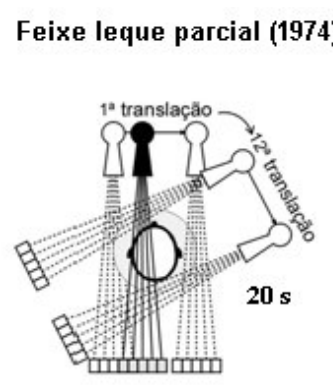

(b) 2a Geração

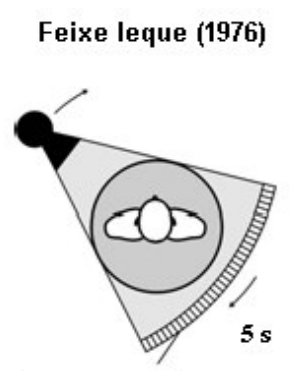

detectores rotativos em arco

(c) 3a Geração

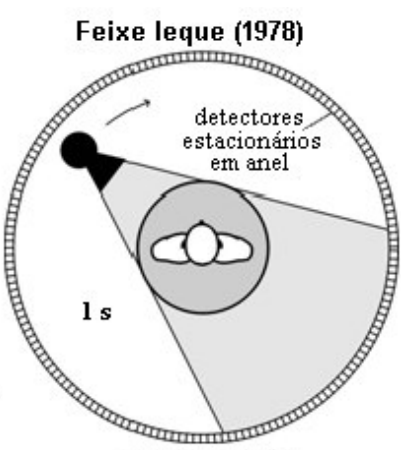

(d) 4 a Geração

Figura 5: Gerações dos tomógrafos. Fonte: SILVA, $2005^{(31)}$. 
Em 1989, com o aprimoramento das técnicas de CT, foi introduzido o tomógrafo helicoidal (ou espiral). As CTs helicoidais permitem a rotação contínua do tubo ao deslocamento simultâneo da cama do paciente (FIG. 6). Os cortes tomográficos são obtidos com a cama em movimento, de modo que as "fatias" não são necessariamente planas, enquanto o método de aquisição assemelha-se a um modelo espiral. Os dados são adquiridos continuamente e é possível reconstruir qualquer imagem ao longo do eixo de translação por meio de um algoritmo de interpolação. A principal vantagem dos CTs helicoidais é a capacidade de se obter a imagem de um grande volume de tecido em uma única respiração, reduzindo os artefatos gerados na imagem devido aos movimentos do paciente $^{(28,29)}$.

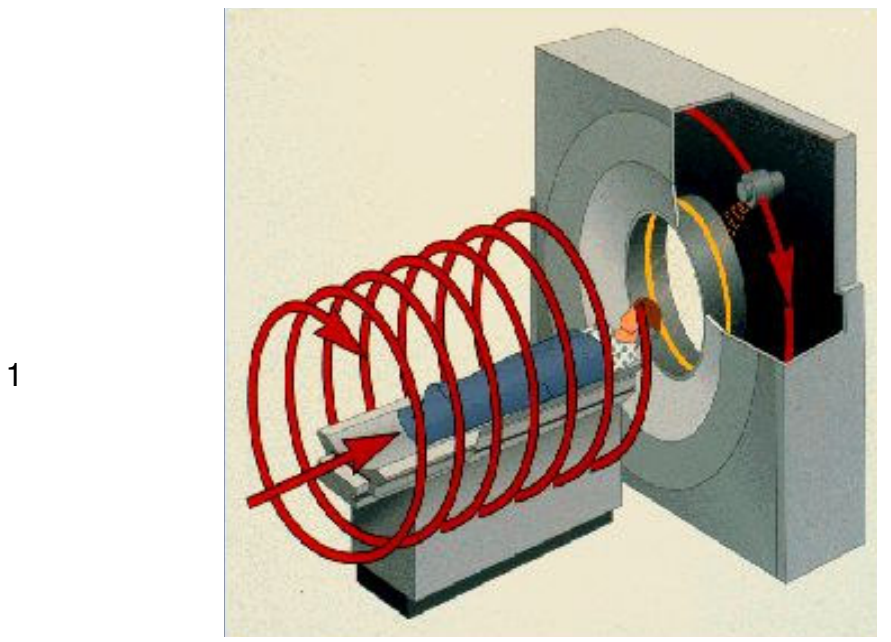

Figura 6 : Tomógrafo Helicoidal.

Com o desenvolvimento da CT helicoidal surgiu a definição passo (pitch). O passo, ou fator de passo, é dado matematicamente pela Equação 1:

$$
p=d / h
$$

onde d é o deslocamento da cama em uma rotação do tubo de raios $\mathrm{X}$ de $360^{\circ}$ e $\mathrm{h}$ é a espessura do corte. Tomógrafos mais rápidos têm sido desenvolvidos devido à necessidade de obtenção de imagens funcionais do corpo humano. Outro exemplo dessa nova geração é o tomógrafo de multicortes. Esses equipamentos 
apresentam múltiplos conjuntos de anéis detectores estrategicamente emparelhados, tornando-se possível a aquisição simultânea de vários cortes de imagens. A abertura do colimador é maior e conseqüentemente mais raios $X$ que são produzidos pelo tubo são utilizados na produção da imagem (FIG. 7).

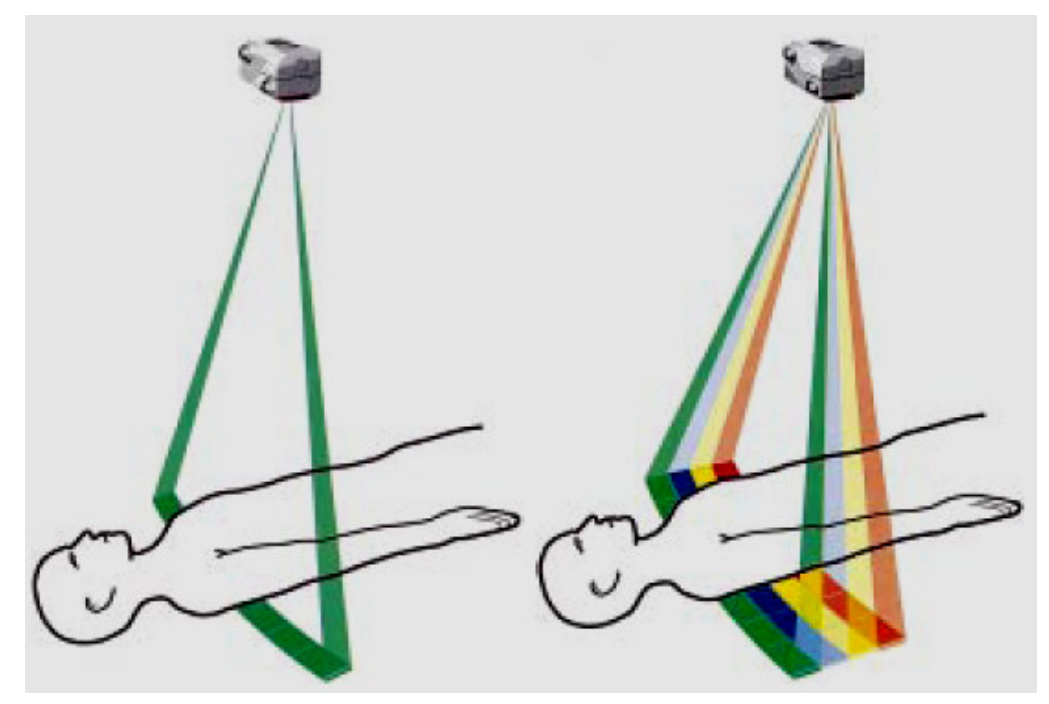

Figura 7 : Feixe de raios-X com uma única linha de detectores e outro com um conjunto de detectores (multicortes).

\subsubsection{Dose de radiação em CT}

A distribuição de dose num paciente submetido a um exame de tomografia é completamente diferente da que ocorre num exame de radiografia convencional. Na radiografia convencional, a dose decresce continuamente desde a entrada do feixe de raios $X$ à sua saída do paciente. Na tomografia computadorizada, que apresenta geometria rotacional do tubo de raios $\mathrm{X}$, a dose é quase igualmente distribuída no plano da varredura. $O$ paciente é uniformemente irradiado em todas as direções.

A informação da dose em CT é importante por diversas razões. A tomografia é uma modalidade de radiodiagnóstico amplamente utilizada, que proporciona uma das mais altas doses em radiologia. Além disso, essa técnica produz melhores imagens quando a dose é aumentada. Por último, trata-se de uma técnica digital cuja imagem não se torna muito escura quando a dose é 
excessiva ${ }^{(32)}$. Na TAB.1 estão as doses efetivas de referência típicas para as várias técnicas radiológicas existentes.

Tabela 1. Referências de doses efetivas típicas para as várias técnicas radiológicas.

\begin{tabular}{|c|c|c|}
\hline Tipo de Procedimento & $\begin{array}{c}\text { Dose Efetiva Média em } \\
\text { Adulto } \\
(\mathrm{mSv})\end{array}$ & $\begin{array}{c}\text { Dose Equivalente } \\
\text { Estimada } \\
\text { (№ de raios X de tórax) }\end{array}$ \\
\hline Raios X dental & $0,005-0,01$ & $0,25-0,5$ \\
\hline Raios X de tórax & 0,02 & 20 \\
\hline Mamografia & 0,4 & $100-800$ \\
\hline CT & $2-16$ & $10-2050$ \\
\hline Medicina Nuclear & $0,2-41$ & $250-3500$ \\
\hline
\end{tabular}

A maioria dos equipamentos de CT emite um feixe de raios $X$ em forma de leque que possui uma seção transversal estreita. Ao longo do eixo longitudinal ao paciente (eixo $z$ ), o feixe é muito fino, de alguns milímetros de espessura ( $1 \mathrm{a}$ $10 \mathrm{~mm}$ ). A FIG. 8 mostra um esquema de um feixe de raios $X$ típico em CT.

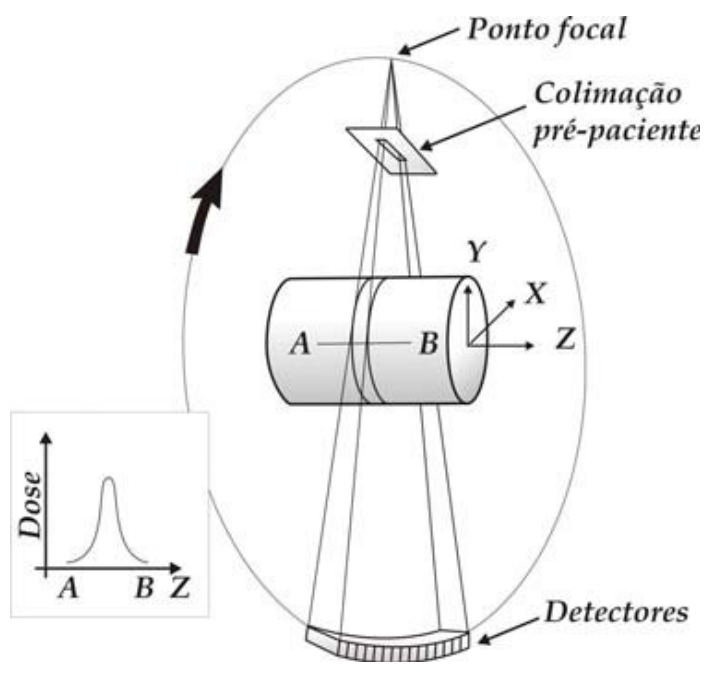

Figura 8: Feixe de raios $\mathrm{X}$ típico em tomografia computadorizada.

A intensidade do feixe de radiação pode ser representada graficamente ao se definir o eixo longitudinal do paciente como eixo z. No caso ideal, a 
intensidade da radiação ao longo do eixo $z$ teria o mesmo valor em qualquer posição dentro do feixe. Na realidade, a intensidade do feixe apresenta uma extremidade suavizada e a curva da intensidade ao longo do eixo $z$ apresenta uma forma de sino. A FIG. 9 apresenta o perfil de dose para um único corte.

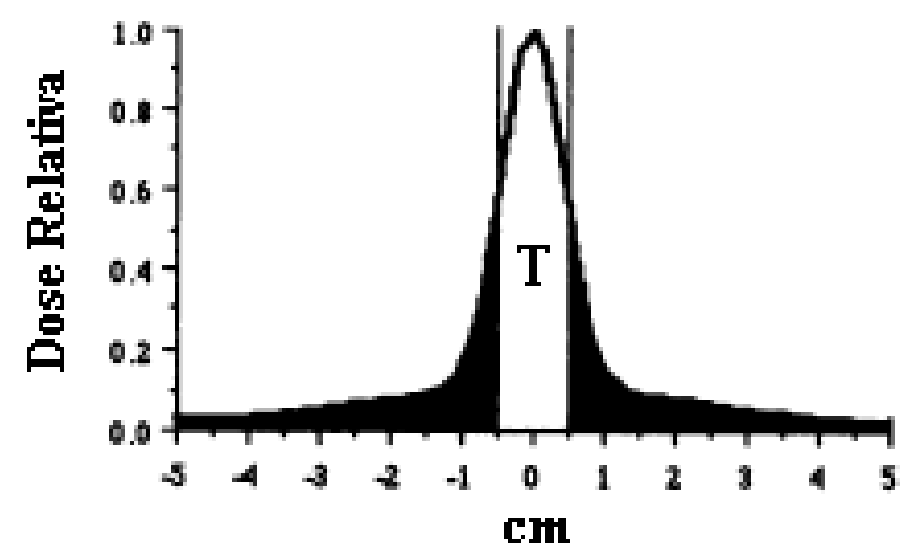

Figura 9: Perfil de dose para um único corte com espessura nominal de $\mathrm{T}=10 \mathrm{~mm}$. Fonte: ROTHENBERG; PENTLOW, $1992^{(32)}$.

A área escura dessa Figura representa a dose recebida pelos tecidos exteriores à seção nominal do corte devido à combinação da divergência do feixe, penumbra e radiação espalhada. Portanto, quando seções adjacentes são escaneadas, a dose em qualquer seção é aumentada pela contribuição das outras seções. A magnitude desse aumento depende do número de cortes, da separação ou intervalo entre os cortes, e das características particulares do perfil de dose de um único corte. A FIG. 10 ilustra o perfil de dose para uma série de 15 cortes, com $10 \mathrm{~mm}$ de espessura e $10 \mathrm{~mm}$ de intervalo entre cortes. 


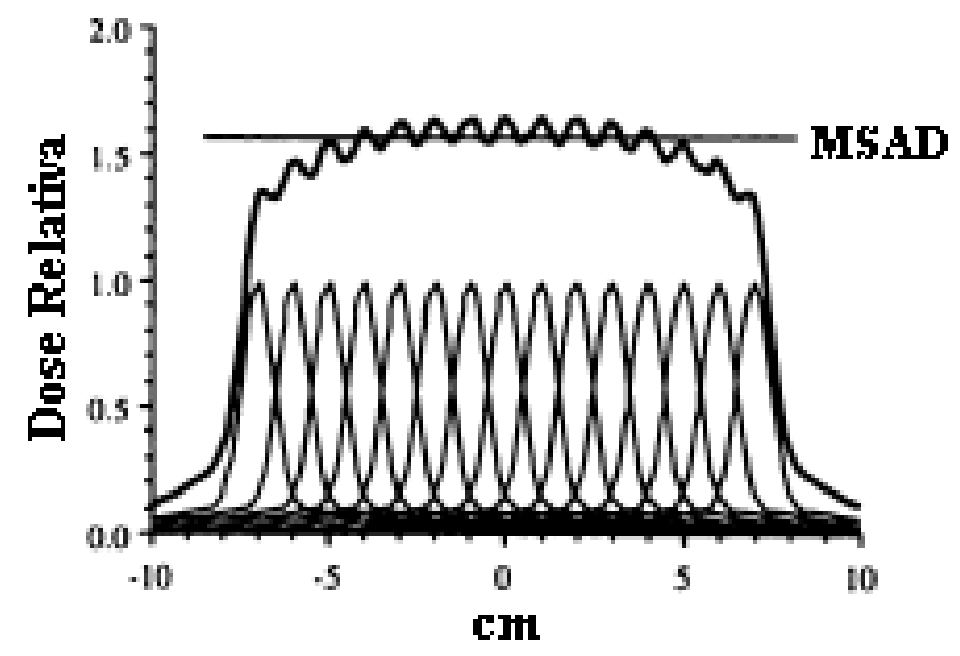

Figura 10: Perfil de dose para 15 cortes, com $10 \mathrm{~mm}$ de espessura e $10 \mathrm{~mm}$ de intervalo entre cortes. Fonte: ROTHENBERG; PENTLOW, $1992^{(32)}$.

$\mathrm{Na}$ avaliação da dose em CT tem-se utilizado: câmaras de ionização, dosímetros termoluminescentes (TLDs) e filmes dosimétricos. O dosímetro mais utilizado é a câmara de ionização do tipo lápis com $100 \mathrm{~mm}$ de comprimento, que é capaz de medir a integral do perfil de dose de um único corte com apenas uma varredura. Para determinar com detalhes esse perfil, geralmente é empregado um arranjo de TLDs ao longo do eixo z. O filme é o menos utilizado, ele apresenta a característica de possibilitar a medição da dose em vários pontos simultaneamente, no entanto, possui grande variação da resposta na faixa de energia dos raios $X^{(32)}$. 


\subsection{DETECÇÃO DA RADIAÇÃO}

A percepção da radiação, seja qualitativa ou quantitativa, só pode ser realizada com a ajuda de materiais ou instrumentos capazes de captar e registrar sua presença, um dispositivo capaz de medir a intensidade ou simplesmente indicar a presença de radiação é chamado de detector. A detecção é realizada pelo resultado produzido da interação da radiação com um meio sensível (detector). Em um sistema detector, os detectores de radiação, os elementos ou dispositivos sensíveis a radiação ionizante são utilizados para determinar a quantidade de radiação presente em um determinado meio de interesse. A integração entre um detector e um sistema de leitura (medidor), como um eletrômetro ou o invólucro de um detector é chamado de monitor de radiação. Existem diversos tipos de detectores, cada um com suas características e funções ${ }^{(33)}$. Na FIG. 11 encontra-se um esquema elétrico para a detecção da radiação, com os componentes de um detector a gás

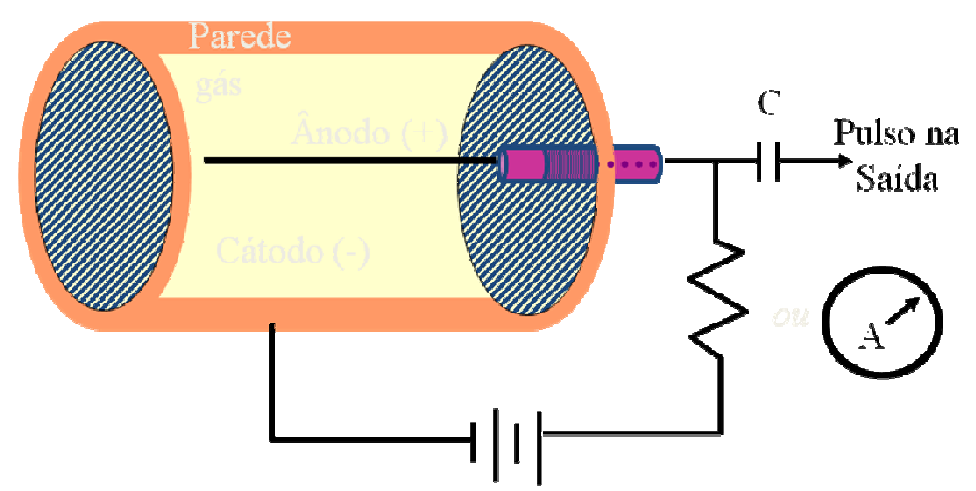

Figura 11: Diagrama simples de um detector a gás.

\subsubsection{Câmaras de lonização}

A dosimetria das radiações sempre esteve diretamente relacionada com a prática da radiologia. Com o objetivo de se controlar a intensidade de radiação, liberada pelos equipamentos de raios $X$ então existentes, foram desenvolvidos diversos tipos de sistemas detectores. Em meados dos anos 30 , devido à alta sensibilidade, à boa estabilidade e à boa reprodutibilidade, que fazem parte de suas características operacionais, a câmara de ionização tornouse o instrumento principal para a detecção de radiação $X$. 
Atualmente, apesar do surgimento de outros sistemas de medida, a câmara de ionização ainda é considerada o instrumento mais prático e preciso para medições de taxas de kerma no ar e de dose absorvida. No Brasil, nos últimos anos, diversas câmaras de ionização foram projetadas e construídas para diferentes aplicações, apresentando bons resultados ${ }^{(5,34,35)}$. As câmaras de ionização possuem basicamente um eletrodo coletor central e uma parede de material apropriado que delimita uma cavidade preenchida por um gás.

Os detectores que se baseiam na ionização de um gás são construídos levando-se em conta a coleta de íons produzidos pela radiação ionizante no volume sensível do detector. A câmara de ionização é o mais simples dos detectores a gás, sendo que sua operação está baseada na coleta de todas as cargas elétricas criadas por ionização direta, por meio da aplicação de um campo elétrico. Um esquema de uma câmara de ionização de ar livre está demonstrado na FIG. 12. O volume sensível do detector é delimitado pela parede da câmara e constitui uma cavidade preenchida por um gás ou mistura de gases, a uma pressão relativamente baixa, ou ambiente.

A correção da leitura de uma câmara de ionização não selada para variação de temperatura e pressão ambientais deve ser feita utilizando-se o fator de correção dado pela Equação 2:

$$
\mathrm{F}_{\mathrm{T}, \mathrm{p}}=[(273,15+\mathrm{T}) /(273,15+20)] \times[101,3 / \mathrm{p}]
$$

onde: $\mathrm{p}$ é a pressão em kPa e T é a temperatura em ${ }^{\circ} \mathrm{C}$.

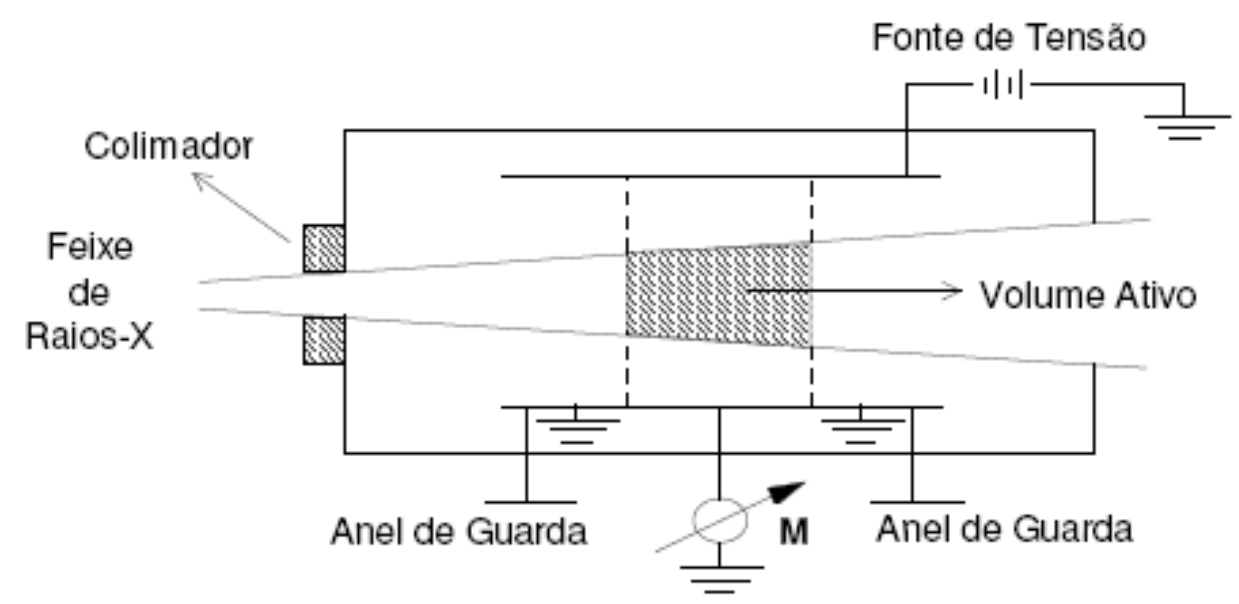

Figura 12: Esquema elétrico de uma câmara de ionização de ar livre. 
Existem vários tipos de câmaras de ionização com dimensões e formas de cavidades diferentes. O uso de cada uma depende da finalidade à qual é destinada (medir exposição, kerma no ar ou dose absorvida), bem como do tipo de radiação a ser medida, de sua intensidade e de sua variação no espaço e no tempo. Alguns modelos de câmaras de ionização disponíveis no mercado estão demosntrados na FIG. 13.
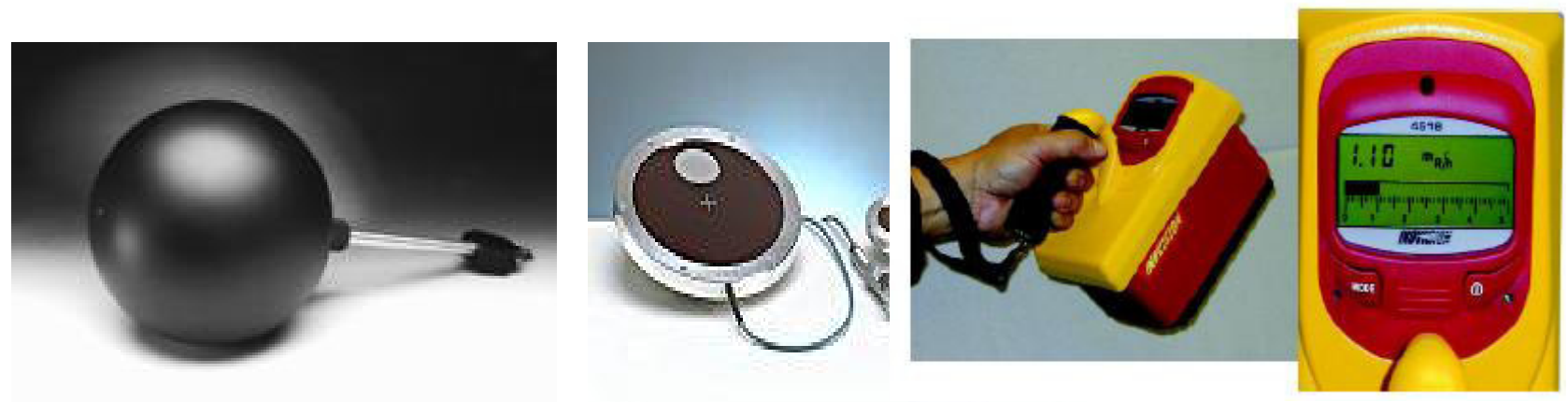

Figura 13: Modelos de câmaras de ionização.

\subsubsection{Câmaras de lonização Tipo Lápis}

A câmara de ionização utilizada em CT é uma câmara cilíndrica não selada e de comprimento entre 10 e $15 \mathrm{~cm}$, chamada câmara de ionização tipo lápis (FIG. 14). Estas câmaras são especialmente confeccionadas para utilização em feixes de radiação de Tomografia Computadorizada (CT), tanto para medições de kerma no ar como também em simuladores. Na FIG. 15 estão demonstrados os arranjos experimentais, tanto para a medição de dose com a câmara posicionada em um simulador de cabeça, quanto para uma medição de dose livre no ar.

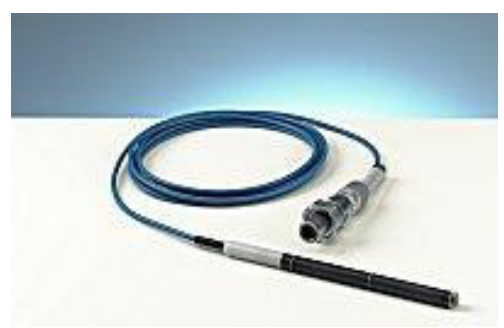

Figura 14: Câmara de ionização tipo lápis. 

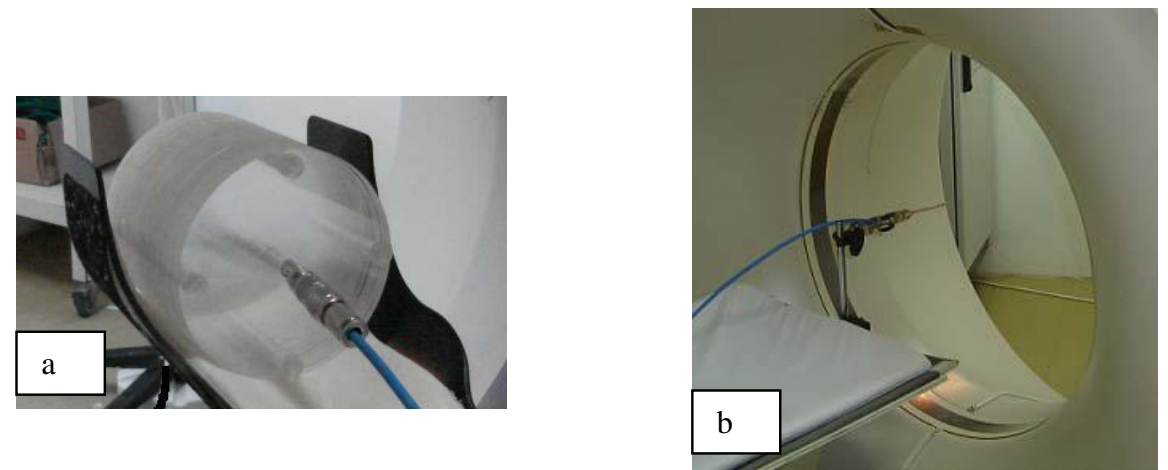

Figura 15: Arranjo experimental para avaliação da dose no simulador de cabeça

(a) e Arranjo experimental para avaliação da dose no ar (b).

A principal característica desta câmara de ionização é apresentar uma resposta uniforme a radiações incidentes em todos os ângulos ao redor do seu eixo, pois sua utilização nos equipamentos de CT exige uma geometria de irradiação específica devido ao movimento de rotação do tubo de raios $\mathrm{X}$.

A leitura apresentada por este tipo de câmara é em unidades de dose ou exposição vezes o comprimento (mGy.cm ou R.cm), facilitando o cálculo do CDTI (grandeza específica para CT). As câmaras de CT são projetadas para serem utilizadas dentro de objetos simuladores, que simulam uma situação clínica, com o objetivo de estimar doses em pacientes. Um esquema típico com as dimensões de uma câmara de ionização do tipo lápis pode ser visto na FIG. 6.

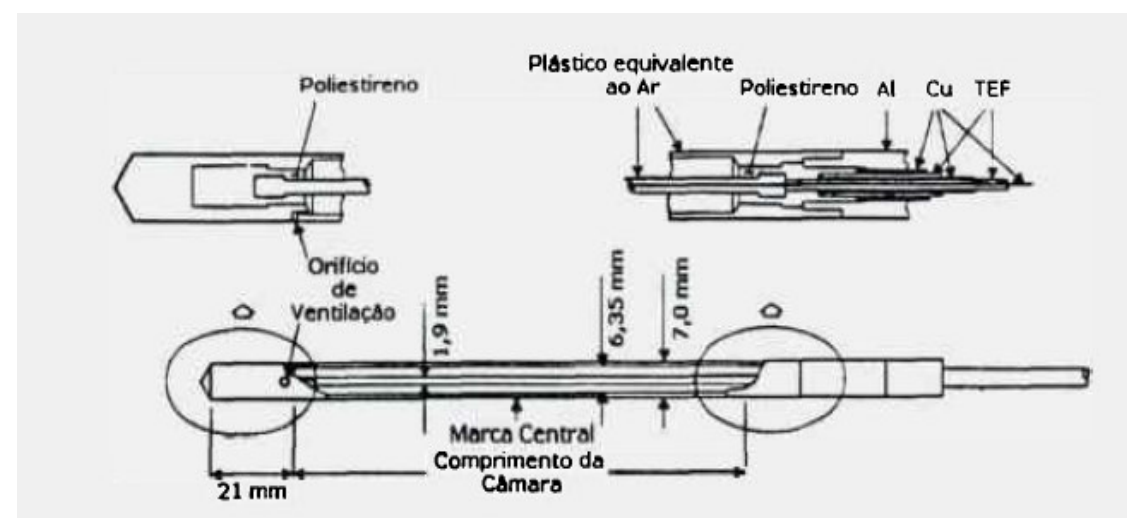

Figura 16: Esquema elétrico de uma câmara de ionização tipo lápis. 


\subsection{CALIBRAÇÃO DE INSTRUMENTOS}

Calibração de um instrumento significa determinar sua resposta a uma exposição de radiação conhecida envolvendo pelo menos um instrumento de referência ou padrão. De acordo com o Vocabulário Internacional de Metrologia, calibração é o conjunto de operações que estabelece, sob condições especificadas, a relação entre os valores indicados por um instrumento de medição ou sistema de medição ou valores representados por uma medida materializada de referência e os valores correspondentes das grandezas estabelecidas por padrões(36)). O coeficiente de calibração é utilizado para converter o valor indicado no instrumento para uma estimativa do valor real.

\subsubsection{Rastreabilidade}

Os instrumentos padrões estão classificados em categorias: padrões primários, secundários, terciários e os padrões nacionais.

Os padrões primários são instrumentos absolutos da mais alta qualidade metrológica. Eles são utilizados para calibração dos padrões secundários nos laboratórios de padronização primária.

Os padrões secundários são instrumentos calibrados em comparação com os padrões primários e são utilizados, pelos laboratórios de padronização secundária, para prestação de serviços de calibração de instrumentos.

Os padrões terciários são instrumentos calibrados em comparação com os padrões secundários e são utilizados nas medições rotineiras. Os padrões nacionais são instrumentos designados por uma autoridade nacional para representar, no país, o valor de todos os padrões de certa grandeza. Estes podem ser primário, secundário ou terciário ${ }^{(15)}$.

Para garantir a rastreabilidade de uma rede metrológica, é necessário que as qualidades dos feixes implantados em todos os laboratórios da cadeia de rastreabilidade sejam semelhantes. Por isso, existem as recomendações internacionais que definem parâmetros específicos para qualidades de feixes, buscando a uniformização entre os laboratórios para as diversas aplicações. No caso do Radiodiagnóstico a Norma IEC $61267^{(9)}$ e o TRS $457^{(8)}$ são atualmente as referências mais importantes. 


\subsection{GRANDEZAS E UNIDADES}

A medição das radiações ionizantes requer a quantificação tanto do campo de radiação no ponto de medida (através de grandezas radiométricas), quanto da energia transferida ou depositada na matéria, sendo de interesse efetuar medições físicas que possam ser diretamente correlacionadas com os efeitos reais ou potenciais da radiação ${ }^{(1)}$. Para tanto utilizam-se as grandezas dosimétricas, que correspondem a produtos de grandezas radiométricas e coeficientes de interação, quantificando assim a energia convertida (transferida para partículas carregadas secundárias). Grande parte dos dispositivos desenvolvidos para dosimetria (mensuração de grandezas dosimétricas) depende da detecção direta ou indireta das cargas elétricas originadas num meio.

\subsubsection{Grandezas radiológicas básicas}

\subsubsection{Exposição}

A grandeza exposição $(X)$ é a razão entre $d Q$ e $d m$, onde $d Q$ é o valor, em módulo, da carga total de íons de mesmo sinal produzidos no ar devido a ionizações provocadas pelo feixe de fótons eminente em um volume de ar de massa $\mathrm{dm}$, volume esse em que todos os elétrons resultados das ionizações foram completamente freados.

$$
X=\frac{d Q}{d m}
$$

A grandeza exposição só pode ser utilizada para medir radiação eletro-magnética em um meio composto de ar. Sua unidade é dada por C. $\mathrm{kg}^{-1}$.

\subsubsection{Dose Absorvida}

A Dose Absorvida (D) é a razão entre a Energia Média $(d \bar{E})$ cedida pela radiação ionizante e a massa $\square \mathrm{M}$, onde a energia média é depositada. Essa grandeza pode ser utilizada para qualquer tipo de radiação e medida em qualquer material.

$$
D=\frac{d \bar{E}}{d m}
$$


A unidade da dose absorvida é $\mathrm{J}^{\mathrm{kg}}{ }^{-1}$ ou Gy, onde 1 Gy equivale a $1 \mathrm{~J} . \mathrm{kg}^{-1}$.

\subsubsection{Kerma no ar}

A grandeza Kerma (kinetic energy in material) é a razão entre $d E_{t r}$ e dm, onde $d E_{t r}$ é a soma de todas as energias cinéticas iniciais referentes as partículas carregadas liberadas por fótons ou partículas neutras incidentes em uma massa $\mathrm{dm}$.

$$
k=\frac{d E_{t r}}{d m}
$$

A unidade da grandeza Kerma é a mesma da grandeza dose absorvida, ou seja, J.kg-1 ou Gy.

\subsubsection{Grandezas radiológicas aplicadas em CT}

Em 1981, o Bureau of Radiological Health sugeriu duas grandezas para CT, uma vez que as grandezas convencionais utilizadas até então, não eram apropriadas para a técnica de $\mathrm{CT}$, sendo a primeira o índice de dose em tomografia computadorizada (CTDI, Computed Tomography Dose Index) e a segunda a dose média em múltiplos cortes (MSAD, Multiple Scan Average Dose) $)^{(37)}$.

O CTDI, atualmente conhecido com CTKI, é a principal grandeza dosimétrica utilizada em CT. Shope et al. (1981) a definiram como a integral do perfil de dose $(D(z))$ para um único corte ao longo de uma linha infinita paralela ao eixo de rotação $z$, dividida pela espessura nominal de corte, a equação abaixo descreve o $\mathrm{CTDI}^{(37)}$.

$$
C T D I=\frac{1}{T} \int_{-\infty}^{\infty} D(z) d z
$$

onde $\mathrm{D}(\mathrm{z})$ é o perfil de dose em um único corte ao longo de uma linha infinita paralela ao eixo z e T é a espessura nominal de corte.

O valor estimado do CTDI representa o valor da dose em um elemento de volume devido à exposição de um único corte como se toda a dose absorvida 
do perfil fosse homogeneamente concentrada num elemento de volume de tamanho igual a um elemento de seção de área e espessura igual à espessura nominal de corte. É possível estimar o CTDI no ar (com pouca contribuição de radiação espalhada) e no simulador (de cabeça ou de tronco, com a contribuição de radiação espalhada). Vale salientar que o CTDI é sempre medido no modo convencional (axial).

Existem outras variações nas definições do CTDI. Uma delas é o $\mathrm{CTDl}_{100}$, que é uma maneira prática de determinar o CTDI modificando seus limites de integração, já que uma câmara de ionização de 100 mm de comprimento ativo é utilizada na maioria dos casos. O $\mathrm{CTDI}_{100}$ está definido na Equação abaixo:

$$
C T D I_{100}=\frac{1}{T} \int_{-50 m m}^{50 m m} D(z) d z
$$

Essas medidas podem ser realizadas no ar, posicionando o detector no eixo de rotação ou paralelo ao mesmo, ou no centro $\left(\mathrm{CTDI}_{100}, \mathrm{C}\right)$ e na periferia $\left(\mathrm{CTDl}_{100}, \mathrm{p}\right)$ de simuladores dosimétricos padrões de CT.

Outras grandezas dosimétricas propostas para CT são o CTDI ponderado (CTDIw, Weighted CTDI) e o produto dose-comprimento (DLP, DoseLenght Product). O CTDlw, dado pela Equação 6, foi proposto por Leitz et al. (1995) para servir como indicador da dose média de um único corte tomográfico e é utilizado no protocolo dosimétrico padrão europeu ${ }^{(38)}$ :

$$
C T D I_{w}=\frac{1}{3} C T D I_{100, c}+\frac{2}{3} C T D I_{100, p} \quad(m G y)
$$

A grandeza $\mathrm{CTDI}_{100}, \mathrm{C}$ é medida no centro do simulador dosimétrico padrão de CT e a $C T D I_{100, p}$ é a média dos valores medidos nas posições periféricas do mesmo simulador. O DLP é utilizado para definir a energia total absorvida por um volume escaneado proveniente de um determinado protocolo. 
Representa a dose integral ao longo do comprimento escaneado e é definido pela Equação abaixo:

$$
D L P=C T D I_{w} \times T \times N \quad(m G y . c m)
$$

onde $\mathrm{T}$ é a espessura do corte e $\mathrm{N}$ é o número de cortes necessários para realizar o exame. Na técnica em espiral, o número de rotações deve substituir o número de cortes da tomografia convencional.

O CTDIw oferece uma melhor estimativa da dose no órgão que o CTDI no ar. Por meio de fatores de conversão apropriados, o CTDlw e o DLP podem ser utilizados para estimar a dose no órgão e a dose efetiva, respectivamente, associada a um exame de CT de cabeça, pescoço e tronco ${ }^{39}$. A TAB. 2 mostra alguns valores de referência de dose para essas duas grandezas dosimétricas.

Tabela 2: Valores de referência de dose para exame de rotina de CT com base na dose absorvida no ar.

\begin{tabular}{|c|c|c|}
\hline \multirow{2}{*}{ Exame } & \multicolumn{2}{|c|}{ Valores de referência de dose } \\
& $\operatorname{CDTI}_{\mathrm{W}}(\mathrm{mGy})$ & DLP (mGy.cm) \\
\hline Cabeça & 60 & 1050 \\
\hline Tórax & 35 & 650 \\
\hline
\end{tabular}

Fonte: EC, 1999.

\subsubsection{Tensão de Pico Aplicada ao Tubo de Raios X (kVp)}

É a tensão nominal selecionada no painel do aparelho de raios $\mathrm{X}$. Em um gerador com tensão variável (monofásica ou trifásica), a tensão de pico é o valor máximo (crista da onda) da tensão em função do tempo, já em um gerador com tensão contínua a tensão de pico é o valor da tensão em qualquer tempo $t$. Essa tensão de pico é responsável pelos fótons de raios $X$ mais energéticos produzidos no tubo de raios X. Portanto, o valor numérico da energia máxima (em eletrovolt) encontrada no espectro de raios $X$ equivale ao valor numérico da 
tensão de pico (em Volts) aplicada ao tubo de raios X. A unidade da grandeza de Tensão de Pico (kVp) é o V (Volt).

\subsubsection{Tensão de Pico Prático "Practical Peak Voltage” (PPV)}

De acordo com H-M Kramer, H-J Selbach e W-J lles, o "Practical Peak Voltage" (40) (PPV) é definido a partir da comparação da tensão produzida por um gerador de forma de onda de potencial constante, com outro tipo arbitrário de forma de onda para o mesmo contraste na imagem como o CEV ${ }^{(41)}$.

O PPV é uma grandeza puramente elétrica, na qual se quer obter uma melhor qualidade de imagem (contraste) com uma menor dose. Existe uma diferença entre os espectros de raios $X$ gerados em aparelhos de raios $X$ de potencial constante e de potencial variável, devido a essa diferença que ocorre mesmo com aparelhos configurados com a mesma tensão e demais parâmetros, criou-se uma nova grandeza denominada Tensão de Pico Prático (PPV), visando estabelecer um mesmo valor para essa nova grandeza para ambos os aparelhos (constante e variável) $)^{(8)}$. 


\subsection{QUALIDADE DE RADIAÇÃO}

A qualidade da radiação permite um melhor conhecimento do poder de penetração do feixe em um determinado meio de interesse. Essa qualidade da radiação é caracterizada pela diferença de potencial aplicada entre os eletrodos do tubo de raios X, pela filtração total (inerente + adicional) e pela CSR, podendo ainda ser utilizado outros parâmetros para a determinação dessa qualidade. Informações mais completas sobre a qualidade de um feixe de raios $X$ e sobre 0 número e a energia dos fótons presentes neste feixe são dados pelo seu espectro de energia. Entretanto, na prática, estas medidas envolvem processos complexos, dificultando a sua realização rotineiramente. Desse modo, um método alternativo e indireto de determinação do poder de penetração de um feixe de raios $X$ em alguns materiais foi utilizado, levando-se em conta a atenuação do feixe de raios $X$. Este método é baseado na determinação das CSR, para as diversas energias do feixe.

A descrição da qualidade de um feixe de radiação apenas em termos da CSR não é suficiente. Muitas vezes pode ocorrer que se obtenha um mesmo valor de CSR para diferentes combinações de filtração adicional e diferença de potencial aplicado entre os eletrodos de um tubo de raios $X$, apesar dos espectros de energia dos feixes de radiação, em cada caso, não serem semelhantes. Esta diferença pode ser caracterizada por meio do coeficiente de homogeneidade desses feixes ${ }^{(28)}$.

\subsubsection{Camada Semi-Redutora (CSR)}

Camada semi-redutora é a espessura de um material que atenua em $50 \%$ um feixe de Raios X, e está diretamente ligada a qualidade do feixe ${ }^{(42)}$. Considera-se excluída a contribuição de qualquer radiação espalhada que não estava presente inicialmente no feixe considerado ${ }^{(28)}$. A CSR é usada como medida de penetrabilidade da radiação. À medida que se colocam filtros para a sua determinação, estes endurecem progressivamente o feixe e com isso espessuras maiores de filtros serão necessárias para termos atenuações em frações iguais. Para sua determinação foram utilizados filtros de alumínio de alta 
pureza (maior ou igual a 99,9\%) conforme as espessuras indicadas na norma para cada qualidade de radiação.

\subsubsection{Filtros ou Atenuadores (Al e Cu)}

Espessuras de materiais colocadas propositadamente diante de um feixe de raios $X$ para que parte de sua radiação seja absorvida e que seu espectro seja modificado, são chamados de filtros ou atenuadores. Quando a intensidade da radiação é reduzida pela absorção de um intervalo particular de sua energia, o processo é chamado de filtração. O feixe primário de raios $\mathrm{X}$ emitidos do alvo tem necessariamente que passar através da área de vidro da ampola, óleo e outros materiais antes de sair totalmente do sistema da ampola. Portanto, o feixe de radiação sofrerá uma filtração inevitável, é a chamada filtração inerente da ampola $^{(26)}$.

Para a realização dos procedimentos definidos pela IEC $61267^{(9)}$, é necessária a utilização de filtros de várias espessuras com o objetivo de caracterizar os feixes de cada equipamento de raios X. A FIG. 17 mostra como é possível se alterar o espectro de um feixe de radiação adicionando-se filtros.

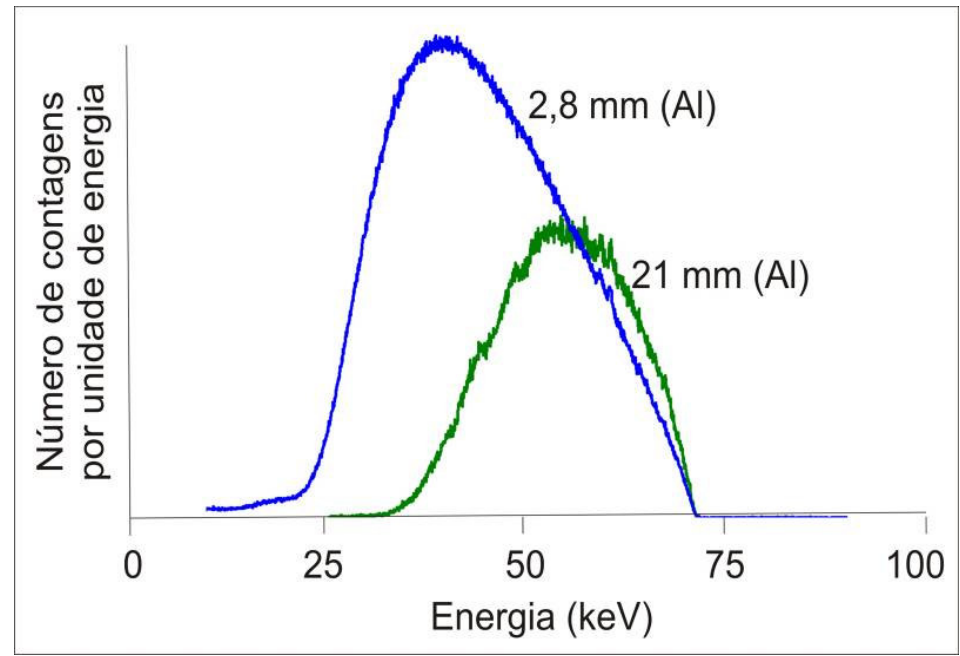

Figura 17 - Espectro de raios $\mathrm{X}$ modificado pelo aumento da filtração adicional. 


\subsection{INCERTEZAS}

É importante reconhecer que qualquer medida está sujeita a erros. Tanto no valor medido como no valor real. A diferença entre estes valores é a medição do erro. Infortunadamente saber precisamente o valor real é difícil e envolve vários parâmetros. De acordo com o Vocabulário Internacional de Termos Fundamentais e Gerais de Metrologia a incerteza de medição é definida como sendo um parâmetro, associado ao resultado de uma medição que caracteriza a dispersão dos valores que podem ser fundamentadamente atribuídos a um mensurando ${ }^{(36)}$. Os parâmetros envolvidos podem ser organizados conforme a necessidade do laboratório ou estabelecimento que fazem uso das mesmas. Utilizando um recurso mais simples da estatística pode-se avaliar algumas flutuações, assim os erros nos valores são amenizados. Tais recursos podem ser a média, desvio do valor médio e desvio padrão e variância.

A avaliação das incertezas é caracterizada por:

- Incerteza do tipo A: A incerteza do tipo A tem como base os parâmetros estatísticos, ou seja, sistemáticos como a média e os seus desvios.

- Incertezas do tipo B: A incerteza do tipo B tem como base os parâmetros não estatísticos, tais como, informações anteriores, certificado de calibração, especificações dos instrumentos, manuais técnicos, e outras bases com informações prévias.

- Incertezas expandidas: A incerteza combinada é estimada por uma equação, que reflete a ação combinada das várias fontes de erros considerados. O valor obtido representa uma faixa de valores em torno de um valor médio, onde se espera encontrar o erro da medição. A equação da incerteza combinada é:

$$
\mathrm{u}_{\mathrm{c}}=\sqrt{u_{1}^{2}+u_{2}^{2}+\ldots . .+u_{n}^{2}}
$$

O valor de uc é a somatória do quadrado de todas as incertezas (tipo A e Tipo B). 


\subsection{NORMAS E RECOMENDAÇÕES}

\subsubsection{Portaria № 453 do Ministério da Saúde (ANVISA) ${ }^{(20)}$}

Embora já existissem documentos regionais sobre a padronização e controle de qualidade em radiodiagnóstico no Brasil, somente em $1^{\circ}$ de junho de 1998 foi aprovada a Portaria Federal 453 do Ministério da Saúde que estabeleceu - Regulamento Técnico e as diretrizes básicas de proteção radiológica em radiodiagnóstico médico e odontológico, que dispõe sobre $\mathrm{O}$ uso dos raios $\mathrm{X}$ diagnósticos em todo o território nacional. Esta norma tem o objetivo de garantir a qualidade dos serviços de radiodiagnóstico prestados à população, assim como de assegurar os requisitos mínimos de proteção radiológica aos pacientes, profissionais e ao público em geral. Para isto padronizou a nível nacional, os requisitos de proteção radiológica para o funcionamento dos estabelecimentos que operam com raios $X$ diagnósticos e a necessidade de detalhar os requisitos de proteção radiológica diagnóstica e intervencionista estabelecidos na Resolução o 6, de 21 de dezembro de 1988, do Conselho Nacional da Saúde. A Portaria 453 do Ministério da Saúde segue as recentes Diretrizes Básicas de Proteção Radiológica estabelecidas em conjunto pela Organização Mundial da Saúde, Organização Pan - Americana da Saúde, Organização Internacional do Trabalho, Organização de Alimento e Agricultura, e Agência Internacional de Energia Atômica, e também as recomendações do Instituto de Radioproteção e Dosimetria da Comissão Nacional de Energia Nuclear, órgão de referência nacional em proteção radiológica e metrologia das radiações ionizantes.

\subsubsection{Atualização da Norma IEC $61267^{(9)}$}

A IEC é uma organização internacional para padronização, que compreende os comitês eletrotécnicos nacionais de diversos países. Seu objetivo é promover a cooperação internacional sobre todas as questões relativas à padronização nos campos da eletricidade e eletrônica. Suas recomendações são publicadas sob a forma de normas, cuja preparação é confiada a comitês técnicos. 
A primeira edição da norma IEC $1267^{(18)}$ foi publicada em outubro de 1994, preparada e longamente discutida em anos precedentes, durante a década de 90. Sua finalidade básica era estabelecer características, aspectos ou propriedades de equipamentos para investigações físicas e médicas disponibilizando condições de radiação bem definidas para aplicações em diversas aplicações em radiologia diagnóstica.

A revisão desta norma veio suprir uma necessidade de condições de radiação padrão e prover fundamento para a harmonização de normas nacionais, além de harmonizar condições para testes de controle de qualidade realizados por fabricantes, laboratórios de calibração de equipamentos e para estudos físicos e médicos em laboratórios e instalações médicas. As condições de radiação padrão podem beneficiar um número de usuários potenciais tais como: fabricantes de equipamento de raios $\mathrm{X}$, laboratório de pesquisas, autoridades regulatórias governamentais e usuários.

\subsubsection{ICRU $74^{(17)}$}

Em 2005 o ICRU publicou um documento dedicado a dosimetria de pacientes submetidos a raios $X$ para diagnóstico médico, que define grandezas $\mathrm{e}$ unidades para dosimetria em radiodiagnóstico. Este documento apresenta métodos para determinar doses em órgãos e tecidos, e é o primeiro ICRU a tratar de dosimetria em radiodiagnóstico. Incluindo todas as áreas de aplicação como a radiologia dental e a irradiação de fetos e grávidas.

\subsubsection{Código de Prática Internacional para Dosimetria em Radiodiagnóstico TRS 457 da AIEA ${ }^{(8)}$}

Em 2007 a AlEA publicou o código de prática intitulado "Dosimetria em Radiologia Diagnóstica: Um Código de Prática Internacional”. Este documento recomenda procedimentos para calibração e realização de medidas dosimétricas, e estabelece critérios tanto para laboratórios de dosimetria, como para centros clínicos de radiodiagnóstico. Segundo a AIEA, sua implementação possibilitará diminuir a incerteza na dosimetria de feixes de radiodiagnóstico, fornecendo uma estrutura unificada e consistente para a dosimetria em radiodiagnóstico. 
O código de prática da AIEA foi desenvolvido em paralelo com o documento do ICRU e é complementar em sua abordagem da dosimetria clínica. Ele objetiva dar suporte ao trabalho essencial de dosimetria em radiodiagnóstico para 5 modalidades gerais, que incluem: radiografia geral, fluoroscopia, mamografia, tomografia computadorizada e radiografia dental.

No capítulo referente aos laboratórios de calibração, além de descrever em detalhes a instrumentação necessária à operação do laboratório, introduz a possibilidade do uso de medidores não-invasivos para a medição da tensão aplicada ao tubo de raios X, em contradição à nova edição da norma IEC 61267 que prescrevia apenas o uso de medidores invasivos.

\subsubsection{Qualidades de Radiação Específicas para Aplicações em CT}

As qualidades de radiação da série RQT simulam o feixe não-atenuado usado em $\mathrm{CT}^{(9)}$. Uma vez que as qualidades de referência da série $R Q R$ estão estabelecidas, aquelas da série RQT são prontamente obtidas pela adição da filtração adicional de cobre conforme TAB. 3 .

Tabela 3. Qualidades de radiação RQT, recomendadas pela norma IEC $61267^{(9)}$, a partir das qualidades $R Q R$.

\begin{tabular}{cccc}
\hline Qualidade & $\begin{array}{c}\text { TeNSÃO NOMINAL APLICADA } \\
\text { AO TUBO } \\
(\mathrm{kV})\end{array}$ & $\begin{array}{c}\text { FILTRO } \\
\text { ADIClONAL } \\
(\mathrm{mmCu})\end{array}$ & $\begin{array}{c}\text { Espessura nominal } \\
\text { da 1ª CSR } \\
(\mathrm{mmAl})\end{array}$ \\
\hline RQT 8 & 100 & 0,20 & 6,9 \\
RQT 9 & 120 & 0,25 & 8,4 \\
RQT 10 & 150 & 0,30 & 10,1 \\
\hline
\end{tabular}

Além disso, no caso de não ser possível se implantar as qualidades RQR, o TRS 457 dá a possibilidade de se implantar estas mesmas qualidades apenas com filtração de cobre até se atingir a CSR dada na quarta coluna da TAB. 3. 


\section{MATERIAIS E MÉTODOS}

\subsection{INSTALAÇÃO}

Todas as etapas deste trabalho foram desenvolvidas no Laboratório de Calibração de Instrumentos (LCl) do Instituto de Pesquisas Energéticas e Nucleares (IPEN/CNEN-SP).

\subsection{DETETORES E SISTEMAS DE IRRADIAÇÃO}

Para o desenvolvimento desse projeto, foram usados os seguintes equipamentos:

\subsubsection{Equipamento de Raios X}

Foi utilizado um sistema de radiação $X$ marca Pantak/Seifert, modelo Isovolt HS 160, que opera na faixa de radiodiagnóstico clínico (40 -160 kV), composto por um tubo de raios X da Comet, modelo MRX 160/22 com anodo estacionário (alvo de Tungstênio) e janela de Berílio com $1 \mathrm{~mm}$ de espessura (FIG. 18). A corrente aplicada foi fixada em $10 \mathrm{~mA}$ para as diferentes séries de qualidades implantadas.

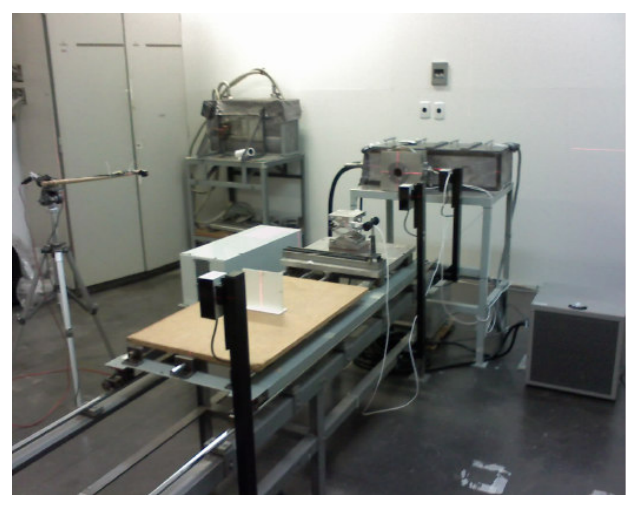

Figura 18. Sistema de raios $X$ marca Pantak/Seifert, modelo do tubo MXR-160/22 na faixa de operação de radiodiagnóstico clínico 40-160 kV. 


\subsubsection{Sistema de Referência Padrão Secundário}

Sistema Dosimétrico de Referência composto por uma câmara de ionização tipo lápis modelo $10 \times 5-3 \mathrm{CT}$, com volume de $3 \mathrm{~cm}^{3}$, da Radcal Corporation, acoplada a um eletrômetro marca PTW, modelo Unidos

, tipo 10001, com rastreabilidade ao Laboratório de Dosimetria Padrão Primário Physikalisch-Technische Bundesanstalt (PTB), localizado na Alemanha. Esta câmara de ionização foi calibrada em 2010, nas qualidades RQT's de acordo com a norma IEC 61267 (FIG. 19).

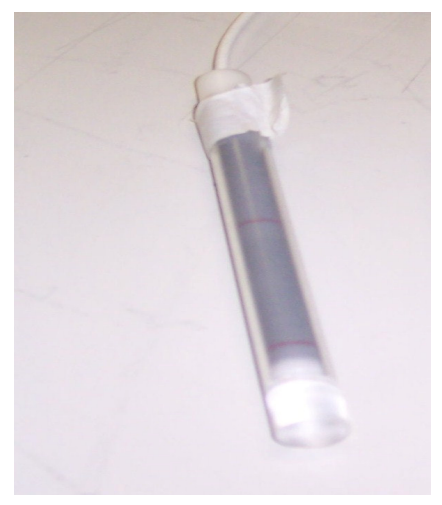

A) Câmara Lápis (Padrão secundário)

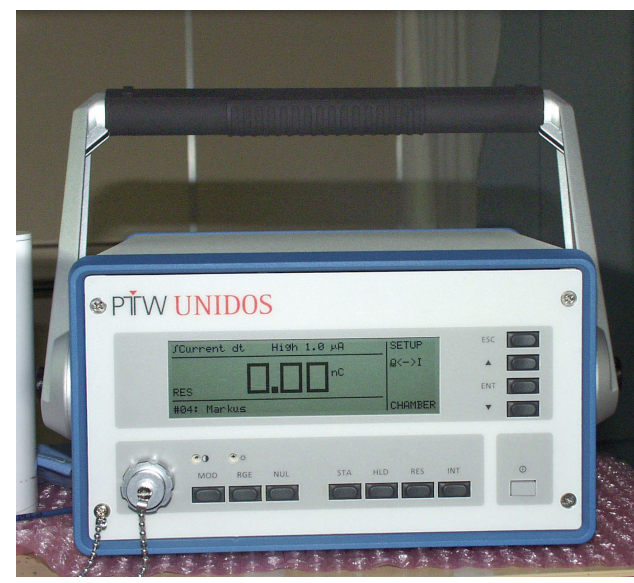

B) Eletrômetro de referência PTW

Figura 19: Sistema dosimétrico de referência.

\subsubsection{Câmara Monitora}

Câmara monitora marca PTW, modelo 34014, série 0031, acoplada a um eletrômetro PTW, modelo UNIDOS E 10010 para monitoração do feixe de radiação, posicionada na saída do feixe de radiação após a filtração adicional, conforme esquema apresentado na FIG. 20. 


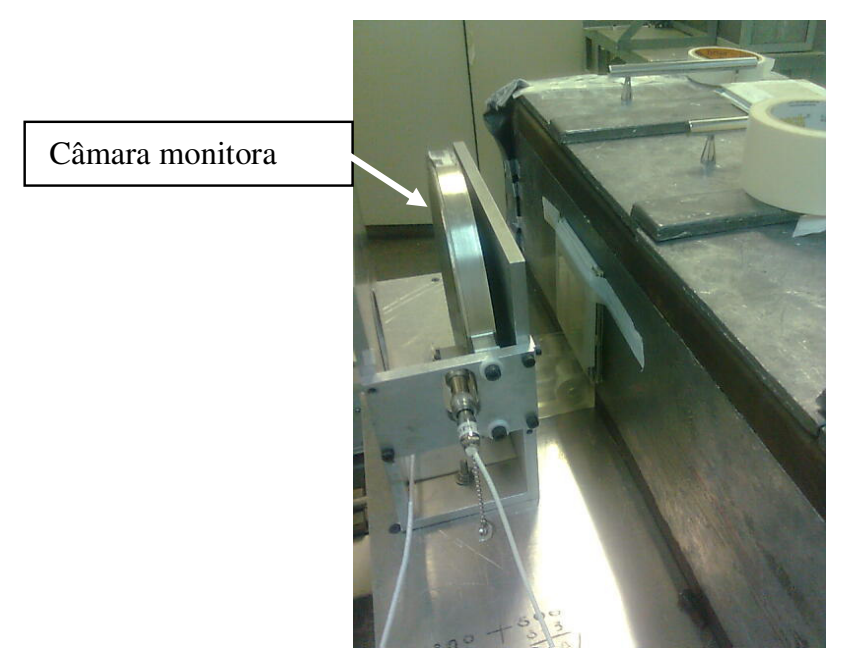

Figura 20: Câmara monitora posicionada na saída do tubo de raios $\mathrm{X}$.

\subsubsection{Medidor de Tensão de Pico Prático}

A norma IEC 61267 recomenda que a grandeza de referência para a tensão aplicada ao tubo seja a tensão de pico prático (PPV) e neste trabalho foi utilizado um medidor não-invasivo marca PTW, Modelo Diavolt, com rastreabilidade ao PTB, cujo certificado se encontra no Anexo 1. Sua imagem pode ser vista na FIG.21.

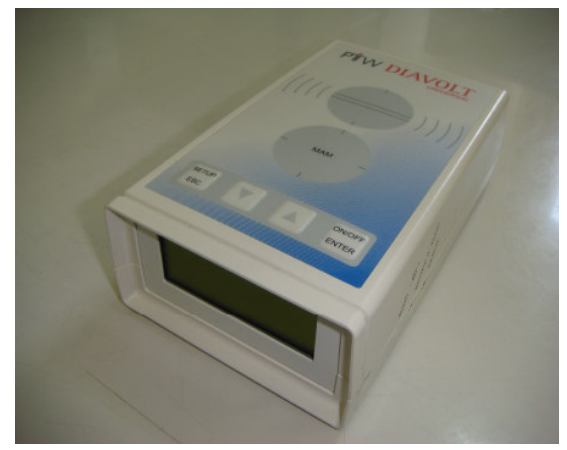

FIGURA 21: Medidor não-invasivo de tensão (PPV), marca PTW, modelo Diavolt, Alemanha. 


\subsection{FILTROS E ATENUADORES}

Para a composição das qualidades de radiações de referência, bem como as medições de camada semi-redutora para a determinação das filtrações adicionais do equipamento de raios $\mathrm{X}$, foram utilizados filtros de alumínio e cobre de alta pureza maior ou igual a $99,9 \%$. Todos os filtros utilizados estão apresentados na FIG.22.

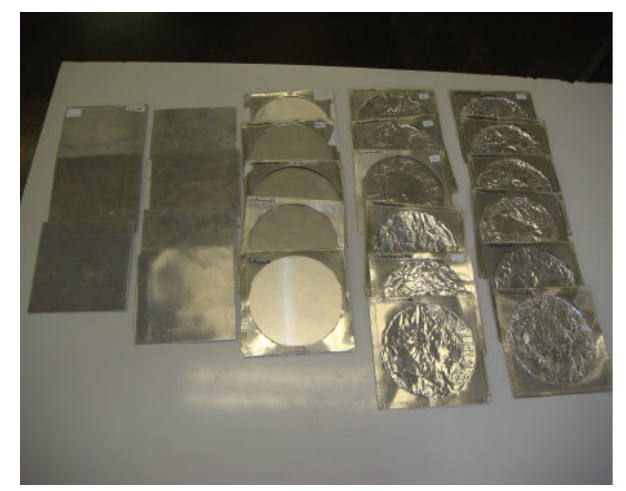

A) Filtros de Al utilizados na determinação das CSR.

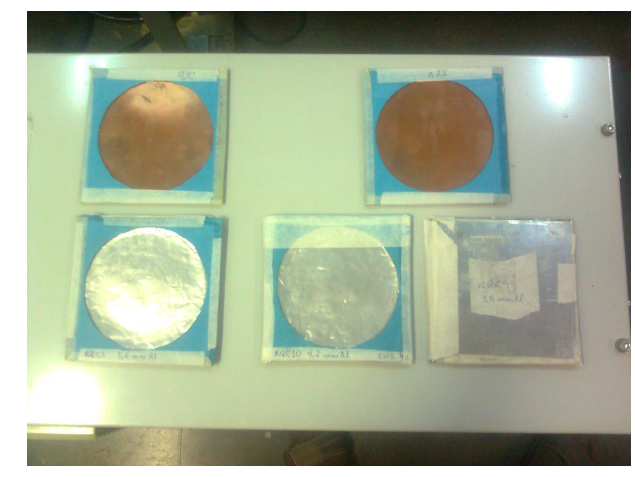

B) Filtrações adicionais ( $\mathrm{Al} \mathrm{e} \mathrm{Cu})$.

Figura 22. Filtros de Al e Cu utilizados na determinação das qualidades de radiação RQT. 


\subsection{FATORES DETERMINADOS NA CARACTERIZAÇÃO DAS QUALIDADES DE RADIAÇÃO}

A caracterização das qualidades de radiação neste trabalho foi realizada por meio da determinação seqüencial de alguns fatores, apresentados a seguir:

- Practical Peak Voltage (PPV): o PPV é uma grandeza puramente elétrica, na qual se quer obter uma melhor qualidade de imagem (contraste) com uma menor dose. Sabendo-se esta grandeza, temse um compromisso de uma imagem melhor conseqüentemente uma dose menor.

- Filtração Inerente: A filtração inerente é formada pelo vidro do tubo de raios $X$, o óleo isolante e o material da janela. Quando o feixe primário de raios $\mathrm{X}$ é emitido do alvo e passa por estes três componentes internos da cúpula do equipamento, o feixe é inevitavelmente filtrado e, portanto esta é chamada de filtração inerente do equipamento.

- Filtração Adicional: Minimiza os fótons de baixa energia, diminuindo a dose de radiação no paciente e obtendo um espectro de maior utilidade com a colocação de filtros espessos no feixe de radiação.

- Camada Semi-Redutora (CSR): A primeira camada semi-redutora é definida pela espessura de um material qualquer, necessário para reduzir pela metade a intensidade inicial de um feixe de raios $X$. A CSR é um indicador de qualidade de radiação, pois quanto mais energético for o feixe de raios $X$, maior será o valor da CSR. O Material utilizado neste trabalho foi alumínio, com uma pureza de no mínimo 99,9\%.

- Taxa de Kerma no Ar: É a grandeza fundamental, na qual os padrões nacionais são calibrados na área de Radiodiagnóstico, e é determinada utilizando-se instrumentos calibrados nesta grandeza. 


\subsection{METODOLOGIA PARA ESTABELECIMENTO DE CAMPOS PADRÕES}

Para ter disponíveis campos padronizados de radiação, usados em investigações médicas, físicas ou metrológicas, conjuntos de qualidades de radiação bem estabelecidas são indispensáveis e constituem uma importante ferramenta em diversas situações. $E$, como dito anteriormente, a última edição revisada da norma IEC $61267^{(9)}$ trouxe como novidade as qualidades definidas por ela como RQT, que simulam feixes não-atenuados e são usadas em aplicações especiais de CT (no caso do $\mathrm{LCl}$, na calibração das câmaras de ionização tipo lápis, utilizadas em Tomógrafos para avaliação de doses nos pacientes). As principais alterações dizem respeito à introdução da grandeza tensão de pico prático (PPV) para medir a tensão do tubo de raios $\mathrm{X}$; introdução de um novo procedimento para estabelecer as camadas semi-redutoras (CSR) e de filtros especiais de cobre $(\mathrm{Cu})$ para simulação do paciente.

Inicialmente, foram realizadas medidas de PPV $(\mathrm{kV})$ utilizando um medidor não invasivo e a determinação das filtrações adicionais de cobre através dos valores de CSR recomendados pela IEC 61267 e pelo TRS 457. Para todas as qualidades de radiação, foram construídas curvas de atenuação, partindo-se de suas respectivas filtrações adicionais.

Além da implantação das qualidades específicas denominadas RQT, que são utilizadas em aplicações de CT, é necessário que se estabeleça uma metodologia de calibração diferenciada no caso das câmaras lápis, devido às suas características especiais de uso e de formato. Para isso, existem algumas diferentes formas de calibração destas câmaras, sendo que as principais diferenças nas metodologias utilizadas pelos SSDL's estão relacionadas à região ao longo da câmara que deve ser irradiada.

Em muitas aplicações da câmara lápis é comum a irradiação total de toda a área da mesma, porém sabemos que em suas extremidades ocorre uma diminuição na sensibilidade, já comprovada com alguns testes de homogeneidade da resposta ao longo do comprimento sensível da câmara ${ }^{(5)}$. Por isso, a metodologia mais adequada e atualmente recomendada pelo TRS 457 baseado na IEC 61674 é a irradiação parcial, pois os melhores resultados são obtidos quando $50 \%$ do volume sensível da câmara lápis é irradiado durante a calibração. 
Para isto foram utilizados colimadores especiais e adequados e um arranjo geométrico específico para calibração das câmaras lápis.

\subsubsection{Metodologia para Caracterização de Qualidades de Feixes de Raios X}

- Controle de qualidade da câmara de ionização tipo lápis de referência: Foi implantado um programa de controle de qualidade da câmara de ionização tipo lápis por meio de testes de estabilidade de sua resposta, utilizando-se uma fonte de referência de ${ }^{90} \mathrm{Sr}$.

- Controle de Qualidade do tubo de raios X: No início do projeto foram feitos alguns testes de controle de qualidade utilizando-se 0 medidor multi-função não invasivo. Foram realizados os testes de Exatidão e Reprodutibilidade do KV; Linearidade e Reprodutibilidade da Taxa de Kerma; Exatidão e Reprodutibilidade do Tempo de Exposição e Reprodutibilidade do mAs.

- Determinação da homogeneidade do campo de radiação: Antes de começar a fazer a caracterização do feixe, também foi determinada a homogeneidade do campo de irradiação medindo-se a exposição gerada pela irradiação em vários pontos. Para tal, foi utilizada uma câmara de ionização tipo dedal, que foi posicionada em diferentes pontos da superfície irradiada, na horizontal e na vertical, separados por $1 \mathrm{~cm}$. Foram feitas duas medições: uma com corrente constante de $10 \mathrm{~mA}$, a $1 \mathrm{~m}$ de distância do ponto focal e outra com 20mA a 2,5m de distância. Ambas as medidas foram feitas com uma filtração de $2,5 \mathrm{~mm}$ de Alumínio e abertura do colimador de 50,8 $\mathrm{mm}$.

- Determinação da filtração inerente do tubo: A metodologia utilizada é a mesma descrita na ISO $4037-1^{(33)}$, onde são feitas 10 leituras de carga, com tempo de exposição de 15 segundos, sem a colocação de filtros adicionais. Em seguida são feitas novas exposições com a adição de filtros de alumínio até reduzir em $50 \%$ a carga inicial. Para isso posicionou-se o centro geométrico da câmara de ionização padrão, acoplada ao eletrômetro PTW, modelo Unidos, 
operando na função de medição de carga, no centro do campo de radiação a um metro do ponto focal do equipamento de raios $X$. $A$ tensão inicial do tubo de raios- $X$ foi ajustada em $60 \mathrm{kV}$ e corrente de

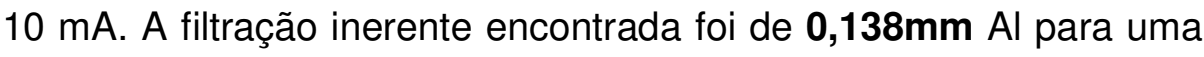
Camada Semi-Redutora (CSR) de 0,1 mm Al. Este valor de filtração inerente foi obtido através de uma extrapolação da curva gerada pelos dados fornecidos pela norma ISO-4037-1, de forma a tornar possível o cálculo da filtração inerente para uma CSR menor que 0,33 $\mathrm{mm}$ de Al, pois esta tabela permite o cálculo da filtração inerente para tubos que apresentem o valor da CSR maior ou igual a $0,33 \mathrm{mmAl}^{(33)}$. A equação foi obtida realizando-se um ajuste polinomial de quinta ordem ${ }^{(11)}$.

- Determinação da Tensão de Pico Prático "Pratical Peak Voltage" (PPV): Segundo as recomendações da norma IEC $61267^{(9)}$ e do TRS $457^{(8)}$, um medidor invasivo deve ser utilizado para se obter o PPV. O medidor ainda deverá ter uma incerteza máxima de medida de PPV de $\pm 1,5 \%(1,5 \mathrm{kV})$. Porém, um medidor não-invasivo também pode ser utilizado, contanto que a incerteza não ultrapasse o estipulado pela norma. As medições foram feitas utilizando-se um medidor não-invasivo da marca PTW, modelo Diavolt, rastreável ao PTB. O medidor foi posicionado na saída do tubo, de forma que o feixe cobrisse completamente a área sensível do sensor. Foram feitas 10 exposições de 30 segundos para cada qualidade de radiação, obtendo-se para cada uma, seu PPV específico. Juntamente com o PPV, foram obtidas também outras duas grandezas: kVp máximo e kVp médio.

- Determinação da Camada Semi-Redutora (CSR): A CSR é usada como medida de penetrabilidade da radiação ${ }^{(43)}$. À medida que se colocam filtros para a sua determinação, estes endurecem progressivamente o feixe e com isso espessuras maiores de filtros serão necessárias para termos atenuações em frações iguais. Para sua determinação foram utilizados filtros de alumínio de alta pureza (> 99.9\%) conforme as espessuras indicadas na norma. 


\subsubsection{Metodologia Alternativa recomendada pela IEC 61267 e pelo TRS-457 para implantação das qualidades RQT}

Caso não seja necessário ou a filtração inerente do tubo seja muito alta para estabelecer as qualidades da série $R Q R$, as qualidades de radiação da série RQT podem ser facilmente obtidas pelo método de tentativa e erro, sem que seja preciso primeiramente se estabelecer as RQR. É recomendado que a quantidade da filtração de cobre dada na coluna 3 da TAB. 2, seja inserida como filtração adicional na saída do feixe e então encontrada a CSR dada na coluna 4. Esta verificação para se chegar nas CSR recomendadas deve ser feita através de medidas de Kerma ou taxa de Kerma no ar, utilizando filtros atenuadores de Al com espessuras equivalentes às CSR recomendadas. Se a razão entre os valores de Kerma no ar, com e sem atenuação, estiverem entre $48,5 \%$ e $51,5 \%$, as qualidades de radiação das séries RQT estarão estabelecidas. 


\section{RESULTADOS E DISCUSSÕES}

\subsection{CONTROLE DE QUALIDADE DA CÂMARA DE IONIZAÇÃO TIPO LÁPIS E DO TUBO DE RAIOS $X$}

Antes de começar a implantação das qualidades neste projeto, foram feitos alguns testes de controle de qualidade na câmara de ionização tipo lápis (padrão secundário) e no equipamento de raios $\mathrm{X}$, como parte do programa de controle de qualidade de padrões e do sistema de raios $\mathrm{X}$ do $\mathrm{LCl}$.

\subsubsection{Controle de Qualidade da Câmara de lonização}

Foi estabelecido um programa de controle de qualidade na câmara de ionização padrão da marca Radcal, modelo RC3CT. A câmara podem ser vista na FIG. 23. Para o estudo da estabilidade a câmara foi acoplada a um eletrômetro marca PTW, modelo UNIDOS-E e em todos os testes foi utilizada uma fonte radioativa de controle $\left({ }^{90} \mathrm{Sr}\right)$ com um suporte adequado ao posicionamento do conjunto fonte-câmara, em condições fixas e reprodutíveis como mostrado na FIG. 23.

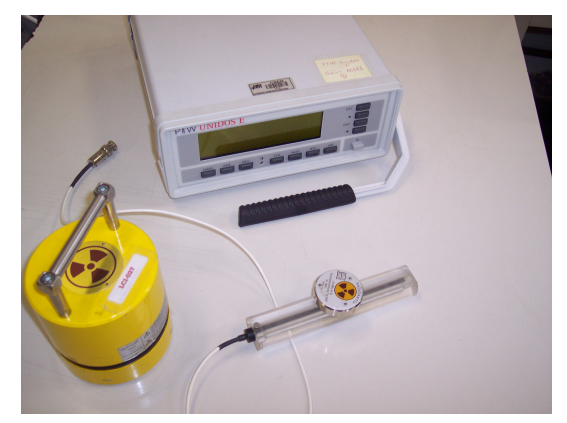

Figura 23: Câmara de ionização tipo lápis acoplada ao eletrômetro UNIDOS-E e com a fonte de controle posicionada. 
O teste de repetitividade consistiu na realização de dez medidas consecutivas com uma fonte de controle, em condições fixas e reprodutíveis, de modo a se verificar o comportamento do instrumento num determinado intervalo de tempo. De acordo com as normas internacionais, o coeficiente de variação máximo das medidas para instrumentos medidores de radiação utilizados em sistemas de radiodiagnóstico não deve exceder a $3 \%{ }^{(19)}$.

Para o teste de estabilidade foi feita a verificação do desempenho da câmara de ionização ao longo de alguns dias, analisando os testes de repetitividade. Os valores encontrados podem ser vistos na FIG. 24. De acordo com a norma IEC, a variação da resposta dos instrumentos em relação ao valor tomado como referência não deve exceder a $2 \%{ }^{(19)}$.

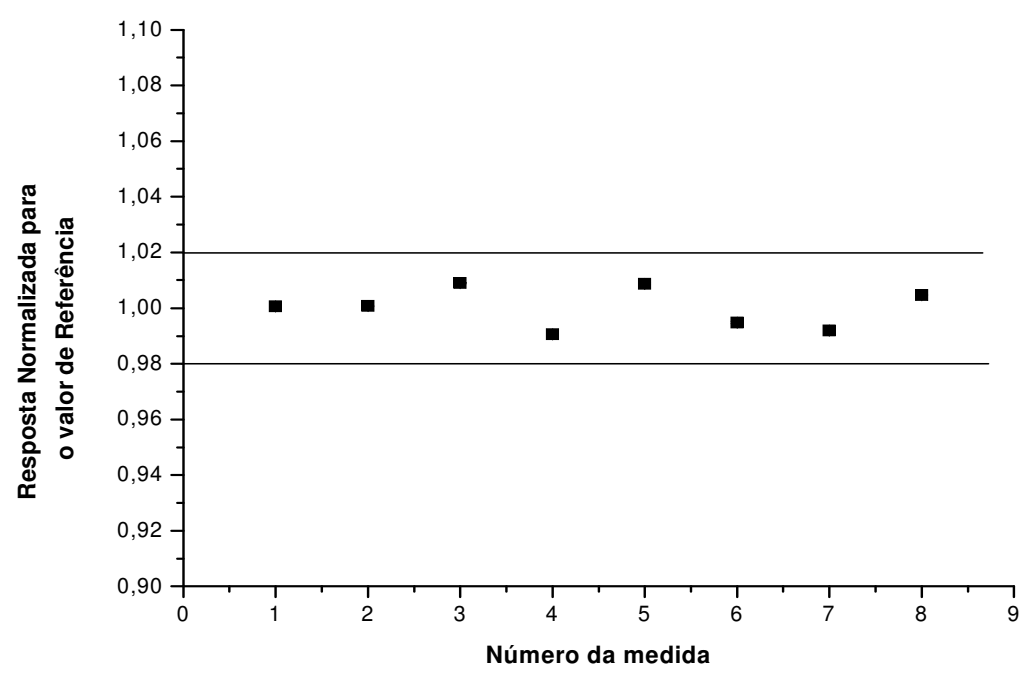

Figura 24. Teste de estabilidade da câmara de ionização (padrão secundário) do tipo lápis de referência. 
No programa de controle de qualidade da câmara foram realizadas séries de 10 medidas sendo que cada série representa a média de 10 valores. Os resultados encontrados estão demonstrados no gráfico da FIG. 24. No teste de repetitividade o maior o coeficiente de variação encontrado para a câmara lápis foi de $0,42 \%$ e o menor de $0,078 \%$.. Para o teste de estabilidade em longo prazo a câmara apresentou um melhor desempenho com variações máximas de 1\%. Durante todo o período de teste a fuga de corrente foi desprezível em todos os casos. Portanto, os testes de repetividade, de estabilidade a longo prazo e de fuga, realizados pela câmara do tipo dedal, atenderam as recomendações da norma vigente.

\subsubsection{Exatidão e Reprodutibilidade da tensão no tubo (kV):}

Para esse teste foi utilizado o detector modelo Diavolt posicionado a $100 \mathrm{~cm}$ do ponto focal, com filtração adicional de $1,5 \mathrm{~mm}$ e $3 \mathrm{~mm}$ de $\mathrm{Al}$, e tempo de exposição de 0,3min. As medições foram feitas para cada uma das tensões correspondentes às RQT's (100kV, $120 \mathrm{kV}$ e $150 \mathrm{kV})$, com corrente constante de $10 \mathrm{~mA}$ e $20 \mathrm{~mA}$. Os resultados obtidos se encontram nas TABs. 4, 5 e 6 . 
Tabela 4: Teste de Exatidão e reprodutibilidade da tensão (kV), com uma filtração adicional de $1,5 \mathrm{~mm}$ de $\mathrm{Al}$, para $20 \mathrm{~mA}$, utilizando o medidor Diavolt.

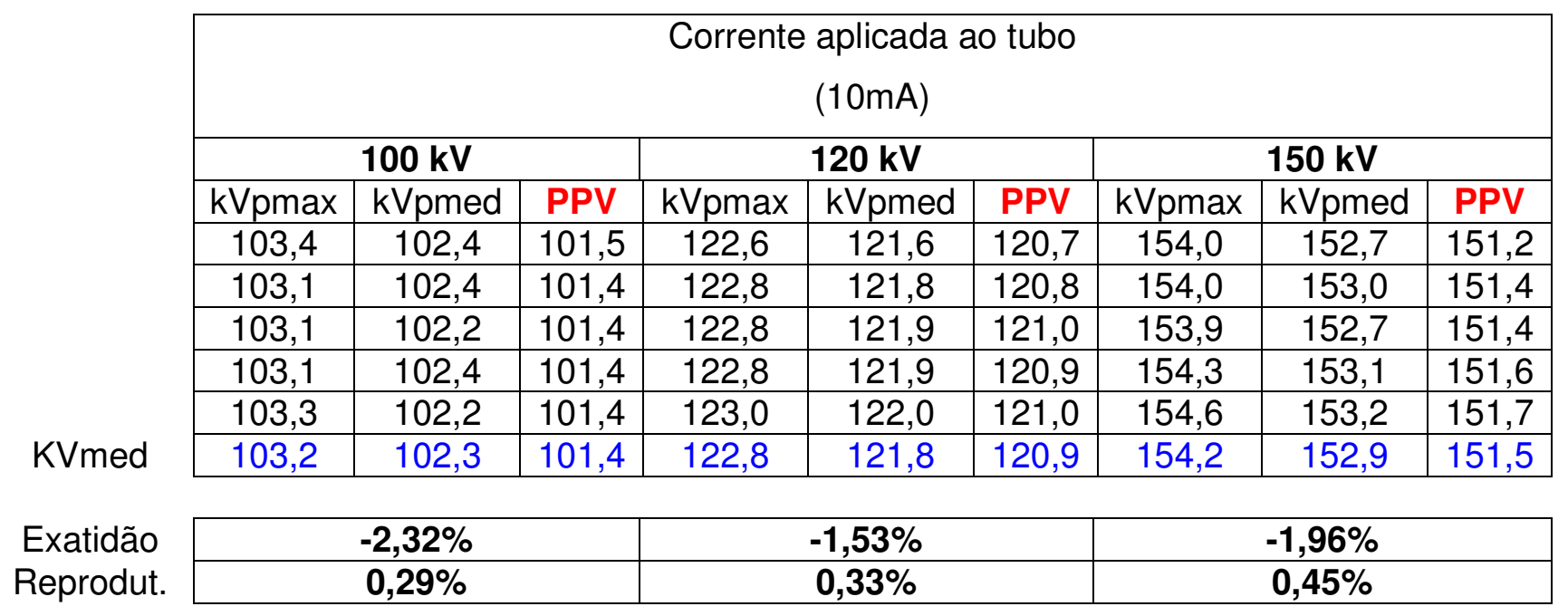

Tabela 5: Teste de Exatidão e reprodutibilidade da tensão (kV), com uma filtração adicional de $1,5 \mathrm{~mm}$ de $\mathrm{Al}$, para $10 \mathrm{~mA}$, utilizando o medidor Diavolt.

\begin{tabular}{|c|c|c|c|c|c|c|c|c|c|}
\hline & \multicolumn{9}{|c|}{$\begin{array}{l}\text { Corrente aplicada ao tubo } \\
\qquad(20 \mathrm{~mA})\end{array}$} \\
\hline & \multicolumn{3}{|c|}{$100 \mathrm{kV}$} & \multicolumn{3}{|c|}{$120 \mathrm{kV}$} & \multicolumn{3}{|c|}{$150 \mathrm{kV}$} \\
\hline & kVpmax & kVpmed & PPV & kVpmax & kVpmed & PPV & kVpmax & kVpmed & PPV \\
\hline & 102,9 & 102,3 & 101,7 & 122,5 & 122,0 & 121,3 & 154,0 & 153,1 & 152,0 \\
\hline & 102,9 & 102,3 & 101,7 & 122,7 & 122,1 & 121,3 & 154,0 & 153,3 & 152,2 \\
\hline & 102,9 & 102,3 & 101,6 & 122,6 & 122,1 & 121,4 & 154,0 & 153,3 & 152,2 \\
\hline & 102,9 & 102,3 & 101,6 & 122,6 & 122,1 & 121,4 & 154,0 & 153,3 & 152,2 \\
\hline & 102,9 & 102,2 & 101,6 & 122,6 & 122,1 & 121,4 & 154,0 & 153,3 & 152,2 \\
\hline KVmed & 102,9 & 102,3 & 101,6 & 122,6 & 122,1 & 121,4 & 154,0 & 153,3 & 152,2 \\
\hline & & $3 \%$ & & & $-1,73 \%$ & & & $-2,17 \%$ & \\
\hline Reprodut. & & $0,00 \%$ & & & $0,16 \%$ & & & $0,00 \%$ & \\
\hline
\end{tabular}


Tabela 6: Teste de Exatidão e reprodutibilidade da tensão (kV), com uma filtração adicional de $3,0 \mathrm{~mm}$ de $\mathrm{Al}$, para $10 \mathrm{~mA}$, utilizando o medidor Diavolt.

\begin{tabular}{|c|c|c|c|c|c|c|c|c|c|}
\hline & \multicolumn{9}{|c|}{$\begin{array}{l}\text { Corrente aplicada ao tubo } \\
\qquad(10 \mathrm{~mA})\end{array}$} \\
\hline & \multicolumn{3}{|c|}{$100 \mathrm{kV}$} & \multicolumn{3}{|c|}{$120 \mathrm{kV}$} & \multicolumn{3}{|c|}{$150 \mathrm{kV}$} \\
\hline & $\begin{array}{c}\text { kVpm } \\
\text { ax }\end{array}$ & kVpmed & PPV & kVpmax & kVpmed & PPV & kVpmax & kVpmed & PPV \\
\hline \multirow[b]{6}{*}{ KVmed } & 102,6 & 101,9 & 100,7 & 124,4 & 123,3 & 121,9 & 150,9 & 149,5 & 147,8 \\
\hline & 102,9 & 101,8 & 100,7 & 124,3 & 123,2 & 121,8 & 150,4 & 149,4 & 147,7 \\
\hline & 102,8 & 101,8 & 100,7 & 124,2 & 123,3 & 121,9 & 150,9 & 149,5 & 147,9 \\
\hline & 102,8 & 101,8 & 100,7 & 124,5 & 123,3 & 121,8 & 151,1 & 149,6 & 148,0 \\
\hline & 102,8 & 101,8 & 100,7 & 124,4 & 123,4 & 121,9 & 151,1 & 149,7 & 148,1 \\
\hline & 102,8 & 101,8 & 100,7 & 124,4 & 123,3 & 121,9 & 150,9 & 149,5 & 147,9 \\
\hline \multirow{2}{*}{$\begin{array}{l}\text { Exatidão } \\
\text { Reprodut. }\end{array}$} & \multicolumn{3}{|c|}{$-1,82 \%$} & \multicolumn{3}{|c|}{$-2,75 \%$} & \multicolumn{3}{|c|}{$0,31 \%$} \\
\hline & \multicolumn{3}{|c|}{$0,29 \%$} & \multicolumn{3}{|c|}{$0,24 \%$} & \multicolumn{3}{|c|}{$0,46 \%$} \\
\hline
\end{tabular}

Analisando os resultados é verifica-se que não há grandes alterações no tubo com relação à tensão, pois a mesma apresenta um baixo desvio em termos de exatidão (menos de $3 \%$ ) para todos os tipos de medidas feitas, além de uma ótima reprodutibilidade.

\subsubsection{Linearidade e Reprodutibilidade da Taxa de Kerma no ar:}

Mantendo uma tensão fixa de 120kV (RQR9) foram feitas dois tipos de exposição: primeiramente variando-se o $\mathrm{mA}$ e mantendo-se um tempo fixo $(0,3$ $\mathrm{min})$, e posteriormente, mantendo-se a corrente fixa (10mA) e variando-se o tempo de exposição. A filtração utilizada foi de $2,5 \mathrm{~mm}$ de Al para ambos os tipos de exposição, de 3mm de Al para a exposição de tempo fixo. As TABs. 7,8 e 9 apresentam os resultados encontrados. 
Tabela 7: Teste de linearidade do kerma no ar, utilizando-se o medidor Diavolt. Tempo de exposição fixo (0,3 min) e filtração de 2,5mm de Al

\begin{tabular}{|c|c|c|c|c|}
\hline Corrente (mA) & $\mathbf{5 ~} \mathbf{~ A}$ & $\mathbf{1 0} \mathbf{~ m A}$ & $\mathbf{1 5} \mathbf{~ m A}$ & $\mathbf{2 0} \mathbf{~ m A}$ \\
\hline \multirow{4}{*}{ Kerma no ar (mGy) } & 16 & 31,69 & 47,36 & 63,06 \\
\cline { 2 - 5 } & 15,98 & 31,66 & 47,33 & 63,04 \\
\cline { 2 - 5 } & 15,95 & 31,65 & 47,32 & 63,01 \\
\cline { 2 - 5 } & 15,9 & 31,69 & 47,37 & 62,98 \\
\cline { 2 - 5 } & 15,94 & 31,65 & 47,34 & 62,98 \\
\hline Kerma no ar médio (mGy) & 15,95 & 31,67 & 47,34 & 63,01 \\
\hline Reprodutibilidade & $\mathbf{0 , 6 3 \%}$ & $\mathbf{0 , 1 3 \%}$ & $\mathbf{0 , 1 1} \%$ & $\mathbf{0 , 1 3} \%$ \\
\hline Linearidade & $\mathbf{5}, \mathbf{5}$ \\
\hline
\end{tabular}

Tabela 8: Teste de linearidade do kerma no ar, utilizando-se o medidor Diavolt. Tempo de exposição fixo (0,3 min) e filtração de 3,0mm de Al

\begin{tabular}{|c|c|c|c|c|}
\hline Corrente (mA) & $\mathbf{5} \mathbf{~ m A}$ & $\mathbf{1 0} \mathbf{~ m A}$ & $\mathbf{1 5} \mathbf{~ m A}$ & $\mathbf{2 0} \mathbf{~ m A}$ \\
\hline \multirow{4}{*}{ Kerma no ar (mGy) } & 12,51 & 24,75 & 36,82 & 49,3 \\
\cline { 2 - 5 } & 12,48 & 24,8 & 37,04 & 49,29 \\
\cline { 2 - 5 } & 12,43 & 24,78 & 37,02 & 49,27 \\
\cline { 2 - 5 } & 12,49 & 24,65 & 37,08 & 49,39 \\
\cline { 2 - 5 } & 12,48 & 24,77 & 37,05 & 49,32 \\
\hline Kerma no ar médio (mGy) & $\mathbf{1 2 , 4 8}$ & $\mathbf{2 4 , 7 5}$ & $\mathbf{3 7 , 0 0}$ & $\mathbf{4 9 , 3 1}$ \\
\hline Reprodutibilidade & $\mathbf{0 , 6 4 \%}$ & $\mathbf{0 , 6 1} \%$ & $\mathbf{0 , 1 6 \%}$ & $\mathbf{0 , 2 4 \%}$ \\
\hline Linearidade & \multicolumn{5}{|c|}{$\mathbf{1 6}$} \\
\hline
\end{tabular}

Tabela 9: Teste de linearidade do kerma no ar, utilizando-se o medidor Diavolt. Corrente no tubo fixa em $10 \mathrm{~mA}$ e filtração de 2,5mm de Al

\begin{tabular}{|c|c|c|c|c|}
\hline Tempo de Exposição (s) & $\mathbf{1 8}$ & $\mathbf{3 6}$ & $\mathbf{5 4}$ & $\mathbf{7 2}$ \\
\hline \multirow{3}{*}{ Kerma no ar (mGy) } & 31,85 & 67,52 & 103,1 & 138,8 \\
\cline { 2 - 5 } & 31,86 & 67,51 & 103,2 & 138,8 \\
\cline { 2 - 5 } & 31,69 & 67,50 & 103,1 & 138,8 \\
\cline { 2 - 5 } & 31,92 & 67,54 & 103,2 & 138,9 \\
\cline { 2 - 5 } & 31,88 & 67,53 & 103,2 & 138,7 \\
\hline Kerma no ar médio (mGy) & $\mathbf{3 1 , 8 4}$ & $\mathbf{6 7 , 5 2}$ & $\mathbf{1 0 3 , 1 6}$ & $\mathbf{1 3 8 , 8 0}$ \\
\hline \multicolumn{4}{|c|}{$\mathbf{8 , 6 0 \%}$} \\
\hline Reprodutibilidade & $\mathbf{0 , 7 2 \%}$ & $\mathbf{0 , 0 6 \%}$ & $\mathbf{0 , 1 0 \%}$ & $\mathbf{0 , 1 4 \%}$ \\
\hline Linearidade & \multicolumn{5}{|c|}{} \\
\hline
\end{tabular}




\subsubsection{Exatidão e Reprodutibilidade do Tempo de Exposição:}

Outro importante teste no controle de qualidade de um tubo de raios $X$ é o de Exatidão e Reprodutibilidade do Tempo de Exposição. Esse teste foi feito para os tempos de 16 a 70 segundos utilizando-se o medidor Diavolt. A TAB. 10 apresenta os resultados.

Tabela 10: Resultados para o teste de linearidade do tempo de exposição, utilizando-se o medidor Diavolt.

\begin{tabular}{|c|c|c|c|c|}
\hline Tempo de Exposição (s) & 16 & 34 & 52 & 70 \\
\hline \multirow{4}{*}{ Tempo Medido (s) } & 16,58 & 34,6 & 52,61 & 70,61 \\
\cline { 2 - 5 } & 16,59 & 34,58 & 52,60 & 70,61 \\
\cline { 2 - 5 } & 16,49 & 34,55 & 52,55 & 70,59 \\
\cline { 2 - 5 } & 16,6 & 34,57 & 52,57 & 70,59 \\
\cline { 2 - 5 } & 16,59 & 34,62 & 52,62 & 70,54 \\
\hline Tempo Médio (s) & $\mathbf{1 6 , 5 7}$ & $\mathbf{3 4 , 5 8}$ & $\mathbf{5 2 , 5 9}$ & $\mathbf{7 0 , 5 9}$ \\
\hline Reprodutibilidade & $\mathbf{0 , 6 6 \%}$ & $\mathbf{0 , 2 0} \%$ & $\mathbf{0 , 1 3 \%}$ & $\mathbf{0 , 1 0} \%$ \\
\hline Exatidão & $\mathbf{- 3 , 4 4 \%}$ & $\mathbf{- 1 , 6 9 \%}$ & $\mathbf{- 1 , 1 2 \%}$ & $\mathbf{- 0 , 8 3 \%}$ \\
\hline
\end{tabular}

\subsubsection{Reprodutibilidade do mAs:}

O último teste de controle de qualidade foi o de Reprodutibilidade do mAs, onde se avalia a variação de Kerma, mantendo o produto corrente-tempomAs fixo (180 mAs), fazendo-se modificações na corrente do tubo e compensando-as com o tempo de exposição, objetivando encontrar desvios na "curva de isodose" de emissão do tubo. Os resultados estão na TAB. 11.

Tabela 11: Reprodutibilidade do mAs, utilizando-se o medidor Diavolt. O produto foi mantido fixo em $180 \mathrm{mAs}$

\begin{tabular}{|l|c|c|c|}
\hline & TEMPO (min) & Corrente (mA) & KERMA (mGy) \\
\hline \multirow{4}{*}{ Tempo Medido (s) } & 0,3 & 10 & 31,72 \\
\cline { 2 - 4 } & 0,6 & 5 & 33,77 \\
\cline { 2 - 4 } & 1,2 & 2,5 & 34,69 \\
\cline { 2 - 4 } & 2 & 1,5 & 35,24 \\
\cline { 2 - 4 } & 3 & 1 & 35,6 \\
\hline
\end{tabular}

\begin{tabular}{|c|c|}
\hline Kerma Médio (mGy) & $\mathbf{3 4 , 2 0}$ \\
\hline Reprodutibilidade & $\mathbf{0 , 0 4 5 3}$ \\
\hline
\end{tabular}




\subsection{DETERMINAÇÃO DA HOMOGENEIDADE DO CAMPO DE RADIAÇÃO}

A determinação da homogeneidade do campo de radiação também foi realizada para saber se o equipamento emissor de raios $X$ está emitindo radiação em todo o campo e de forma homogênea. Como os testes de controle de qualidade mostraram resultados satisfatórios, o teste de homogeneidade do campo de radiação foi realizado. Os gráficos das FIG. 25 e 26 mostram as intensidades relativas dos feixes de raios $X$ em posições distintas, visando varrer os campos de radiação nas direções verticais e horizontais.

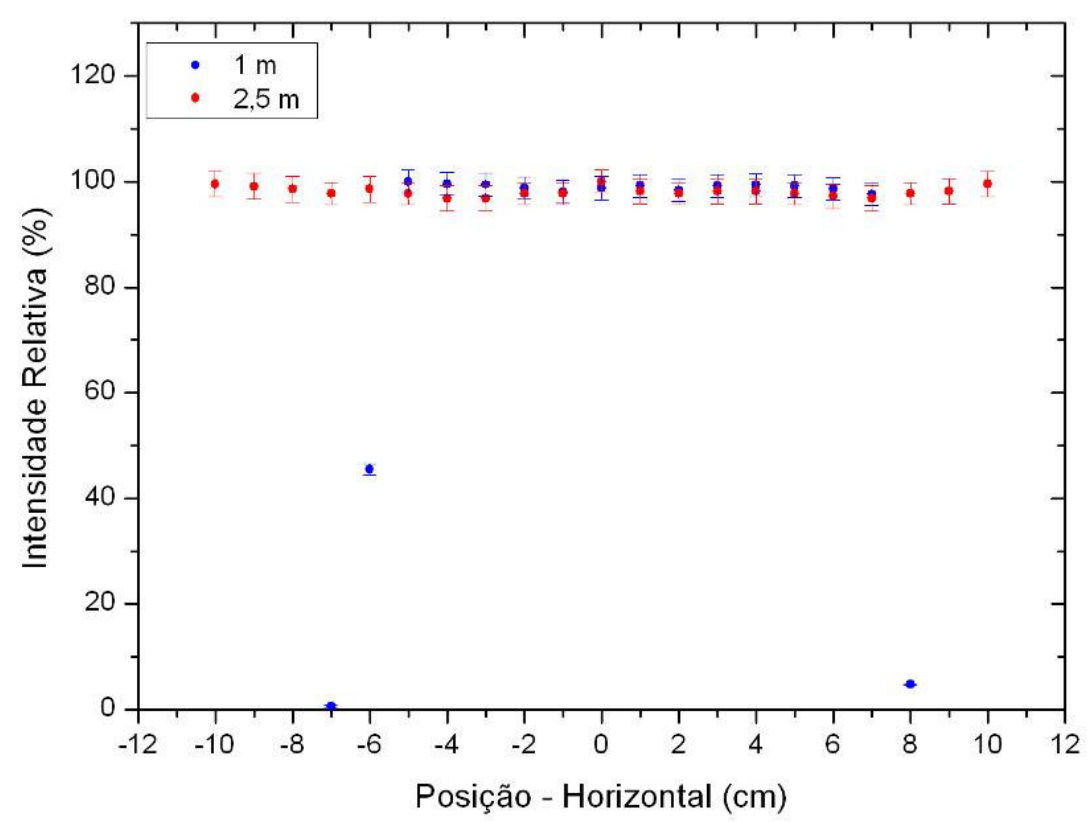

FIGURA 25 - Homogeneidade do campo de radiação X na direção horizontal a 1 e 2,5 m de distância com colimadores de 50,8 e 70,5 mm de diâmetro, respectivamente. 


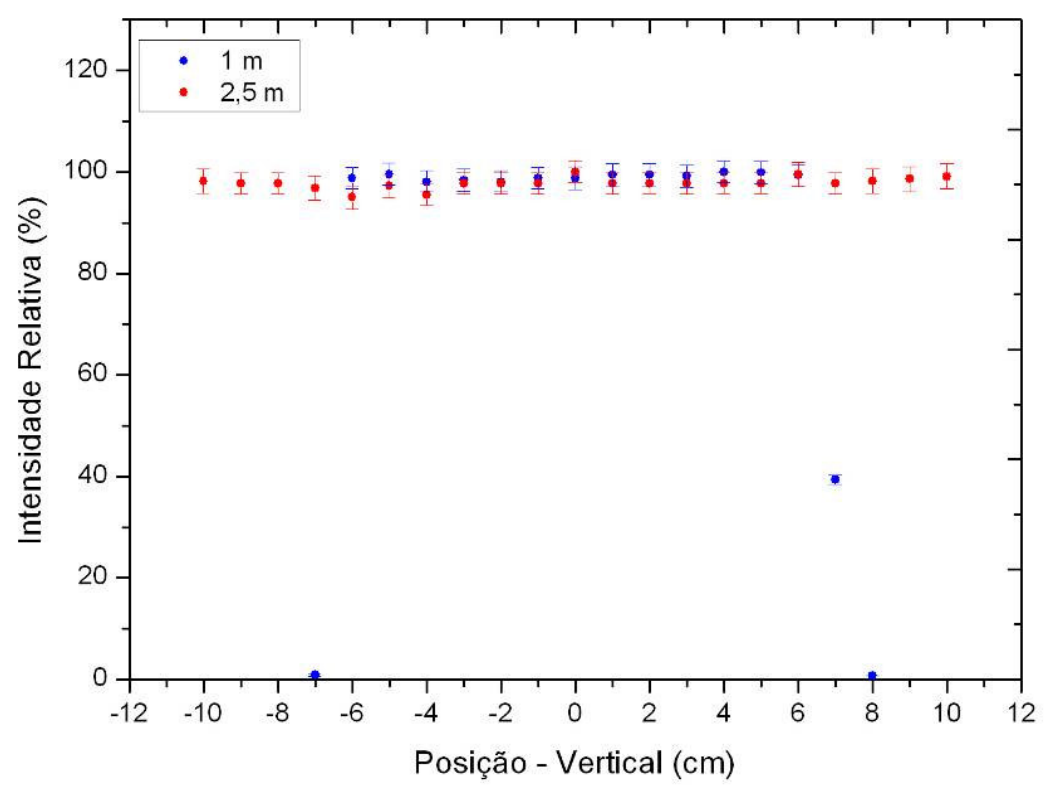

FIGURA 26 - Homogeneidade do campo de radiação $X$ na direção vertical a 1 e 2,5 m de distância com colimadores de 50,8 e 70,5 mm de diâmetro, respectivamente.

O esperado é que o valor da carga medida seja maior no centro e que decaia à medida que afastamos o detector do centro do campo. Observando os gráficos das FIG. 25 e 26, nota-se que os pontos referentes às medições das intensidades relativas da radiação $X$ nas distâncias 1 e 2,5 m respeitam, aproximadamente, uma simetria ao redor da posição $0 \mathrm{~cm}$. Essa simetria aproximada indica uma homogeneidade no campo de radiação $X$, ou seja, o efeito anódico não é verificado. Essa homogeneidade também é comprovada pelo fato das leituras da intensidade relativa apresentarem valores superiores a 95\% (porcentagem referente à leitura na posição zero), de acordo com os Requisitos para Operação de Laboratórios de Calibração de Instrumentos de Medição para Radiação Ionizante Usados em Radioproteção (2004) ${ }^{(13)}$.

\subsection{DETERMINAÇÃO DA FILTRAÇÃO INERENTE DO TUBO}

Como foi dito anteriormente a filtração inerente encontrada foi de $\mathbf{0 , 1 3 8 \mathrm { mm }}$ Al para uma Camada Semi-Redutora (CSR) de 0,1 mm Al. Este valor de filtração inerente foi obtido através de uma extrapolação da curva gerada pelos dados fornecidos pela norma ISO-4037-1, de forma a tornar possível o cálculo da filtração inerente para uma CSR menor que $0,33 \mathrm{~mm}$ de Al, pois esta tabela 
permite o cálculo da filtração inerente para tubos que apresentem o valor da CSR maior ou igual a $0,33 \mathrm{mmAl}$. A equação foi obtida realizando-se um ajuste polinomial de quinta ordem por Franciscatto ${ }^{(11)}$.

\subsection{DETERMINAÇÃO DO “PRACTICAL PEAK VOLTAGE” (PPV)}

Juntamente com os dados de tensão que foram usados nos testes de controle de qualidade, com relação à reprodutibilidade da tensão no tubo, o medidor (marca PTW, modelo Diavolt) apresenta o PPV para cada exposição. Esses dados foram utilizados para se analisar o PPV para as diferentes RQT's tratadas nesse trabalho.

Segundo a norma IEC $61267^{(9)}$, deve-se preferencialmente utilizar um medidor invasivo para avaliar a acurácia e a estabilidade da tensão aplicada ao tubo de raios $X$, que deve ser medida através da grandeza PPV. O Código de Prática TRS $457^{(8)}$ introduz a possibilidade do uso de medidores não invasivos para a medição da tensão aplicada ao tubo de raios $\mathrm{X}$, como alternativa à nova edição da norma IEC 61267 que recomenda apenas o uso de medidores invasivos.

O medidor de tensão invasivo deve ser capaz de medir o PPV dentro dos limites de $+1,5 \%$ ou $1,5 \mathrm{kV}$. Como alternativa pode-se usar um medidor não invasivo, desde que, a incerteza final não ultrapasse $5 \%{ }^{(8)}$.Esta modificação favorece os laboratórios padrão secundário dos países membros da AIEA, que não dispõem de dispositivos invasivos. Neste trabalho optou-se por esta alternativa, devido à dificuldade de se acoplar um medidor invasivo no sistema de radiação $X$ disponível.

Foram realizadas medidas a partir da aquisição não-invasiva da forma de onda através do medidor PTW/Diavolt, que foi posicionado na saída do tubo de raios $X$, de modo que o feixe de radiação cobrisse todo o sensor. $O$ arranjo de medida está demonstrado na FIG.27.

Foram realizadas 10 medidas de 30 segundos para cada qualidade de radiação, obtendo-se no final, o valor específico de PPV para cada uma. Obtiveram-se também os valores de kVp máximo e kVp médio. Em seguida, observou-se que o valor do PPV para todas as qualidades estava na faixa de 
tensão estipulada pela norma IEC 61267, ou seja, dentro das incertezas estipuladas de $1,5 \%$ ou $1,5 \mathrm{kV}$ para medidores invasivos e $5 \%$ para medidores não invasivos, como mostra a TAB. 8.

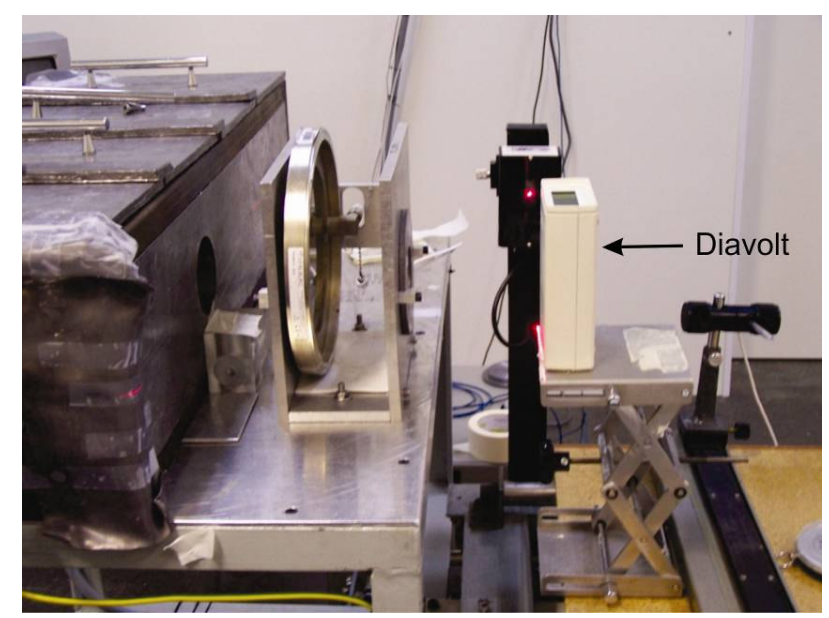

Figura 27: Posicionamento do medidor Diavolt em relação ao sistema de radiação X.

Foram consideradas como incerteza do tipo $\mathrm{A}$, o desvio padrão das médias para cada tensão, e como incerteza do tipo B, a incerteza de calibração apresentado pelo certificado de calibração do Diavolt de $2 \%$, apresentado no anexo 2.

É importante salientar, que mesmo utilizando um medidor não invasivo, os resultados apresentaram-se todos no limite de incerteza para um medidor invasivo. O PPV foi determinado utilizando uma corrente de $10 \mathrm{~mA}$.

$\mathrm{Na}$ TAB. 12, são mostrados os resultados obtidos para os três valores de tensão medidos com corrente fixa de $10 \mathrm{~mA}$.

Tabela 12: Medidas do kVp médio e do PPV para as tensões equivalentes a cada RQT (100, 120 e $150 \mathrm{kV})$.

\begin{tabular}{|c|c|c|c|c|c|c|}
\hline & \multicolumn{2}{|c|}{100 kV } & \multicolumn{2}{c|}{120 kV } & \multicolumn{2}{c|}{150 kV } \\
\hline Corrente & kVpmed & PPV & kVpmed & PPV & kVpmed & PPV \\
\hline \multirow{2}{*}{$10 \mathrm{~mA}$} & $102,3 \pm$ & $101,4 \pm$ & $121,8 \pm$ & $120,9 \pm$ & $152,9 \pm$ & $151,5 \pm$ \\
& 2,0 & 0,09 & 2,4 & 0,15 & 3,01 & 0,69 \\
\hline
\end{tabular}


Dos dados obtidos percebemos que a variação entre os valores médios medidos e o PPV não ultrapassa 1,5\%, e a variação do PPV quando comparada ao valor nominal da tensão chega no máximo a 1,6\%.

\subsection{ESTABELECIMENTO DAS QUALIDADES DE FEIXE (RQT8, RQT9 E RQT10)}

A norma estabelece valores aproximados de espessura dos filtros de cobre, para cada uma das qualidades RQT, e esses valores, TAB. 13, foram considerados como iniciais no processo de tentativa e erro.

Tabela 13: Características das qualidades de radiação RQT, norma IEC $61267^{(9)}$

\begin{tabular}{|c|c|c|c|}
\hline Qualidade & $\begin{array}{c}\text { Tensão nominal aplicada ao } \\
\text { tubo } \\
(\mathrm{kV})\end{array}$ & $\begin{array}{c}\text { Filtro Adicional } \\
(\mathrm{mmCu})\end{array}$ & $\begin{array}{c}\text { Espessura nominal } \\
\mathrm{da} \\
1^{\text {a }} \mathrm{CSR} \\
(\mathrm{mmAl})\end{array}$ \\
\hline RQT 8 & 100 & 0,20 & 6,9 \\
\hline RQT 9 & 120 & 0,25 & 8,4 \\
\hline RQT 10 & 150 & 0,30 & 10,1 \\
\hline
\end{tabular}

Como as RQR tinham sido previamente estabelecidas ${ }^{(11)}$, os valores delas foram utilizados para se obter a filtração adicional de cobre, utilizando-se para isso a metodologia de tentativa e erro. Os resultados encontrados de PPV, da filtração adicional de cobre e da filtração total para se obter cada uma das qualidades são mostrados na TAB. 14. 
Tabela 14: Principais características das qualidades para CT implantadas neste trabalho, seguindo a metodologia proposta pela IEC 61267.

\begin{tabular}{|c|c|c|c|c|}
\hline $\begin{array}{c}\text { Qualidades de } \\
\text { Radiação }\end{array}$ & $\begin{array}{c}\text { Tensão } \\
\text { nominal (kV) }\end{array}$ & PPV (kV) & $\begin{array}{c}\text { F.A. } \\
\text { (mmCu) }\end{array}$ & $\begin{array}{c}\text { Filtração total } \\
\text { (RQR + F.A.) } \\
\text { (mmAl + mmCu) }\end{array}$ \\
\hline RQT 8 & 100 & $\begin{array}{c}101,38 \\
\pm 0,09\end{array}$ & 0,30 & $3,2+0,30$ \\
\hline RQT 9 & 120 & $\begin{array}{c}121,02 \\
\pm 0,15\end{array}$ & 0,35 & $3,5+0,35$ \\
\hline RQT 10 & 150 & $\begin{array}{c}151,36 \\
\pm 0,69\end{array}$ & 0,35 & $4,2+0,35$ \\
\hline
\end{tabular}

F.A. = Filtração adicional

Neste método de caracterização, foram permitidos ajustes na filtração adicional de cobre $(\mathrm{Cu})$ para que os valores de CSR recomendados fossem obtidos. E baseando-se nesta metodologia todas as CSR foram atingidas nos exatos valores recomendados pelo atual padrão anteriormente citado.

$\mathrm{Na}$ TAB. 14 são apresentados os resultados das medidas de PPV, os quais foram satisfatórios em relação às incertezas estipuladas pela IEC $61267^{(9)}$. Também são mostradas as espessuras em $\mathrm{Cu}$ encontradas relativas às filtrações adicionais e para efeito explicativo, a filtração total que caracteriza a qualidade $\mathrm{RQT}$.

Após a determinação das filtrações adicionais, foram construídas as curvas de atenuação mostradas na FIG. 28. Onde podem ser identificados graficamente os valores da 1a e $2^{\underline{a}}$ CSR (transmissão de 50\% e 25\% respectivamente). As curvas de atenuação do feixe para cada uma das RQT foram encontradas com as filtrações constantes na TAB. 14. 
Curva de Atenuação da RQT 8

$100 \mathrm{kV}-$ F.A. de $3,2 \mathrm{mmAl}+0,30 \mathrm{mmCu}$

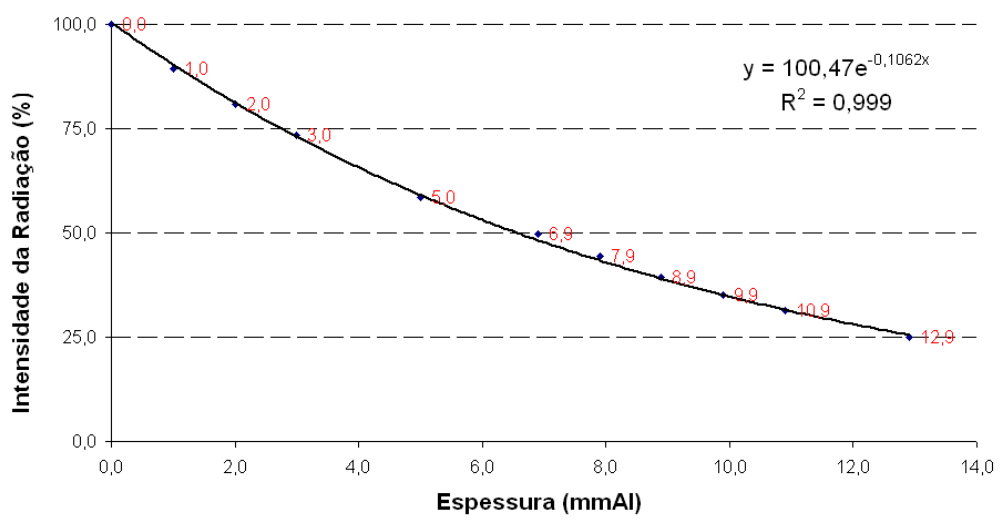

Curva de Atenuação da RQT 9

$120 \mathrm{kV}-\mathrm{F}$.A. de $3,5 \mathrm{mmAl}+0,35 \mathrm{mmCu}$

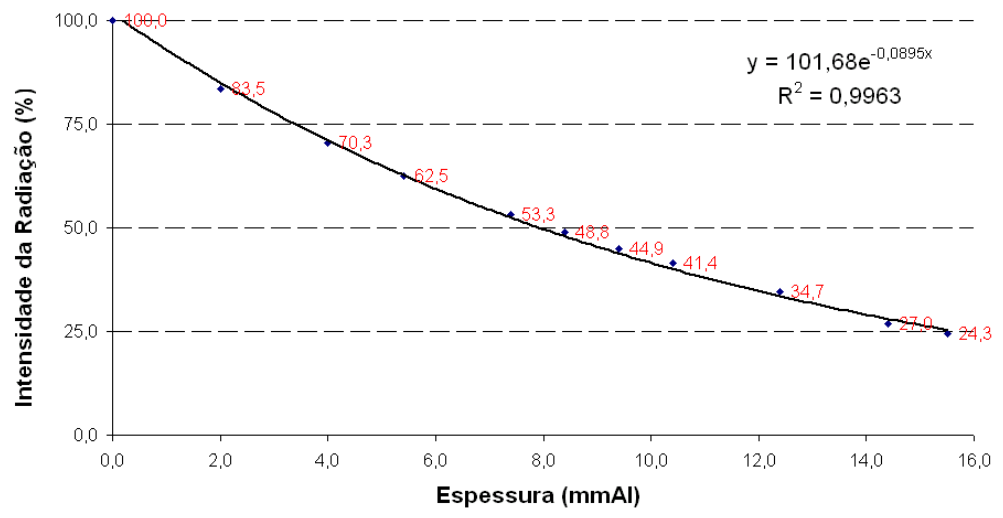

Curva de Atenuação da RQT 10

$150 \mathrm{kV}$ - F.A. de $4,2 \mathrm{mmAl}+0,35 \mathrm{mmCu}$

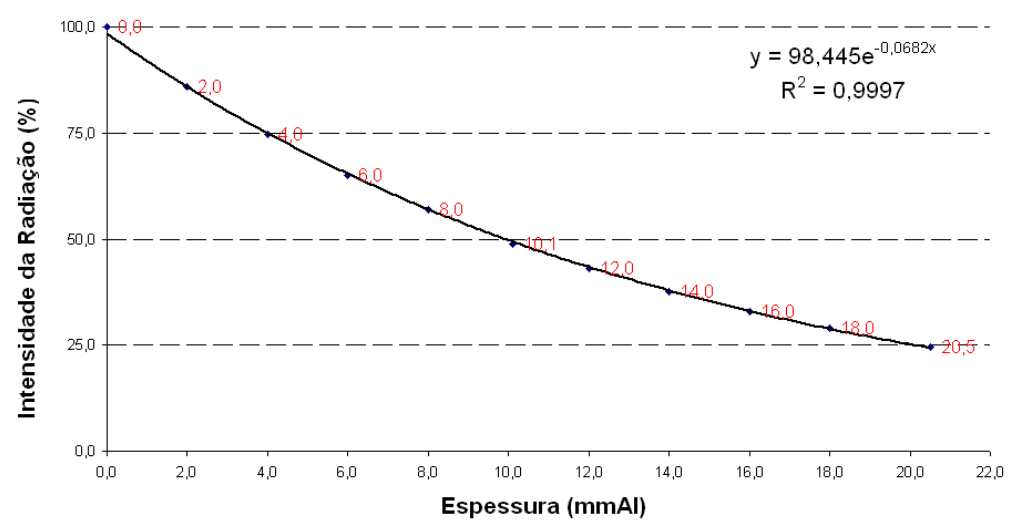

Figura 28: Curvas de atenuação para as qualidades RQT8, RQT 9 e RQT10. 


\subsection{ESTABELECIMENTO DAS QUALIDADES DE RADIAÇÃO (RQT 8, RQT 9, RQT 10) PELA METODOLOGIA ALTERNATIVA}

Uma metodologia alternativa foi utilizada, através da qual, deve ser encontrada uma espessura de filtros de cobre, que seja equivalente ao conjunto "RQR + Filtração Adicional" mostrada anteriormente. Neste caso, a espessura de Cu recomendada na TAB. 13 segundo a IEC 61267 foi tomada como valor inicial, e a partir deste, pelo método de tentativa e erro, é procurada a espessura de filtração que resulta nas qualidades procuradas. Os resultados encontrados são mostrados na TAB. 15.

Tabela 15: Características encontradas para as qualidades RQT8, RQT9 e RQT10 considerando somente as filtrações de Cobre $(\mathrm{Cu})$.

\begin{tabular}{|c|c|c|c|}
\hline Qualidades de Radiação & $\begin{array}{c}\text { Tensão } \\
\text { nominal (kV) }\end{array}$ & PPV (kV) & $\begin{array}{c}\text { Filtração total } \\
\text { (mmCu) }\end{array}$ \\
\hline RQT 8 & 100 & $\begin{array}{c}101,38 \\
\pm 0,09\end{array}$ & 0,50 \\
\hline RQT 9 & 120 & $\begin{array}{c}121,02 \\
\pm 0,15\end{array}$ & 0,50 \\
\hline RQT 10 & 150 & $\begin{array}{c}151,36 \\
\pm 0,69\end{array}$ & 0,50 \\
\hline
\end{tabular}

A FIG. 29 mostra as curvas de atenuação do feixe para cada uma das RQT encontradas com as filtrações constantes na TAB. 15. 
CURVA DE ATENUAÇÃO DA RQT 8

$100 \mathrm{kV}$ - F.A. de $0,5 \mathrm{mmCu}$

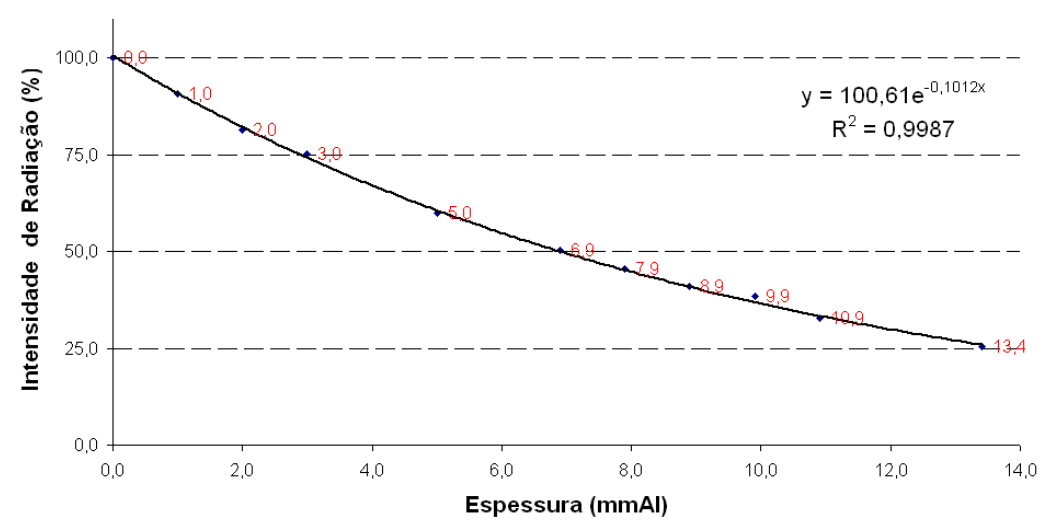

CURVA DE ATENUAÇÃO DA RQT 9

$120 \mathrm{kV}$ - F.A. de $0,5 \mathrm{mmCu}$

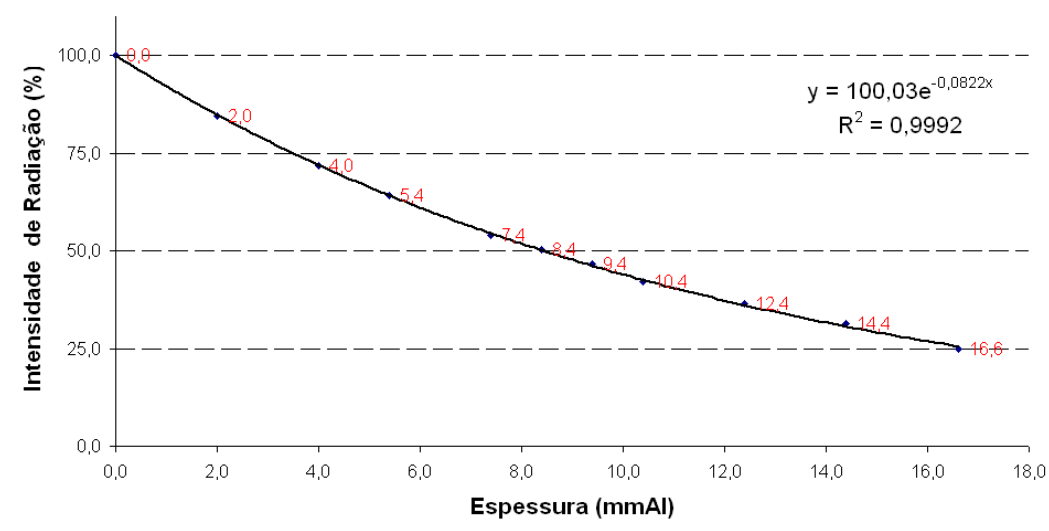

CURVA DE ATENUAÇÃO DA RQT 10

$150 \mathrm{kV}$ - F.A. de $0,5 \mathrm{mmCu}$

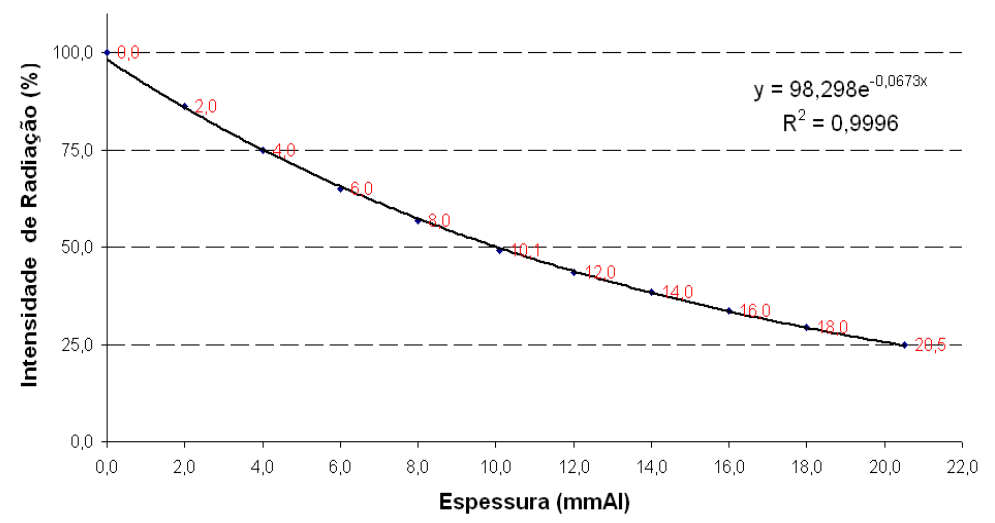

Figura 29: Curvas de atenuação para as qualidades RQT8, RQT 9 e RQT10. (Método Alternativo) 


\subsection{DETERMINAÇÃO DOS FATORES DE QUALIDADE E DAS TAXAS DE KERMA NO AR PARA AS QUALIDADES RQT}

O coeficiente de calibração $N_{K L}$ para a câmara de ionização tipo lápis de (referência) foi fornecido pelo laboratório primário alemão PTB, com rastreabilidade às novas qualidades RQT como recomenda a norma IEC 61267. Também foi fornecido no certificado de calibração os fatores de qualidade de radiação $\left(K_{Q}\right)$ para cada uma das qualidades.

Utilizando-se os fatores de qualidade e coeficientes de calibração fornecidos pelo PTW referentes à câmara lápis padrão secundário, a taxas de kerma no ar $\mathrm{K}_{\mathrm{ar}}$, em $\mathrm{Gy} / \mathrm{min}$, para cada qualidade de feixe estabelecida foram calculadas pela fórmula:

$$
\dot{K_{a r}}=\mathrm{N}_{\mathrm{k}} \mathrm{K}_{\mathrm{Q}} \mathrm{M}
$$

Onde,

$M=$ leitura com o instrumento de referência $(\mathrm{C} / \mathrm{min})$

$\mathrm{NK}=$ coeficiente de calibração fornecido por um laboratório padrão $(\mathrm{Gy} / \mathrm{C})$,

$\mathrm{NK}=9,157 \times 10^{7} \mathrm{~Gy} / \mathrm{C}$ para RQT (PTB)

$K Q=$ fator de correção para cada qualidade de radiação

Todas as medidas foram realizadas com a câmara lápis com rastreabilidade ao PTB a $100 \mathrm{~cm}$ de distância foco-câmara e com uma corrente fixa no tuboe de $10 \mathrm{~mA}$. Utilizou-se também a e na saída do tubo de raios $X$ um colimador para delimitar o campo de radiação padrão como mostra a FIG. 30. 


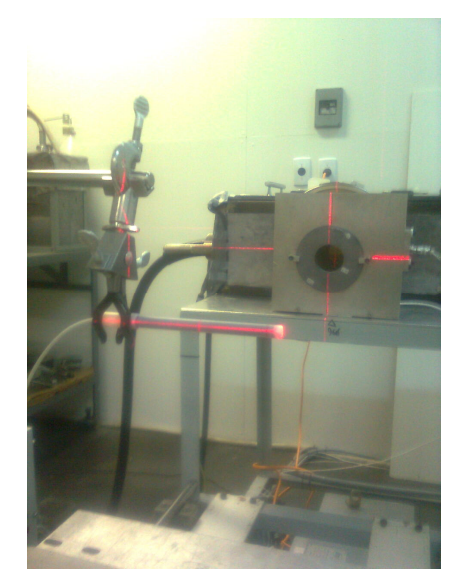

Figura 30. Arranjo dosimétrico para determinação das taxas de Kerma no ar, com a câmara de ionização tipo lápis posicionada a $100 \mathrm{~cm}$.

Os valores obtidos estão relacionados nas TABs. 16 e 17, juntamente com as outras características determinadas dos feixes, tanto para a série baseada nas RQR's quanto para as qualidades baseadas no método alternativo. Estes campos padrões serão utilizados nas calibrações das câmaras lápis, utilizadas na dosimetria clínica de sistemas de CT.

Tabela 16: Parâmetros característicos das qualidades de radiação RQT's baseadas nas qualidades RQR's.

\begin{tabular}{|c|c|c|c|c|c|c|c|}
\hline \multirow[t]{2}{*}{ Qual. } & \multirow{2}{*}{$\begin{array}{c}\text { Filtração } \\
\text { Total } \\
\text { (mmCu } \\
+ \text { +mmAl) }\end{array}$} & \multirow{2}{*}{$\begin{array}{c}\text { Tensão } \\
(k v)\end{array}$} & \multirow{2}{*}{\begin{tabular}{|c|} 
Corrente \\
$(\mathrm{mA})$
\end{tabular}} & \multirow{2}{*}{$\begin{array}{l}\text { Dist. } \\
\text { (cm) }\end{array}$} & \multirow{2}{*}{$\begin{array}{c}\text { Taxa de } \\
\text { Kerma no ar } \\
\text { (mGy/min) }\end{array}$} & \multicolumn{2}{|c|}{ Câmara de referência } \\
\hline & & & & & & Nk $(G y / C)$ & Kq \\
\hline 0 & $0,30+3,2$ & & 10 & 100 & (2) & & 0,997 \\
\hline & & & & & & & 1 \\
\hline & ? & 150 & 10 & 100 & $56,764^{\star * *}$ & $9,157 \times 10^{7}$ & 1,005 \\
\hline
\end{tabular}


Tabela 17: Parâmetros característicos das qualidades de radiação RQT's (Método Alternativo)

\begin{tabular}{|l|c|c|c|c|c|c|c|}
\hline Qual. & $\begin{array}{c}\text { Filtração } \\
\text { Total }\end{array}$ & Tensão & Corrente & Dist. & $\begin{array}{c}\text { Taxa de } \\
\text { Kerma no } \\
\mathbf{a r}\end{array}$ & \multicolumn{2}{|c|}{ Câmara de referência } \\
\hline RQT 8 & $\mathbf{( m m C u )}$ & $\mathbf{( k v )}$ & $\mathbf{( m A )}$ & $\mathbf{( c m )}$ & $\mathbf{( m G y / m i n )}$ & $\mathbf{N k}(\mathbf{G y} / \mathbf{C})$ & $\mathbf{K q}$ \\
\cline { 5 - 8 } & 0,50 & 100 & 10 & 100 & $19,540^{*}$ & $9,157 \times 10^{7}$ & 0,997 \\
\hline RQT 9 & 0,50 & 120 & 10 & 100 & $34,094^{* *}$ & $9,157 \times 10^{7}$ & 1,000 \\
\hline RQT 10 & 0,50 & 150 & 10 & 100 & $62,559^{* * *}$ & $9,157 \times 10^{7}$ & 1,005 \\
\hline
\end{tabular}

$(\mathrm{k}=1,96 * \pm 0,006 * * \pm 0,009 * * * \pm 0,021)$

As incertezas associadas aos valores de taxas de kerma no ar estiveram sempre abaixo de 2,1\%. Verifica-se que as taxas de kerma no ar obtidas pela metodologia convencional (baseadas nas RQR's) diferem um pouco das taxas de kerma no ar da série referente ao método alternativo. Isto ocorre devido às diferentes composições nas filtrações adicionais que são inseridas na saída do tubo de raios $X$. No caso da série convencional, estas filtrações são compostas pela combinação de filtros de $\mathrm{Al}$ e $\mathrm{Cu}$, já na série alternativa das RQT's, as filtrações são compostas apenas por Cu. Por isso, as taxas de kerma no ar são diferentes para as mesmas qualidades, pois seus espectros são alterados pelo material dos filtros adicionais, apesar de todos os outros parâmetros radiológicos serem iguais. 


\subsection{METODOLOGIA DE CALIBRAÇÃO DAS CÂMARAS DE IONIZAÇÃO TIPO LÁPIS}

Além da implantação das qualidades específicas denominadas RQT, que são utilizadas em aplicações de CT, é necessário que se estabeleça uma metodologia de calibração diferenciada no caso das câmaras de ionização do tipo lápis, devido às suas características especiais de uso e de formato. Para isso, existem algumas diferentes formas de calibração destas câmaras, sendo as principais diferenças nas metodologias utilizadas pelos SSDL's relacionadas à região ao longo da câmara que deve ser irradiada. O TRS 457 propõe que se utilize o arranjo que está esquematizado na FIG. 31 .

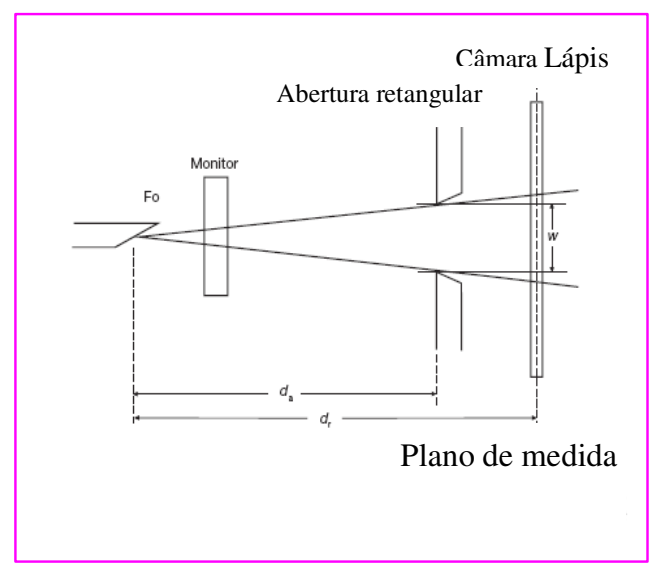

Figura 31: Esquema do arranjo experimental para a calibração de câmaras de CT proposto pelo TRS 457. $d_{a=}$ distância foco-colimador e $d_{r}=$ distância foco-plano de medida.

Em muitas aplicações da câmara lápis é comum a irradiação total de toda a área da mesma, porém sabemos que em suas extremidades ocorre uma diminuição na sensibilidade, já comprovada com alguns testes de homogeneidade da resposta ao longo do comprimento sensível da câmara ${ }^{(5)}$. Por isso, a metodologia mais adequada e atualmente recomendada pelo TRS 457 e pela IEC 61674 é a irradiação parcial, pois os melhores resultados são obtidos quando $50 \%$ do volume sensível da câmara lápis é irradiado durante a calibração. Para isto é indispensável o uso de colimadores adequados e um arranjo geométrico específico para calibração das câmaras lápis. 
Na FIG. 31 pode ser verificado o arranjo geométrico utilizado neste trabalho para o posicionamento e calibração de uma câmara lápis, onde um colimador posicionado em frente à câmara delimita a irradiação parcial $(50 \%)$ na região central da mesma. Com isso é possível evitar que o feixe atinja as extremidades desta câmara e prejudique a confiabilidade das medidas de kerma no ar.

Para garantir uma colimação precisa, o sistema de colimação deve ser colocado próximo da câmara sob calibração, a uma distância de 50 mm ${ }^{(8)}$.

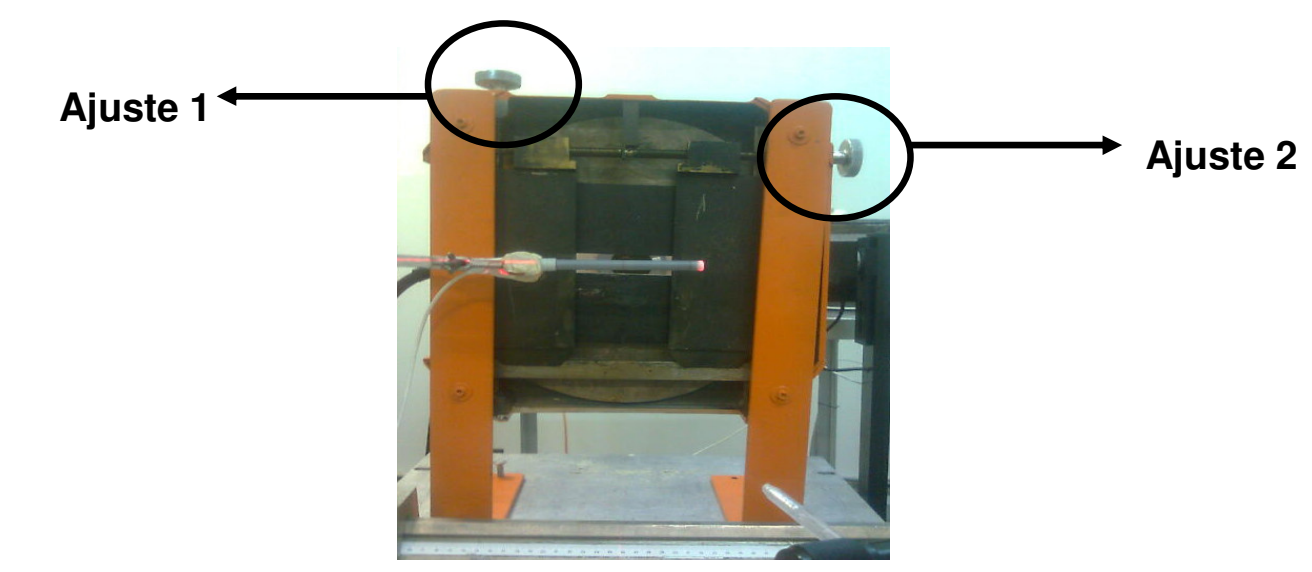

Figura 31 - Arranjo de calibração de câmaras lápis do LCI, utilizando o colimador desenvolvido para este propósito.

O uso do comprimento na calibração das câmaras de ionização tipo lápis envolve considerações especiais e no caso dos laboratórios SSDL's o procedimento a ser seguido é o que recomenda o TRS $457^{(10)}$.

\subsubsection{Procedimento de calibração:}

Com uma câmara de referência, uma medida de kerma no ar, kar, é feita no plano da medida para a qualidade de radiação RQT. Então a fenda retangular de chumbo (colimador) é posicionada em frente a câmara de ionização a ser calibrada, atrás da câmara de transmissão monitora. A fenda deve estar centralizada em relação ao comprimento da câmara e localizada como descrito anteriormente. A separação da fenda do ponto de teste deve ser precisamente conhecida. A largura da fenda deve está entre 20 e $50 \mathrm{~mm}$ para uma respectiva irradiação parcial de $20 \%$ a $50 \%$ do comprimento sensível da câmara. A altura da fenda deve corresponder a 2 vezes o diâmetro da câmara. As dimensões externas 
da montagem da fenda deve ser larga suficiente para proteger a integridade da câmara. No plano de medida, a largura do campo é mais larga que a largura da fenda devido ao feixe divergente ${ }^{(8)}$.

A câmara é calibrada em seu centro. O coeficiente de calibração dessa câmara é determinado pela equação:

$\mathrm{N}_{\mathrm{Pkl}, \mathrm{Q}}=\mathrm{Kw} \cdot \mathrm{d}_{\mathrm{r}} / \mathrm{Md}_{\mathrm{a}}$

Onde:

M: é a leitura da câmara corrigida para as condições ambientais

$\mathrm{K}$ : é o kerma no ar no ponto de teste

W: é a largura da fenda

$\mathrm{d}_{\mathrm{T}}$ : é a distância entre o ponto focal e o ponto de medida

$\mathrm{d}_{\mathrm{a}}$ : é a distância entre o ponto focal e o plano do colimador

$\mathrm{N}_{\mathrm{Pkl}, \mathrm{Q}}$ : é o produto do $\mathrm{K}_{\mathrm{ar}}$ pelo comprimento do coeficiente de calibração para qualidade de radiação $Q$

\subsubsection{Aplicação da Metodologia Implantada}

Para a aplicação da metodologia, foram testadas quatro câmaras de ionização específicas para tomografia, utilizadas em medidas de controle de qualidade em clínicas de radiodiagnóstico, todas da marca Radcal, sendo uma modelo RC-3CT e as outras três modelo 10X5-3CT.

O método utilizado foi o de substituição, sendo que o centro geométrico do detector foi tomado como ponto de referência para a calibração. Os valores medidos foram comparados com os valores de referência, ou valor verdadeiro convencional (VVC) obtidos com o instrumento padrão do LCl.

As incertezas padrão expandidas declaradas foram calculadas de acordo com as recomendações da Edição Brasileira da ISO GUM, para um fator de abrangência k=2 e nível de confiança de 95,45 \%.

Para a determinação do coeficiente de calibração foi utilizado o método da irradiação parcial, ou seja, irradiação de $80 \%$ do comprimento sensível da câmara de ionização. O valor do kerma no ar, K, é encontrado pela seguinte relação: 


$$
\mathrm{K}(\mathrm{Gy})=\left(N_{\mathrm{kl}} \times \mathrm{M} \times \mathrm{d}_{\mathrm{a}}\right) /\left(\mathrm{w} \times \mathrm{d}_{\mathrm{r}}\right)
$$

Onde :

$\mathrm{K}$ = taxa de kerma no ar

$N_{\mathrm{kl}}=$ coeficiente de calibração em termos do produto kerma no ar-comprimento

$M$ = leitura corrigida da câmara de ionização

$d_{a}=$ distância entre o ponto focal e o colimador

$d_{r}=$ distância entre $o$ ponto focal e $o$ instrumento sob calibração ou ponto de medida

$\mathrm{w}$ = tamanho do campo de radiação sobre o eixo longitudinal da câmara de ionização

Condições durante a calibração:

$d_{a}=95 \mathrm{~cm}$

$\mathrm{d}_{\mathrm{r}}=100 \mathrm{~cm}$

$\mathrm{w}=08 \mathrm{~cm}$

Os coeficientes de calibração encontrados e as características de calibração estão relacionados na TAB. 18. A incerteza encontrada em todos os casos foi de $3,0 \%$. 
Tabela 18: Coeficientes de calibração encontrados para as quatro câmaras de ionização tipo lápis testadas na nova metodologia implantada.

\begin{tabular}{|c|c|c|c|c|c|c|}
\hline Qualidade & $\begin{array}{c}\text { Tensão } \\
\text { (kV) }\end{array}$ & $\begin{array}{c}\text { Filtração } \\
(\mathrm{mm})\end{array}$ & $\begin{array}{l}\text { Camada } \\
\text { Semi- } \\
\text { Redutora } \\
\text { (mmAl) }\end{array}$ & $\begin{array}{c}\text { Taxa de Kerma } \\
\text { no Ar } \\
\text { (mGy/min) }\end{array}$ & $\begin{array}{l}\text { Modelo da } \\
\text { Câmara de } \\
\text { lonização }\end{array}$ & $\begin{array}{c}\text { Coeficiente } \\
\text { de } \\
\text { Calibração } \\
\text { (Gy.cm/u.e.) }\end{array}$ \\
\hline RQT 8 & 100 & $3,2 \mathrm{Al}+0,30 \mathrm{Cu}$ & 6,90 & 22,0 & $\begin{array}{c}\text { RC-3CT } \\
\text { 10X5-3CT-1 } \\
10 \times 5-3 C T-2 \\
10 \times 5-3 C T-3\end{array}$ & $\begin{array}{c}0,00896 \\
0,00978 \\
0,0100 \\
0,00926\end{array}$ \\
\hline RQT 9 & 120 & $3,5 \mathrm{Al}+0,35 \mathrm{Cu}$ & 8,40 & 34,0 & $\begin{array}{c}\text { RC-3CT } \\
\text { 10X5-3CT-1 } \\
10 \times 5-3 C T-2 \\
10 \times 5-3 C T-3\end{array}$ & $\begin{array}{c}0,00916 \\
0,00997 \\
0,0102 \\
0,00947\end{array}$ \\
\hline RQT 10 & 150 & $4,2 \mathrm{Al}+0,35 \mathrm{Cu}$ & 10,1 & 57,0 & $\begin{array}{c}\text { RC-3CT } \\
\text { 10X5-3CT-1 } \\
10 \times 5-3 C T-2 \\
10 \times 5-3 C T-3\end{array}$ & $\begin{array}{c}0,00910 \\
0,00986 \\
0,0101 \\
0,00941\end{array}$ \\
\hline
\end{tabular}




\section{CONCLUSÕES}

Neste trabalho o principal objetivo foi o estabelecimento de uma nova metodologia de calibração das câmaras de ionização tipo lápis, respeitando os parâmetros recomendados pela International Electrotecnhical Commission (IEC 61267) que especifica as qualidades de radiação utilizadas em aplicações de CT (RQT's). Além disso, foi estabelecido um procedimento de calibração de câmaras lápis para SSDL's, baseado em recomendações do TRS 457, cujo arranjo geométrico de calibração foi modificado em alguns dos seus parâmetros em relação à metodologia anterior, sendo as principais diferenças relacionadas ao posicionamento e colimação da câmara em relação ao feixe.

Essa metodologia foi utilizada na implantação destas qualidades no equipamento de raios $X$ Pantak/Seifert do Laboratório de Calibração de Instrumentos do IPEN. Primeiramente foram medidos os valores de PPV não invasivamente para cada qualidade, com resultados dentro dos limites de variação permitidos pela norma IEC 61267 e de acordo com a TRS 457. A partir daí foram implantadas as qualidades de radiação de referência recomendadas pela norma IEC 61267(9), denominadas como RQT 8, RQT 9, e RQT 10, com filtros de alumínio e cobre de alta pureza, respeitando-se os valores de $1^{1}$ camada semi-redutora fixados pela norma.

Após a implantação destes campos de radiação padrão, foram então determinadas as taxas de Kerma no ar referentes às novas qualidades implementada, sendo este último parâmetro essencial para o procedimento de calibração das câmaras lápis dentro da nova metodologia. Com isso, o LCl está apto a calibrar as câmaras de ionização tipo lápis nas qualidades específicas para aplicações de CT e dentro dos atuais padrões metrológicos internacionais. 


\section{REFERÊNCIAS BIBLIOGRÁFICAS}

1. ZOETELIEF, J., PERNICKA, F., CARLSSON, G. A., DANCE, D.R., DeWERD, L.A., DREXLER, G., JÄRVINEN, H., KRAMER, H.-M., NG, K.-H. Dosimetry in diagnostic and interventional radiology: International Commission on Radiation Units and Measurements an IAEA Activities. Standards and Code of Practice in Medical Radiation Dosimetry. Proceedings of an International Symposium, Vienna, 25-28 November, 2002.

2. INTERNATIONAL ATOMIC ENERGY AGENCY. Radiological protection of patients in diagnostic and interventional radiology, nuclear medicine and radiotherapy. Proceedings of an international conference held in Málaga, Spain, 26-30 march 2001. Vienna, 2001

3. INTERNATIONAL ATOMIC ENERGY AGENCY, PAN AMERICAN HEALTH ORGANIZATION, WORLD HEALTH ORGANIZATION. Radiological protection for medical exposure to ionizing radiation, Safety Guide. Safety Standards Series No. RS-G-1.5, IAEA, Vienna, 2002

4. JESSEN KA, SHRIMPTON PC, GELEIJNS J, ET AL. Dosimetry for optimisation of patient protection in computed tomography. Appl Radiat Isot., v. 50, p. 165-172, 1999.

5. MAIA, A.F. Padronização de feixes e metodologia dosimétrica em tomografia computadorizada. São Paulo : 2005. tese (Doutoramento) Instituto de Pesquisas Energéticas e Nucleares/Univ. de São Paulo.

6. FOOD AND AGRICULTURE ORGANIZATION OF THE UNITED NATIONS, INTERNATIONAL ATOMIC ENERGY AGENCY, INTERNATIONAL LABOUR ORGANIZATION, OECD NUCLEAR ENERGY AGENCY, PAN AMERICAN HEALTH ORGANIZATION, WORLD HEALTH ORGANIZATION. International basic standards for protection against ionizing radiation and for the safety of radiation sources, Safety Series No. 115, IAEA, Vienna, 1996.

7. INTERNATIONAL COMMISSION ON RADIOLOGICAL PROTECTION. Protection and safety in medicine, Publication 73, Pergamon Press, Oxford and New York, 1996

8. INTERNATIONAL ATOMIC EBERGY AGENCY. Dosimetry in diagnostic radiology: an international code of practice. Technical Reports Series $\mathbf{N}^{\circ}$ 457, IAEA, Vienna, 2007.

9. INTERNATIONAL ELECTROTECHNICAL COMMISSION. IEC 61267. Medical diagnostic X-ray equipment - Radiation conditions for use in determination of characteristics. Revisão 2005. Genève, 2005. 
10. MIRANDA, J. A. Desenvolvimento de uma metodologia para a calibração de instrumentos de medida utilizados no controle de qualidade em radiodiagnóstico intervencional. São Paulo : 2009. Dissertação (Mestrado) - Instituto de Pesquisas Energéticas e Nucleares/Univ. de São Paulo

11. FRANCISCATTO, P. C. Caracterização das Qualidades de Radiação X Seguindo as Recomendações da Norma IEC 61267 no Laboratório de Calibração do IPEN. 2009. São Paulo. Dissertação (Mestrado) - Instituto de Pesquisas Energéticas e Nucleares, Universidade de São Paulo.

12 .CORRÊA, E.L. Metodologia de controle de qualidade e implantação de campos padrões de radiação $X$, nível mamografia, seguindo a norma IEC 61267. 2010. São Paulo. Dissertação (Mestrado) - Instituto de Pesquisas Energéticas e Nucleares, Universidade de São Paulo

13. LUCENA, R. F. Implementação de um Programa de Controle de Qualidade em Equipamentos de Raios X por meio de Medidores Não Invasivos. 2010. São Paulo. Dissertação (Mestrado) - Instituto de Pesquisas Energéticas e Nucleares, Universidade de São Paulo.

14. HOURDAKIS, C.J., BOZIANI, A. AND KOUMBOLI, A. Calibration of pencil type ionization chambers at various irradiation lenghts and beam qualities. Proceedings of IDOS, Vienna, 9-12 november 2010, E2-CN-182, p.171$172,2010$.

15. Bërmann, L., Büttcher, R. Performance test of multi-parameter measuring devices used for quality assurance in diagnostic radiology. Proceedings of IDOS, Vienna, 9-12 november 2010, E2-CN-182, p.169-170, 2010.

16. Toroi, $\mathrm{P}$, , Kosunen, $\mathrm{A}$. Calibration of kerma-area product meters with a patient dose calibrator. Proceedings of IDOS, Vienna, 9-12 november 2010, E2-CN-182, p.169-170, 2010.

.17. INTERNATIONAL COMISSION ON RADIATION UNITS AND MEASUREMENTS, ICRU 2005, "Patient Dosimetry for X Rays used inmedical imaging", ICRU Report 74, Bethesda, MD

18. INTERNATIONAL ELECTROTECHNICAL COMMISSION. IEC 1267. Medical diagnostic X-ray equipment - Radiation conditions for use in determination of characteristics. 1994

19. INTERNATIONAL ELECTROTECHNICAL COMMISSION. IEC 61674. Medical electrical equipment-Dosimeters with ionization chambers and/or semiconductor detectors as used in X-ray diagnostic imaging. Genève, 1997. 
20. MINISTÉRIO DA SAÚDE. Portaria 453. Diretrizes de proteção radiológica em radiodiagnóstico médico e odontológico. Diário Oficial da União, Brasília, 02 de junho de 1998.

21. INTERNATIONAL ATOMIC ENERGY AGENCY. Applying radiation safety standards in diagnostic radiology and interventional procedures using $\mathrm{X}$ rays. Safety Report Series No. 39, IAEA, Vienna, 2006.

22. FOOD AND AGRICULTURE ORGANIZATION OF THE UNITED NATIONS, INTERNATIONAL ATOMIC ENERGY AGENCY, INTERNATIONAL LABOUR ORGANIZATION, OECD NUCLEAR ENERGY AGENCY, PAN AMERICAN HEALTH ORGANIZATION, WORLD HEALTH ORGANIZATION. International basic standards for protection against ionizing radiation and for the safety of radiation sources, Safety Series No. 115, IAEA, Vienna, 1996.

23. POTIENS, M.P.A. Metodologia dosimétrica e sistema de referência para radiação X nível diagnóstico. São Paulo : 1999. Tese (Doutoramento) Instituto de Pesquisas Energéticas e Nucleares/Univ. de São Paulo.

24. POTIENS, M.P.A.; CALDAS, L.V.E. Calibration of $k V p$ meters used in quality control tests in diagnostic radiology by spectrometry. Radiat.Prot.Dosim. . 98(3), 343-346, 2002.

25. FREITAS, R. N., VIVOLO. V.; POTIENS, M.P.A. evaluation of the calibration of instruments in diagnostic radiology qualities. Proceedings of 2007 International Nuclear Atlantic Conference - INAC 2007 Santos, SP, Brazil, September 30 to October 5, 2007. Associação Brasileira de Energia Nuclear - ABEN. ISBN: 978-85-99141-02-1

26. BUSHBERG, J. T.; SEIBERT, J. A.; LEIDHOLDT, E. M.; BOONE, J. M. The essential physics of medical imaging. 2.ed., Philadelphia: Lippinccot Williams \& Wilkins, 2001.

27. SEERAM. Computer tomography physical principles, clinical applications, and quality control. 2.ed. Philadelphia: W. B. Saunders, 2001. $1270 \mathrm{p}$.

28. BUSHONG, S. C. Radiologic Science for Technologists Physics, Biology and Protection. 6.ed., St. Louis: Mosby, 1997. 586 p. cap. 29, p. 377-406.

29. NÓBREGA, A. I. Manual de Tomografia Computadorizada. São Paulo: Editora Atheneu/Centro Universitário São Camilo, 2005. 90 p

30. COSTA, E. B. Tomografia Computadorizada com Raios-X Quase Monoenergéticos. 1999. 97p. (Doutorado em Ciências em Engenharia 
Nuclear), COPPE, Universidade Federal do Rio de Janeiro, Rio de Janeiro, 1999.

31. SILVA, J. S. S. Segmentação Pulmonar em estudos de tomografia axial computadorizada. 2005. 182p. (Doutorado em Engenharia Electrotécnica), Departamento de Electrónica e Telecomunicações, Universidade de Aveiro, Aveiro, Portugal, 2005.

32. ROTHENBERG, L. N.; PENTLOW, K. S. Radiation Dose in CT. Radiographic. v.12, n. 6, p.1225-1246, 1992

33. INTERNATIONAL ORGANIZATION FOR STANDARDIZATION, $X$ and Gamma Reference Radiations for Calibrating Dosemeters and Doserate Meters and for Determining their Response as a Function of Photon Energy - Part 1: Radiation Characteristics and Production Methods, ISO 4037, Part 1, ISO, Geneva (1996).

34. OLIVEIRA, M.L. Desenvolvimento de um sistema de referência e de uma metodologia para calibração de aplicadores oftálmicos utilizados em braquiterapia. São Paulo : 2005. Tese (Doutoramento) - Instituto de Pesquisas Energéticas e Nucleares/Univ. de São Paulo.

35. YOSHIZUMI, M.T. Projeto, construção e caracterização de câmaras de ionização especiais para monitoração de feixes de radiação $X$. São Paulo : 2010. Tese (Doutoramento) - Instituto de Pesquisas Energéticas e Nucleares/Univ. de São Paulo.

36. INSTITUTO NACIONAL DE METROLOGIA, NORMALIZAÇÃO E QUALIDADE INDUSTRIAL. Vocabulário internacional de termos fundamentais e gerais de metrologia. 3rd Ed. Rio de janeiro: INMETRO, 2003.

37. SHOPE, T.B.; GAGNE, R.M.; JONHSON, G.C. A A method for describing the doses delivered by transmission $X$ Ray computed tomography. Med. Phys. v. 8, n.4, p. 488-495, 1981.

38. EUROPEAN COMMISSION. European guidelines on quality criteria for computed tomography. Luxembourg, 1999. EUR 16262 EN.

39. HIDAJAT, N., MAURER, J.,SCHRODER,R-J., NUNNEMANN, A., WOLF, M., PAULI, K., FELIX, R. Relationships between physical dose quantities and patient dose in CT. Brit. J. Radiol, v.72, p. 556-561, 1999.

40. KRAMER, H.M.; SELBACH, H.J.; ILES, W.J. The Practical Peak Voltage of Diagnostic X-Ray Generators. Brit. J. Radiol., v.71, p. 200-209. 1998.

41. PIRES, J.S.J.da Avaliação da Grandeza Tensão de pico prático em equipamento clínicos utilizados em Radiodiagnóstico. 
2007.Dissertação (Mestrado em Ciências na Área de Tecnologia Nuclear)Instituto de Pesquisas Energéticas e Nucleares, Universidade de São Paulo.

42. ATTIX, F. H. Introduction to radiological physics and radiation dosimetry. 2. ed. New York, NY: Wiley, 1986.

43. INTERNATIONAL ATOMIC ENERGY AGENCY. Calibration of radiation protection monitoring instruments. IAEA, Vienna, 2000, (Safety Reports Series No. 16). 


\section{ANEXO 1}

\section{Certificado de Calibração da Câmara de Ionização Tipo Lápis}

Padrão Secundário do LCl 


\section{Physikalisch-Technische Bundesanstalt}

Braunschweig und Berlin

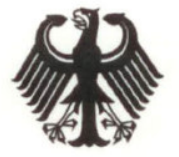

\section{Kalibrierschein \\ Calibration Certificate}

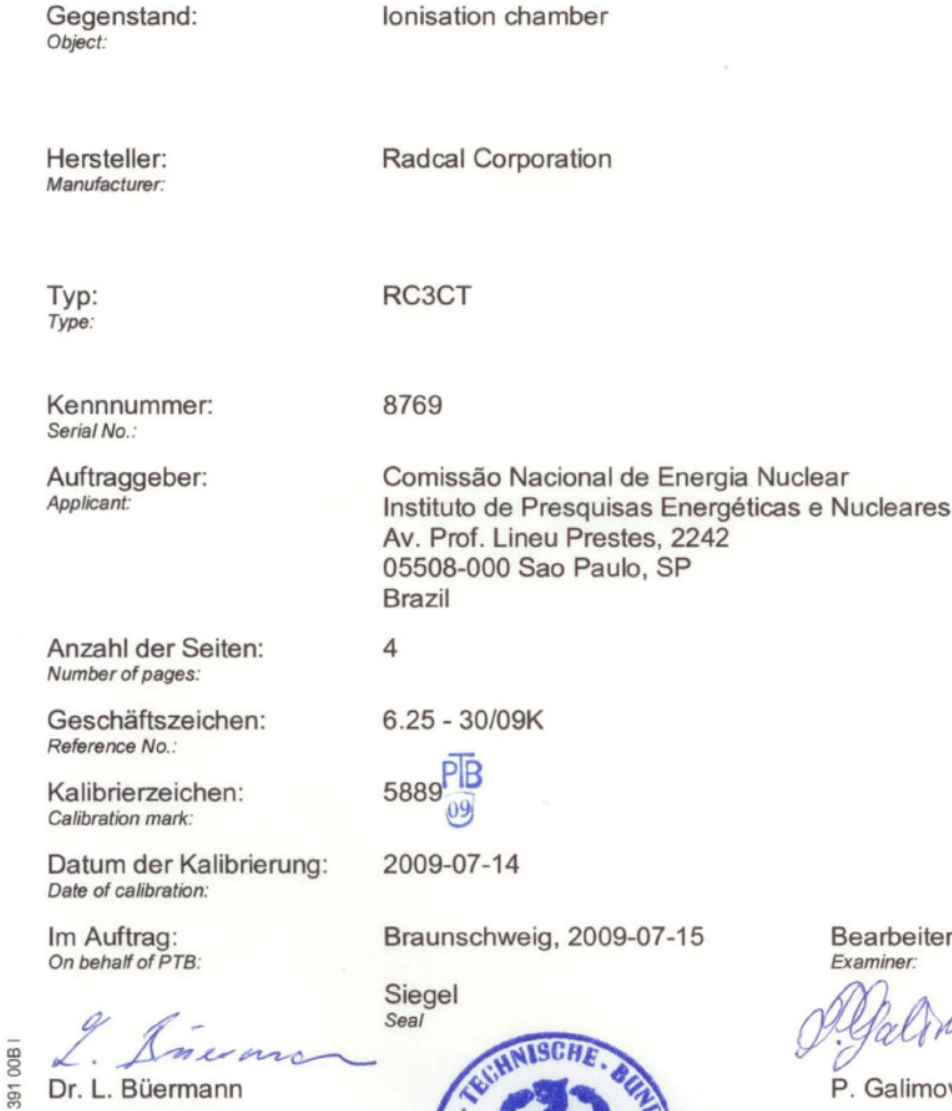

Kalibrierscheine ohne Unterschrift und Siegel haben keine Gültigkeit. Dieser Kalibrierschein darf nur unverändert weiterverbreitet werden. Auszüge bedürfen der Genehmigung der Physikalisch-Technischen Bundesanstalt.

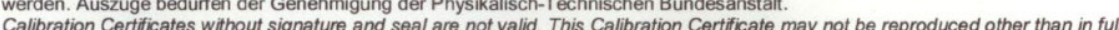
Extracts may be taken only with the permission of the Physialisch-Technische Bundesenstatt r 


\section{Physikalisch-Technische Bundesanstalt}

Seite 2 zum Kalibrierschein vom 2009-07-15, Kalibrierzeichen: 5889

Page 2 of the Calibration Certificate dated 2009-07-15, calibration mark: 5889

1. General information

1.1 Scope of the calibration

Calibration of the $\mathrm{CT}$ ionisation chamber in terms of air kerma-length product.

$1.2 W$-value

The reference value of the air kerma as obtained by the primary standard measurement is based on $(\text { W/e })_{\text {air }}=33,97 \mathrm{~V}$.

1.3 Conditions prevailing during the calibration (see also 2.1)

1.3.1 Radiation

X-radiation produced with constant potential generators.

1.3.2 Climatic conditions

temperature:

air pressure:

rel. humidity:

$21,7^{\circ} \mathrm{C}$ to $23,2^{\circ} \mathrm{C}$

$1000,6 \mathrm{hPa}$ to $1001,0 \mathrm{hPa}$

around $50 \%$

1.3.3 Geometrical arrangement

A rectangular aperture with an opening of width $81,55 \mathrm{~mm}$ and height $30,4 \mathrm{~mm}$ was centred on the central axis of the beam at a distance of $97,85 \mathrm{~cm}$ from the focal spot. The chamber was positioned horizontally perpendicular to the beam axis with the centre of the marked ring on the middle of the chamber located on the beam axis at $1 \mathrm{~m}$ from the focal spot. The black point on the stem was facing to the focus.

1.3.4 Leakage current

The effect of leakage currents was eleminated by appropriate corrections. 


\section{Physikalisch-Technische Bundesanstalt}

Seite 3 zum Kalibrierschein vom 2009-07-15, Kalibrierzeichen: 5889

Page 3 of calibration certificate of 2009-07-15, calibration mark: 5889

2. Results of the calibration

The calibration factor, $N_{\mathrm{KL}}$, is the ratio of the conventional true value of the air kerma-length product at reference conditions to the indication of the instrument to be tested. The value of the air kerma length product, $P_{\mathrm{KL}}$, in units of Gy.cm, is obtained from the reading, $M$ :

$P_{\mathrm{KL}}=N_{\mathrm{KL}}{ }^{*} M^{*} k_{\mathrm{Q}}{ }^{*} k_{\rho}$

where

$N_{\mathrm{KL}}$ ist the calibration factor in terms of air kerma-length product, reference conditions $\mathrm{T}=20^{\circ} \mathrm{C}, \mathrm{p}=1013,25 \mathrm{hPa}$

$k_{Q}$ is the correction factor for the radiation quality $Q$

$k_{\mathrm{p}}$ is the correction factor for the density of air, reference conditions $\mathrm{T}=20^{\circ} \mathrm{C}, \mathrm{p}=1013,25 \mathrm{hPa}$.

2.1 Calibration factor for the reference radiation quality and correction factor for other radiation qualities

\subsubsection{Ionisation chamber RC3CT S/N 8769}

Q radiation quality

b additional filtration

$s_{1}$ first half value layer

a distance between source and point of test

$\boldsymbol{N}_{\mathrm{KL}}$ calibration factor in terms of air kerma-length produkt for reference radiation quality RQT $9^{+}$; potential of the high voltage electrode: $+300 \mathrm{~V}$ potential of the collector electrode: w width of the radiation field along the chamber axis at the point of test ( $50 \%$ Isodose)

$\boldsymbol{k}_{\mathrm{Q}} \quad$ correction factor for the radiation quality $\mathrm{Q}$

Ka air kerma rate

$U$ rel. uncertainty of $N_{\mathrm{KL}} * k \mathrm{Q}$ according to the "Guide to the Expression of Uncertainty in Measurement' (ISO, 1995) as derived from the standard uncertainty by applying a coverage factor $k=2$

$N_{\mathrm{KL}}=9,157 * 10^{7} \mathrm{~Gy} \mathrm{~cm} / \mathrm{C}$

\begin{tabular}{|c|c|c|c|c|c|c|c|}
\hline $\mathrm{Q}^{+}$ & $\begin{array}{c}\mathrm{b}^{*} \text { in } \\
\mathrm{mm}\end{array}$ & $\begin{array}{c}s_{1} \text { in } \\
\mathrm{mm} \mathrm{Al}\end{array}$ & $\begin{array}{c}a \text { in } \\
\mathrm{cm}\end{array}$ & $\begin{array}{c}w \text { in } \\
\mathrm{cm}\end{array}$ & $\begin{array}{c}K_{2} \text { in } \\
\mathrm{mGy} / \mathrm{min}\end{array}$ & $k_{\mathbf{Q}}$ & $\begin{array}{c}U \text { in } \\
\%\end{array}$ \\
\hline RQT 8 & $3,36 \mathrm{Al}+0,2 \mathrm{Cu}$ & 6,79 & 100 & 8,33 & 2,93 & 0,997 & 1,5 \\
RQT 9 & $3,73 \mathrm{Al}+0,25 \mathrm{Cu}$ & 8,48 & 100 & 8,33 & 3,78 & 1 & 1,5 \\
RQT 10 & $4,38 \mathrm{Al}+0,3 \mathrm{Cu}$ & 10,22 & 100 & 8,33 & 5,86 & 1,005 & 1,5 \\
\hline
\end{tabular}

* Inherent filtration: $7 \mathrm{~mm} \mathrm{Be}$

${ }^{+}$Radiation qualities according to IEC 61267:2005-11 


\section{Physikalisch-Technische Bundesanstalt}

Seite 4 zum Kalibrierschein vom 2009-07-15, Kalibrierzeichen: 5889 Page 4 of the Calibration Certificate dated 2009-07-15, calibration mark: 5889

Die Physikalisch-Technische Bundesanstalt (PTB) in Braunschweig und Berlin ist das nationale Metrologieinstitut und die technische Oberbehörde der Bundesrepublik Deutschland für das Messwesen und Teile der Sicherheitstechnik. Die PTB gehört zum Dienstbereich des Bundesministeriums für Wirtschaft und Technologie. Sie erfüllt die Anforderungen an Kalibrier- und Prüflaboratorien auf der Grundlage der DIN EN ISO/IEC 17025

Zentrale Aufgabe der PTB ist es, die gesetzlichen Einheiten in Übereinstimmung mit dem Internationalen Einheitensystem (SI) darzustellen, zu bewahren und - insbesondere im Rahmen des gesetzlichen und industriellen Messwesens - weiterzugeben. Die PTB steht damit an oberster Stelle der metrologischen Hierarchie in Deutschland. Kalibrierscheine der PTB dokumentieren die Rückführung des Kalibriergegenstandes auf nationale Normale.

Dieser Ergebnisbericht ist in Übereinstimmung mit den Kalibrier- und Messmöglichkeiten (CMCs), wie sie im Anhang $C$ des gegenseitigen Abkommens (MRA) des Internationalen Komitees für Maße und Gewichte enthalten sind. Im Rahmen des MRA wird die Gültigkeit der Ergebnisberichte von allen teilnehmenden Instituten für die im Anhang C spezifizierten Messgrößen, Messbereiche und Messunsicherheiten gegenseitig anerkannt (nähere Informationen unter http://www.bipm.org).

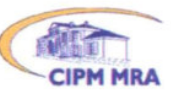

The Physikalisch-Technische Bundesanstalt (PTB) in Braunschweig and Berlin is Germany's National Metrology Institute and the supreme technical authority in the Federal Republic of Germany for metrology and certain sectors of safety engineering. The PTB comes under the auspices of the Federal Ministry of Economics and Technology. It meets the requirements for calibration and testing laboratories as defined in EN ISO/IEC 17025.

The central task of the PTB is to realize and maintain the legal units in compliance with the International System of Units (SI) and to disseminate them - in particular within the framework of legal and industrial metrology. The PTB thus is on top of the metrological hierarchy in Germany. The calibration certificates issued by the PTB document that the calibrated object is traceable to national standards.

This certificate is consistent with the Calibration and Measurement Capabilities (CMCs) included in Appendix C of the Mutual Recognition Arrangement (MRA) drawn up by the International Committee for Weights and Measures (CIPM). Under the MRA, all participating institutes recognize the validity of each other's calibration and measurement certificates for the quantities, ranges and measurement uncertainties specified in Appendix C (for details, see $h$ ttp://www.bipm.org).

Physikalisch-Technische Bundesanstalt

Bundesallee 100

38116 Braunschweig

Abbestraße 2-12

GERMANY 
2. ANEXO 2

Certificado de calibração do PTW Diavolt universal 
KALIBRIERSCHEIN NR.

Calibration Certificate No.

0713503

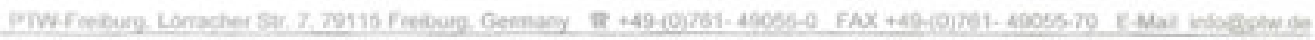

Kalibriergegenstand / Calibration Object

Nicht-invasives KV-Messgerat und Dosimeter / Non-imvasive KV-Moter and Dosimeter

DIAVOLT UNIVERSAL

T43014-01153

Hersteler I Manufacturer

Auftraggeber / Customer

Auftragsnummer $I$ Order No Auftragsdatum / Order Date
PTW-Freiburg

CNEN - Comissao Nacional de Energia Nuclear

Avenida Prof. Lineu Prestes, 2242

Cidade Universitaria

05508-000 Sao Paulo - SP - Brasill

AU703827

06.092007

\section{Ergobnis der Kalibrierung / Calibration Results}

\begin{tabular}{|c|c|c|}
\hline $\begin{array}{l}\text { Messgrobe } t \\
\text { Measuring Quantiy }\end{array}$ & $\begin{array}{l}\text { PPV } \\
\text { apractical peak wotape / IEC } 61676\end{array}$ & Kar (Luftkerma / Air Kerma) \\
\hline $\begin{array}{l}\text { Messergebnis in I } \\
\text { Measurement resul in }\end{array}$ & kV & Gy \\
\hline $\begin{array}{l}\text { Kalibrierfaktor I } \\
\text { Calbration Factor }\end{array}$ & $N_{n v}=1,00$ & $N_{\kappa}=1,00$ \\
\hline $\begin{array}{l}\text { Unsicherheit der Kalibrierung ' } \\
\text { Uncertainty of cafibration }\end{array}$ & $\begin{array}{l}\varepsilon=2 \% \\
(\kappa \leq 1 \mathrm{kV} \text { for } / \text { at } P P V<40 \mathrm{kV})\end{array}$ & $\ell=2 \%$ \\
\hline $\begin{array}{l}\text { Kavibrierdatum / } \\
\text { Catbration Dato }\end{array}$ & \multicolumn{2}{|l|}{28.09 .2007} \\
\hline $\begin{array}{l}\text { Emplohienes Rekalbrierinterval I } \\
\text { Recommended recalibration intervaf }\end{array}$ & \multicolumn{2}{|l|}{2 Jahre / 2 yoars } \\
\hline $\begin{array}{l}\text { Messbereiche und Strahlenqualitaten / } \\
\text { Moasuming range and radiation qualities }\end{array}$ & \multicolumn{2}{|c|}{ 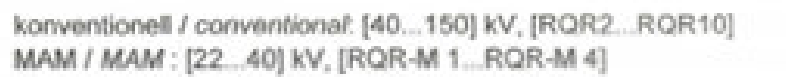 } \\
\hline
\end{tabular}

$\begin{array}{lll} & \text { W-Anode }[40.150] \mathrm{kV} & \text { Mo-Anode }[22.40] \mathrm{kV} \\ \text { Anodemwinkel / Anode Angle } & 12^{*} & 20^{*} \\ \text { HV.Wellenform / HV Waveform } & \text { CP (constant potential) } & \text { HF (high frequency) } \\ \text { Feldgroese / Field Size } & 12 \mathrm{~cm} \times 12 \mathrm{~cm} & 16 \mathrm{~cm} \times 16 \mathrm{~cm} \\ \text { Fokusabstand / Focal Distance } & 50 \mathrm{~cm} & 60 \mathrm{~cm} \\ \text { Belichtungszeit / Irradiation Time } & 0,4 \mathrm{~s} & 0.4 \mathrm{~s}\end{array}$

PTW-Freiburg

Freiburg, den 28.09 .2007 
Kalibrierbedingungen und Aufbau / Calibration Conditions and Set-up

$\begin{array}{lllll}\text { Klimatische Bedingungen / } & \text { Temperaturbereich } / \text { Temperature Range } & {[18 \ldots 24]^{\circ} \mathrm{C}} \\ \text { Climatic Conditions } & \text { Luftdruck } & \text { / Air Pressure Range } & {[950 \ldots 1050] \mathrm{hPa}} \\ & \text { Relative Lufteuchte } & \text { Relative Humidity Range } & {[40 \ldots 60] \%}\end{array}$

Anordnung im Strahlenfeld / Die Oberseite des Gerats zeigte zur Strahlenquelle /

Arrangemont in radiation field The top side of the instrument faced towards the radiation source

Bezugsort am Gerat / siehe Gebrauchsanweisung / refer to user manual

Reference point of device

Strahlungsqualitaten I $\quad$ RQR und RQR-M Qualitaten gemaB IEC 61267

Beam Qualities $\quad R Q R$ und RQR-M qualities according to IEC 61267

Invasive kV-Referenz I

Invasive $k V$-reference

DYNALYZER III A HVU

(SN 73-05-1-1523, Cert. No. 14327) (SN 61-06-8-0124, Cert. No. 014302)

for / for $[40 \ldots 150] \mathrm{kV}$ for / for [22...40] kV

Dosis und Dosisleistung $/ \quad[4.0 \ldots 55] \cdot 10^{-3} \mathrm{~Gy}$

Dose and Dose Rate $\quad[0.3 \ldots 8.0] \mathrm{Gy} / \mathrm{min}$

Bemerkungen / Remarks

1. Die angegebene Unsicherheit entspricht der 2-fachen Standardabweichung $(k=2)$. Die Unsicherheit der Kalibrierung wurde entsprechend ISO GUM aus den Teilunsicherheiten der Normale, des Kalibrierverfahrens, der Umgebungsbedingungen und des Kurzzeitverhaltens des Gerats berechnet. Die Gesamtunsicherheit einer Messung setzt sich zusammen aus der Unsicherheit der Kalibrierung und allen Unsicherheiten, die durch ein Abweichen von den Referenzbedingungen bedingt sind. Ein Anteil fur die Langzeitinstablitat des Prôflings ist nicht enthalten. I

The uncertainty stated corresponds to the double standard deviation $(k=2)$. The uncertainty of the calibration was calculated according to ISO GUM from the partial uncertainties arising from the standards used, the calibration procedure, the environmental conditions and short time effocts of the object of measurement. The overall uncertainy of a measurement is composed of the uncertainty of the calibration as well as uncertainty contributions that are causod by deviations from the reference conditions. A share for the long term instability of the object under calibration is not included.

2. Die Kalibrierung ist ruckfohrbar auf Normale der Physikalisch Technischen Bundesanstalt (PTB), Braunschweig und des National Institute of Standards and Technology, USA (NIST). Unvollständige oder auszugsweise Wiedergabe dieses Kalibrierscheins bedarf der Genehmigung des ausstellenden Labors. Dieser Kalibrierschein gilt nur im Zusammenhang mit dem unverletzten Aubleber mit der

Kalibrierscheinnummer. Die Kalibrierung von Geraten, die zur Reparatur geoffnet wurden, sind mit froheren Kalibrierungen nicht vergleichbar. Kalibrierscheine ohne Unterschrift sind ungultig. I

The calibration of all $k$ V-reference components is troceable to national standards of the German Nationat Laboratory, PTB, Braunschweig and to the National Institute of Standards and Technology, USA (NIST). This calibration certificate may not be reproduced other than in full except with the permission of the issuing laboratory. This certificate is valid only with the instrument showing the intact sticker with the certificate number. The calibration of instruments having been opened for repair are not comparable to previous calibrations. Calibration certificates without signature are not valid. 